\title{
Crowdsourcing and Participatory Mechanisms in Crowdfunded Design Projects
}

\author{
By \\ Michael Pape \\ A thesis submitted to the Faculty of Graduate and Postdoctoral Affairs in \\ partial fulfillment of the requirements for the degree of \\ Master of Design \\ in \\ Industrial Design \\ Carleton University \\ Ottawa, Ontario \\ (C) 2014, Michael Pape
}




\begin{abstract}
The emergence of the internet has facilitated tremendous communicative and collaborative opportunities amongst dispersed crowds of individuals. In the wake of this development, centralized organizations have utilized crowdsourcing as a method of directing crowds' intellectual resources and creativity towards specific predefined tasks or problems. Similarly, the practice of crowdfunding has enabled entrepreneurs to leverage crowds' financial resources towards project-oriented goals by incentivizing financial contribution. Reward-based crowdfunding platforms such as Kickstarter specifically target prospective users by offering project deliverables as investment incentives, leading to the formation of project-specific groups of active and motivated user-investors. This research seeks to investigate the convergence of crowdsourcing and crowdfunding practices to affect co-design activities between project founders and user-investors through reward-based crowdfunding. To that end, it examines successful design-centered projects on Kickstarter in order to firstly establish five 'participatory mechanisms' for defining and discussing participatory practice in the crowdfunding context, and subsequently quantifying the prevalence of such mechanisms and correlating them to other project variables. We find that projects' context and proposed outcomes are significantly related to participation, which was most often observed in the Technology and Games categories, and in software and hardware projects. We find the implementation of participatory mechanisms to be tied to project scope, in terms of fundraising goals, funds raised, number of backers, and communication between founders and the crowd.
\end{abstract}

Keywords: Crowdfunding, Crowdsourcing, Co-Design, Collective Intelligence 


\section{ACKNOWLEDGEMENTS}

A special thank you to my thesis supervisors,

Dr. Lorenzo Imbesi, \&

Dr. Sana Mohsni,

for their guidance and contributions

to this work over the past two years. 


\section{TABLE OF CONTENTS}

GLOSSARY OF TERMS ...........................................................................ii

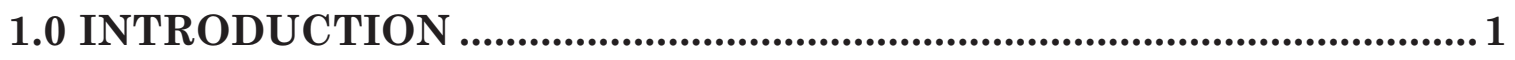

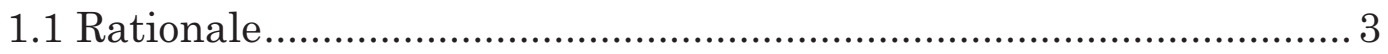

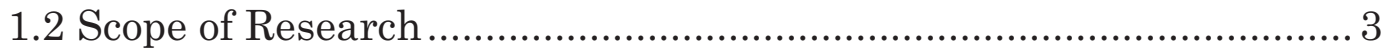

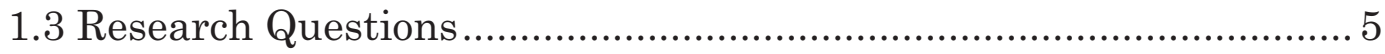

1.4 Contribution to Interdisciplinary Design Research ......................... 6

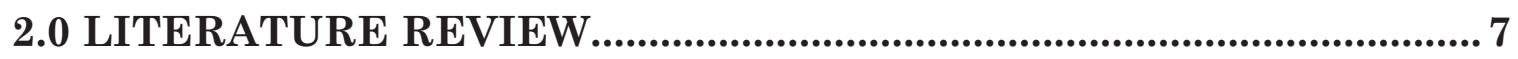

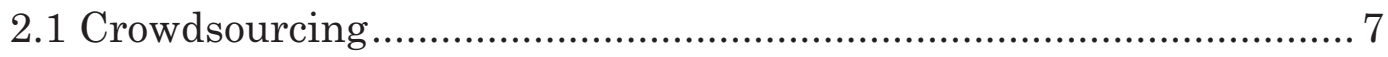

2.1.1 Crowd Motivation ........................................................... 8

2.1.2 User Crowdsourcing \& Working Consumers....................... 9

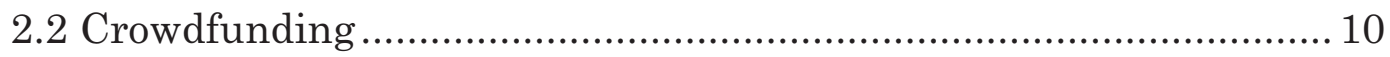

2.2.1 Crowdfunding Versus Traditional Finance ....................... 11

2.2.2 Crowd Participation In Reward-Based Crowdfunding .... 13

2.2.3 Crowdfunding Platforms \& Social Media.......................... 15

2.2.4 Gaps in Crowdfunding Literature ..................................... 16

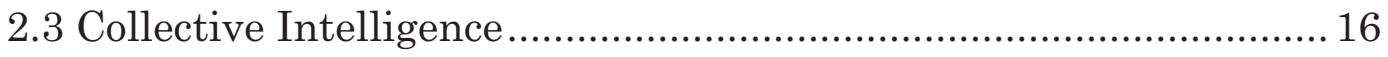

2.3.1 The Wisdom of Crowds.................................................. 16

2.3.2 Conditions for Collective Intelligence ……......................... 17

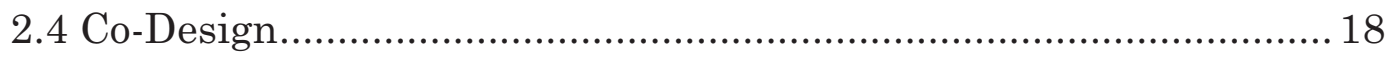

2.4.1 Participatory Design Methods........................................... 19

2.4.2 Levels of Participation ........................................................ 19

2.5 Post-Industrial Design \& Participatory Cultures ............................ 21

2.5.1 Post-Industrial Design ....................................................... 21

2.5.2 Co-Creation \& Co-Production ..............................................2 23 
2.6 Conclusions

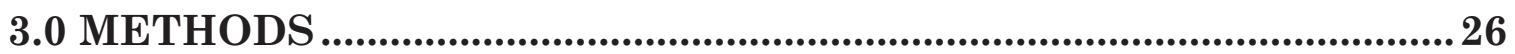

3.1 Approach \& Research Overview ................................................... 27

3.2 Sample for Data Collection ........................................................... 28

3.2.1 Kickstarter Categories ....................................................... 28

3.3 Variables for Data Collection ....................................................... 29

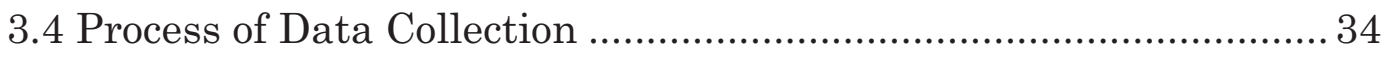

3.5 Data Processing \& Analysis .................................................................. 34

3.5.1 Classifying Participatory Activities .................................... 34

3.5.2 Determining the Exclusivity of Participatory Practices..... 36

3.5.3 Quantifying the Prevalence of Participatory Practices ...... 36

3.5.4 Plotting Quantifiable Project Variables.............................. 37

\subsection{RESULTS \& DISCUSSION ....................................................................39}

4.1 Classifying Participatory Activities ................................................ 39

4.1.1 Defining Participatory Mechanisms ................................... 42

4.1.2 Exclusivity of Participatory Mechanisms ........................... 47

4.2 Determining the Prevalence of Participatory Practices................. 49

4.2.1 Overall Prevalence of Participation ...................................... 49

4.2.2 Prevalence of Individual Participatory Mechanisms......... 51

4.3 Plotting Quantifiable Project Variables ............................................ 53

4.3.1 Funding Goal................................................................... 54

4.3.2 Total Funds Raised ............................................................ 55

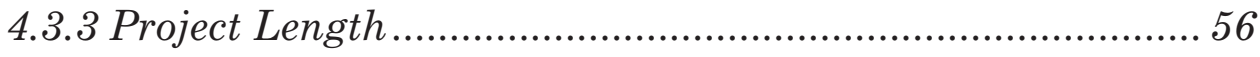

4.3.4 Project Backers ................................................................... 57 
4.3.5 Project Comments ..................................................... 58

4.3.6 Project Updates........................................................ 58

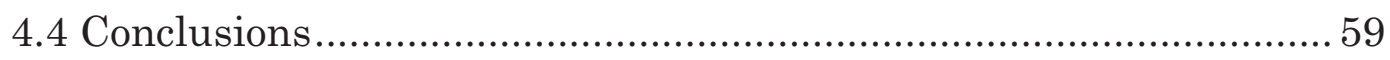

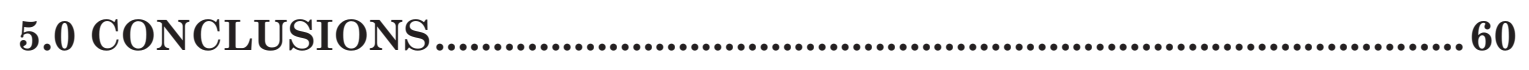

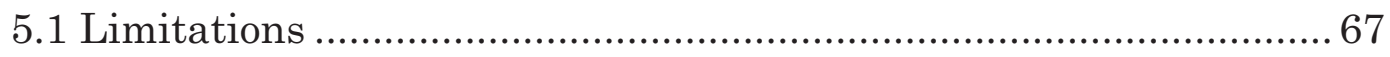

5.2 Contribution to the Field .................................................... 67

5.3 Suggestions for Future Research ............................................ 68

BIBLIOGRAPHY ..................................................................................... 70

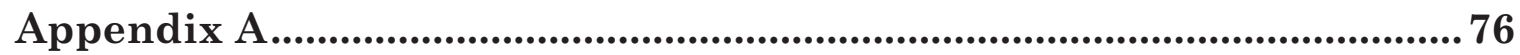




\section{LIST OF FIGURES}

Figure 1. Approach \& Research Overview...................................................... 26

Figure 2. Sample Kickstarter Project Page with Recorded Variables ............. 33

Figure 3. Defining Open-Ended Feedback.................................................. 42

Figure 4. Defining Collective Decision-Making.................................................. 43

Figure 5. Defining Supplemental Development .............................................. 44

Figure 6. Defining Individual Collaboration ……........................................... 45

Figure 7. Defining Open Collaboration............................................................ 46

Figure 8. Overall Prevalence of Participatory Mechanisms............................ 50

Figure 9. Prevalence of Open-Ended Feedback................................................. 51

Figure 10. Prevalence of Collective Decision-Making...................................... 51

Figure 11. Prevalence of Supplemental Development ...................................... 52

Figure 12. Prevalence of Individual Collaboration ......................................... 52

Figure 13. Prevalence of Open Collaboration................................................... 53

Figure 14. Graphing Average Funding Goals ................................................ 54

Figure 15. Graphing Average Funds Raised ................................................ 55

Figure 16.Graphing Average Funds Raised [Relative to Funding Goals] ...... 56

Figure 17. Graphing Average Project Length ................................................. 56

Figure 18. Graphing Average Project Backers .................................................. 57

Figure 19. Graphing Average Donation Size Per Backer ................................. 57

Figure 20. Graphing Average Project Comments ............................................ 58

Figure 21. Graphing Average Project Updates ................................................ 58 


\section{LIST OF TABLES}

Table 1. Grouping Participatory Activites by Participant Input...................... 41

Table 2. Measuring the Exclusivity of Participatory Mechanisms ................. 48

Table 3. Average Values of Quantifiable Project Variables............................. 54 


\section{GLOSSARY OF TERMS}

Crowdsourcing: An organization-user relationship whereby the organization executes a top-down, managed process that seeks the bottom-up, open, creative input of users in an online community (Brabham, 2012).

Crowdfunding: A model of financing that involves an open call, mostly through the Internet, for the provision of financial resources either in the form of donation or in exchange for an incentive in order to support initiatives for specific purposes. (Belleflamme, Lambert \& Schwienbacher, 2013a)

\section{Crowdfunding Terminology:}

Project: An initiative that forms the focus of a crowdfunding campaign, generally expressed through stated goals and funding requirements. (Kickstarter, 2014a)

Founder: The person or organization responsible for initiating a crowdfunding project, proposing a goal, and managing any subsequently acquired funds in order to realize the project. (Kickstarter, 2014a)

Backer: A financial contributor to a crowdfunding campaign. (Kickstarter, 2014a)

Crowdfunding Platform: An online platform that serves as a centralized financial intermediary between founders of crowdfunding projects and prospective project backers. (Giudici et al., 2012) 
Reward: An incentive offered to prospective project backers in exchange for financial contributions. Such incentives are generally to be delivered following a project's realization. (Kickstarter, 2014a)

Reward Tier: An incentivization method wherein specialized rewards are offered to project backers whose financial contributions meet or exceed a specified total. Projects may utilize multiple reward tiers, and specific reward tiers may be limited to a maximum number of donors. (Kickstarter, 2014a)

Collective Intelligence: Collective intelligence refers to the cognitive capacities of a society, a community or a collection of individuals. (Lévy, 2012)

Co-Design: A process that leverages the creativity of designers and people not trained in design working together in the design development process. (Sanders, \& Stappers, 2008) 


\subsection{INTRODUCTION}

Crowdfunding is an emerging method of entrepreneurial finance that dramatically alters the conventional role of financial stakeholders in the design and development of innovative products, services, and systems (Belleflamme et al., 2013a \& 2013b; Rubinton, 2011; Schwienbacher \& Lerralde, 2010). Reward-based crowdfunding incentivizes donation with project-specific rewards in order to leverage the financial resources of a dispersed digital community or 'crowd', and in doing so allows project founders to maintain full creative control over their design process (Belleflamme et al., 2013a). Given that these incentives generally take the form of product preorders, successful reward-based crowdfunding projects are often necessarily supported by groups of motivated and enthusiastic userstakeholders rather than profit-driven investors (Belleflamme et al., 2013b; Schwienbacher \& Lerralde, 2010). Kickstarter is the world's largest and most dominant crowdfunding platform (Mollick, 2013a), and is increasingly viable as a platform for design projects (Kuppuswamy \& Bayus, 2013; Mollick, 2013a).

Co-design refers to the practice of integrating users or primary stakeholders into the design and development of products, services, and systems (Sanders \& Stappers, 2008). Users possess localized expertise and are capable of innovative co-creation when motivated by self-interest and guided by designers or generative design tools (Kleemann et al., 2008; Sanders, Brandt, \& Binder, 2010; Sanders \& Simons, 2009; Tufte $\&$ Mefalopulos, 2009). By borrowing methods from crowdsourcing and codesign, reward-based crowdfunded design initiatives are able to funnel the enthusiasm and collective intelligence of user-investors towards collaborative activities to improve the quality of project deliverables, simultaneously benefiting project founders and backers (Belleflamme et al., 2013b). 
Recently, prominent Kickstarter campaigns such as the Oculus Rift, a virtual reality hardware development project, have combined crowdfunding with crowdsourcing approaches by enabling early investors to participate in a collaborative design and development process. In the case of the Rift, the project's founders incentivized donation by offering hardware prototypes, software development tools, access to an exclusive developer forum, and centralized technical support to backers who contributed at least $\$ 275$ to the project. This enabled developers to get an early start on creating or re-appropriating software applications to work in tandem with the Rift's hardware, while also allowing the project's founders to gather feedback in order to optimize the hardware for both consumer and developer purposes. (Kickstarter, 2014b). By externalizing the financing of hardware development, as well as the labor of software development and hardware testing, the Rift's founders were able to cover early development costs while simultaneously ensuring that their feedback originated from group of motivated supporters and self-interested user-stakeholders.

Collaborations such as the Oculus Rift indicate significant potential in the overlap of crowdfunding and crowdsourcing practices. As crowdfunding continues to grow, its capacity to enable collaborative communities through financial exchange may enable the development of participatory cultures, in which the open exchange of ideas, knowledge, and resources can be harnessed to co-create, co-produce, and collectively fund solutions to complex problems (Kleemann et al., 2008; Lévy, 1997; Lévy, 2012; Manzini, 2013; Mortati \& Villari, 2012). This research aims to investigate, classify, and quantify the present participatory practices through which successful design-centered initiatives on Kickstarter incentivize and implement creative contribution from user-investors. 


\subsection{Rationale}

Presently, while there is literature related to participatory and codesign practices, there is a significant lack of scholarly literature on these subjects in the context of crowdfunding. This gap will be further explored in the literature review. The combination of crowdfunding and crowdsourcing presents an opportunity to affect a significant positive impact on the design and subsequent success of products, services, and systems, which should be of particular interest to practitioners and researchers from the fields of design and entrepreneurship. By developing a common language to refer to participatory practices in this context, we aim to suggest and inform future research in this emerging area of study.

\subsection{Scope of Research}

This research seeks to build upon existing literature from the fields of co-design, crowdsourcing, collective intelligence, post-industrial design, participatory cultures, participatory development, and entrepreneurial finance in order to synthesize a common language to describe participatory practices in crowdfunding. Due to the broad range of projects and contexts in which crowdfunding can be applied, we utilized four key criteria in order to focus the aims and methods of our study:

1. Design-Centered Goal: Given our focus on participatory activities that influence project outcomes via the potential for co-design or crowdsourcing, we are primarily interested in crowdfunding projects that have proposed to design, develop, produce, or distribute a product, system, or service. 
2. Reward-based Incentivization: In order to investigate the collaborative relationships between project founders and user-investors, we are focusing on projects that offered the aforementioned product, system, or service as a primary incentive to prospective backers. These are referred to as 'private good' projects (Kuppuswamy \& Bayus, 2013; Mollick, 2013a, Qiu, 2013).

3. Successfully Funded: A large number of varied factors can act as determinants of projects' fundraising success. While it is relevant to determine whether or not certain types of participation have an influence on project success, we must first classify the various participatory activities at work within the crowdfunding context. This study does not aim to assess participatory activities as a determinant of project success, and as such will only investigate successful projects in order to reduce variability.

4. Run via a Crowdfunding Platform: Crowdfunding platforms presently facilitate the majority of crowdfunding projects and funds raised. Due to the various tools and formats provided by different websites, we aimed to gather our entire sample from a single platform to reduce variability. In addition to meeting our other criteria, Kickstarter was chosen based on its increasing popularity and viability as a platform for design initiatives (Kuppuswamy \& Bayus, 2013; Mollick, 2013a), which we concluded would best allow us to observe current and emerging trends in reward-based crowdfunding efforts. While our 
research focuses on Kickstarter, our findings may have broader applications for participation in alternative crowdfunding contexts.

\subsection{Research Questions}

The emergence of users as stakeholders in reward-based crowdfunding facilitates tremendous potential for crowdsourcing, in that project backers represent a cohesive, enthusiastic, and accessible crowd for designers and founders of design-centered projects to tap into. Crowdfunding platforms such as Kickstarter already facilitate backer comments and communication with project founders, though the degree to which feedback and collaborative or co-design opportunities are leveraged or implemented by project founders is presently unknown. This research aims to address the following key questions:

Q1: How can we classify the various types of participatory practice that the founders of successful design-centered Kickstarter projects are utilizing to influence the design of project outcomes?

Q2: How prevalent are these participatory activities in successful design-centered Kickstarter projects?

Q3: Can the prevalence of participation in successful design-centered Kickstarter projects be correlated to other project variables? 


\subsection{Contribution to Interdisciplinary Design Research}

Crowdfunding literature and practice already represent an overlap between a variety of fields, as discussed in the following literature review. The occurrence of creative crowd participation in crowdfunded design projects further complicates this intersection via the addition of principles from co-design, post-industrial design, participatory development, and collective intelligence. This inter-disciplinary research investigates the convergence of crowdfunding, crowdsourcing, and co-design practices in order to begin addressing the relative lack of academic attention in this area. Our findings enabled us to synthesize a common language for the activities and mechanisms through which participation was leveraged in our sample data, which may inform or suggest future research on this emerging phenomenon. While our study focuses on successful design-centered Kickstarter projects, our findings and definitions on the subject of participatory mechanisms are relevant first steps towards affecting a comprehensive understanding of participatory practices and collaborative design in the crowdfunding context. 


\subsection{LITERATURE REVIEW}

This research aims to investigate crowd participation in designcentered crowdfunding projects that were successfully funded through Kickstarter, a reward-based crowdfunding platform. This phenomenon intersects with established scholarly literature on the subjects of co-design, crowdsourcing, crowdfunding, collective intelligence, post-industrial design, and participatory cultures. The following review aims to identify and summarize relevant findings from the aforementioned literature in order to inform and contextualize this research.

\subsection{Crowdsourcing}

Crowdsourcing describes "an organization-user relationship whereby the organization executes a top-down, managed process that seeks the bottom-up, open, creative input of users in an online community" (Brabham, 2012). Kleemann, Voß, and Rieder further describe the process of crowdsourcing as follows:

[Crowdsourcing] takes place when a profit oriented firm outsources specific tasks essential for the making or sale of its product to the general public (the crowd) in the form of an open call over the internet, with the intention of animating individuals to make a contribution to the firm's production process for free or for significantly less than that contribution is worth to the firm. Firms engage in crowdsourcing to inexpensively mobilize the creative work of sometimes highly skilled persons as a resource for the generation of value and profits. Tasks that lend themselves to crowdsourcing include product design, advertising, quality monitoring, and the solution of specific technical problems. (2008). 
Established firms use crowdsourcing in product development, "from simple opinion polls to elaborate schemes for the collaborative development of actual products by users" (Kleemann et al., 2008). Examples include Fiat's "Fiat 500", which generated approximately 170,000 design contributions, 10,000,000 page views, and 20,000 comments and suggestions from potential consumers, and Dell's "Idea Storm", which offered tailored suggestions that members of the public could vote to support or oppose (Kleemann et al., 2008).

Crowdsourcing is utilized by firms in order to reduce costs and production time (Brabham, 2012; Kleemann et al., 2008; Schwienbacher \& Lerralde, 2010), which is made possibly by the crowd having "virtually unlimited time and energy" (Anderson, 2009, p. 219). As Surowiecki puts it, "You can let a thousand flowers bloom and then pick the one that smells the sweetest" (2005).

\subsubsection{Crowd Motivation}

According to Brabham (2012), "for crowdsourcing to be successful, it must rely on a robust, active, motivated crowd." Crowdsourcing relies on participants' willingness to complete tasks voluntarily or for reduced compensation, and as such it is important to identify the methods by which crowds are motivated to contribute. Participants offer their services for rewards that can be extrinsic, such as recognition, compensation, knowledge, or reaching common goals, or intrinsic, such as enjoyment, satisfaction, or moral fulfillment (Kleemann et al., 2008; Howe, 2006). Crowdsourcing operates best when crowd members are offered an incentive for accurate or high quality contributions (Surowiecki, 2005), rewarding and encouraging volunteers with the most appropriate skill sets to fulfill given needs. 
Spreadshirt.net is an example of a company that incentivizes crowdsourcing via profit sharing, allowing users to create shirt designs that are then marketed and sold by the company. Contributors are paid an incentive that is directly tied to the sales of their design work, motivating these users to produce designs that they predict will be profitable to the company. This benefits both the contributors, who normally lack access to the means of production, and the company, who can outsource their design work by leveraging the self-interested behaviour of contributors (Kleemann et al., 2008). Surowiecki compares the motivation and output of these contributors with that of academic researchers, stating that while the latter are "undoubtedly as self-seeking and self-interested as the rest of us ... the way science is organized, though, makes their self-interested behavior redound to the benefits of all of us" (2005).

\subsubsection{User Crowdsourcing \& Working Consumers}

Consumers who are or expect to become users of a product or service may be inclined to contribute feedback or suggestions based on their own self-interest, which can consequently benefit both the developer and other customers (Kleemann et al., 2008; Poetz \& Schreier, 2012). These users importantly "best know their own needs" and are "the real expert[s] in the use of a firm's products and services", and can thus greatly contribute to improving the design of a product, service or system with which they are familiar (Kleemann et al., 2008).

Users can be particularly leveraged for their creativity relative to professionals, in that "[they] innovate because they expect to benefit from an innovation by using it" (Shah, Smith \& Reedy, 2012). In a study by Poetz and Schreier (2012) that compared the idea generation capabilities of users 
versus professionals, user ideas and solutions were more novel and had greater consumer benefits than professional ideas. While professionals' ideas were slightly more feasible to realize due to their familiarity with production techniques, both groups scored high in this regard, leading to a much smaller disparity than the study's authors and prior literature had predicted.

The dichotomy of active producers versus passive consumers is blurred by the emergence of these 'working consumers' who add value to the production process, are valuable economic assets, and are systematically integrated into systems of production where they can be monitored and guided by centralized management (Kleemann et al., 2008). This relates to the notions of co-design and participatory development, which will be discussed later in this chapter.

\subsection{Crowdfunding}

Crowdfunding is "an open call, mostly through the Internet, for the provision of financial resources either in form of donation or in exchange for the future product or some form of reward to support initiatives for specific purposes" (Belleflamme, Lambert \& Schwienbacher, 2013a). Crowdfunding literature further defines three main subtypes of crowdfunding as distinguished by the types of incentive offered to prospective crowd investors:

Equity crowdfunding: Contributors can invest in exchange for sharing in the profits or ownership of a project (Ahlers, Cumming, \& Schweizer, 2012; Giudici, Guerini, \& Lamastra, 2013).

Reward-based crowdfunding: Contributors can invest in exchange for a specific non-pecuniary reward from project founders, generally 
in the form of tangible new products or services (Belleflamme et al., 2013a; Kim \& Hann, 2013; Mollick, 2013a).

Donation-based crowdfunding: Contributors can invest voluntarily, but are not offered products, services, or pecuniary returns in exchange for their contribution (Burtch, Ghose, \& Wattal, 2012).

\subsubsection{Crowdfunding Versus Traditional Finance}

Crowdfunding is an emerging method of financing projects and entrepreneurial ventures, providing a viable alternative to existing methods of finance such as venture capital firms, angel investors, friends and family, and bank loans (Kim \& Hann, 2013; Mollick, 2013a \& 2013b; Schwienbacher \& Lerralde, 2010). Belleflamme et al. suggest that crowdfunding "should be considered a distinct form of financing that centers on funding from the crowd rather than professional investors (i.e., for whom making risky investments are their business activity)" (2013a), noting that crowdfunding is similar to friends and family investing since both methods involve unsophisticated investors. Mollick (2013b) asserts that the primary differences between crowdfunding and venture capital are in the nature of crowds, which are democratic, loosely organized, transparent, and cannot necessarily exert control over developers or project outcomes.

Given that the crowd is ostensibly composed of amateur investors, several authors are doubtful of the crowd's ability to invest in promising projects (Giudici, Nava, \& Lamastra, 2012; Mollick, 2013a \& 2013b; Schwienbacher \& Lerralde, 2010). Additionally, substantial information asymmetries exist between projects founders and backers, which are exacerbated when prospective backers lack the investment experience to be 
able to evaluate an opportunity based on limited knowledge (Ahlers et al., 2012; Mollick, 2013a).

In spite of this, crowds' investment patterns have been favorably compared to the sophisticated investment behaviour of professionals in terms of evaluating credible signals of projects' prospective quality (Burtch et al., 2012; Kim \& Viswanathan, 2013; Kuppuswamy \& Bayus, 2013; Mollick, 2013a \& 2013b). These signals include both quantitative measures, such as progress towards funding goals or present number of project backers, and qualitative measures, such as project popularity or the perceived quality of a product pitch (Burtch et al., 2012; Kim \& Viswanathan, 2013; Kuppuswamy \& Bayus, 2013). Additionally, there is no evidence of irrational herding towards campaigns with ill-suited funding goals or outlandish promises (Kuppuswamy \& Bayus, 2013), indicating that prospective backers collectively filter attention and financing towards projects of high apparent quality (Mollick, 2013a \& 2013b). Some authors go on to posit that crowdfunding was responsible for some of the most innovative technology design projects of 2013, several of which had been previously turned down by venture capital firms (Jeffries, 2013; Mollick, 2013b).

Giudici et al. (2012) purport that while venture capital firms support entrepreneurs with management, recruiting, marketing, networking, and guidance, there is "no evidence neither theoretical argument that [crowdfunding platforms] are able to provide such support for their customers", providing only "information analysis, rating or reviews elaborated by the crowd or by specialists, shared with the public". Conversely, reward-based crowdfunding can provide benefits unavailable in conventional funding, including market validation at the proof-of-concept stage and advanced feedback from prospective users (Belleflamme et al., 
2013a \& 2013b; Burtch et al., 2012; Giudici et al., 2012; Rubinton, 2011; Schwienbacher \& Lerralde, 2010). Additionally, crowdfunding can help entrepreneurs to overcome barriers in securing funds traditionally, such as geographical distance between developers and investors (Agrawal et al., 2011; Kim \& Hann, 2013, Mollick 2013a \& 2013b), or having non-pecuniary goals (Lehner, 2013).

While current literature examines positive and negative elements of crowdfunding as an emergent method of finance, none of the reviewed papers found negative elements to be significant enough to suggest that crowdfunding is without use in the entrepreneurial environment. Most authors assert that crowdfunding and traditional finance can coexist, with some suggesting that projects can benefit from both either simultaneously or in sequence (Agrawal et al., 2011; Belleflamme et al., 2013a).

\subsubsection{Crowd Participation In Reward-Based Crowdfunding}

There are many examples of scholarly papers on the topic of crowdfunding that describe it as a form of crowdsourcing (Belleflamme et al., 2013a; Gambardella, 2012; Giudici et al., 2013; Giudici et al., 2012; Kim \& Viswanathan, 2013; Kuppuswamy \& Bayus, 2013; Lehner, 2013; Mollick, 2013a \& 2013b; Mortati \& Villari, 2012; Qiu, 2013; Rubinton, 2011; Schwienbacher \& Lerralde, 2010). However, while crowdfunding and crowdsourcing are both centralized, crowdfunding projects simply have to communicate their goals to prospective donors in order to utilize the full sum of subsequent financial contributions (Mollick, 2013b), where crowdsourcing initiatives must manage crowd members, distribute tasks, and filter incoming contributed content for quality (Brabham, 2012).

While they are structurally distinct, crowdfunding and crowdsourcing 
are not mutually exclusive. By directly involving financial supporters in decision-making, project founders can potentially extract additional value from the crowdfunding process (Belleflamme et al., 2013b; Schwienbacher \& Lerralde, 2010). Given that backers in reward-based crowdfunding are motivated less by altruism than by the expectation that they will become future consumers of the product (Belleflamme et al., 2013a; Kuppuswamy \& Bayus, 2013; Mollick, 2013a; Qiu, 2013), founders can tap into the creativity and local expertise of users to inform the design and development process (Kleemann et al., 2008; Poetz and Schreier 2012; Shah, Smith \& Reedy, 2012). The active implication of backers' contributions is not without risks however, as founders "must surrender a bit of their own power by letting online communities become meaningful stakeholders" (Brabham, 2012).

Of the assembled literature, only one paper attempts to describe or quantify non-pecuniary user participation in reward-based crowdfunding. In a study on crowdfunding projects run without the assistance of crowdfunding platforms, Belleflamme et al. (2013b) found that one third of observed projects incentivized investment via 'active implication', consisting of opportunities for involvement "in the creative process, in the decision-making, or in various operating tasks" (Belleflamme et al., 2013b). Pre-established firms offered active implication more often than individual entrepreneurs, likely due to the limitations of requisite structure and resource costs associated with engaging the crowd (Belleflamme et al., 2013b). While active implication displayed a positive correlation with reward-based crowdfunding, a negative correlation was found with equity crowdfunding, which "suggests that reward-based models are more conducive to integrate crowdfunders within the organization" (Belleflamme et al., 2013b). Additionally, a tentative correlation was observed between active 
implication and project success, "implying that direct involvement by the crowd exerts an important role on the amount of funds raised" (Belleflamme et al., 2013b). It is worth noting that for purposes of data coding, 'active implication' was very broadly and simply defined as "[projects wherein] crowdfunders are involved in any way whatsoever in the venture they fund" (Belleflamme et al., 2013b).

\subsubsection{Crowdfunding Platforms \& Social Media}

Crowdfunding's present rise in prominence is correlated with an increase in the number of online crowdfunding platforms (Giudici et al., 2012). These platforms are websites that leverage the sharing capabilities of social media to promote and host crowdfunding campaigns, facilitating a consistent method of interaction and financial exchange between project founders and prospective backers (Belleflamme et al., 2013a; Burtch et al., 2012; Giudici et al., 2012; Kuppuswamy \& Bayus, 2013; Mollick, 2013a \& 2013b; Mortati \& Villari, 2012; Qiu, 2013). The majority of these new platforms specifically encourage and facilitate the reward-based crowdfunding model (Kuppuswamy \& Bayus, 2013), the largest of which is Kickstarter (Mollick, 2013a).

Crowdfunding campaigns have been shown to contribute to public awareness and market exposure for both the product and the founders (Burtch et al., 2012; Jeffries, 2013; Mollick, 2013a \& 2013b; Schwienbacher \& Lerralde, 2010). Belleflamme et al. (2013b) found that $78 \%$ of surveyed crowdfunding projects utilized social media to promote their campaigns, and $85 \%$ of founders stated that project and product publicity was a major reason to utilize the crowdfunding model. 


\subsubsection{Gaps in Crowdfunding Literature}

Crowdfunding literature is currently in a nascent state due to the relatively recent emergence and popularization of reward-based crowdfunding platforms (Agrawal et al., 2011; Ahlers et al., 2012; Belleflamme et al., 2013a \& 2013b; Burtch et al., 2012; Giudici et al., 2013; Giudici et al., 2012; Kim \& Viswanathan, 2013; Kuppuswamy \& Bayus, 2013; Lehner, 2013; Mollick, 2013a; Schwienbacher \& Lerralde, 2010). The majority of these papers maintain that crowdfunding both needs and warrants greater scholarly attention across a variety of related fields, including entrepreneurial management, sociology, crowd behaviour, information systems, and finance (Giudici et al., 2012; Mollick, 2013a). Currently, no crowdfunding research attempts to explore either the specific methods by which participation occurs or the impact of backer collaboration on project outcomes, representing a significant gap in the current body of crowdfunding literature.

\subsection{Collective Intelligence}

Collective intelligence refers "to the cognitive capacities of a society, a community or a collection of individuals" (Lévy, 2012). Individuals in the modern world are constantly creating, sharing, and interacting with tremendous volumes of knowledge. This process is characterized by the speed, quantity, and availability of the information involved, and is enabled by information communication technology and tools for filtering this mass of new knowledge (Lévy, 1997).

\subsubsection{The Wisdom of Crowds}

The average result of a large number of individual assessments tends 
to have a high degree of accuracy; "[t]he idea of the wisdom of the crowds is not that a group will always give you the right answer but that on average it will consistently come up with a better answer than any individual could provide" (Surowiecki, 2005). While collective or collaborative intelligence does not guarantee perfect results, it has shown through democracy, the scientific community, and free markets to improve upon methods that depend on individual or hierarchical decision-makers, in terms of satisfying the greatest number of people (Lévy, 2012).

An average group that meets the criteria for collective intelligence will consistently outperform an average expert (Surowiecki, 2005). While we can observe that a few outstanding individuals are capable of outperforming large and diverse groups, such individuals cannot be easily identified or verified (Surowiecki, 2005). Individual experts have a narrow focus and tend to be overconfident in their own predictions, though no evidence suggests that anything beyond a minimum level of expertise contributes to an expert's ability to forecast (Surowiecki, 2005). This relates to the previously discussed notion of user innovation in crowdsourcing, where users tended to outperform design professionals in terms of creativity (Poetz \& Schreier, 2012), as well as to the idea that crowds' investment behaviour is comparable to professional investors (Burtch et al., 2012; Kim \& Viswanathan, 2013; Kuppuswamy \& Bayus, 2013).

\subsubsection{Conditions for Collective Intelligence}

Surowiecki (2005) posits that groups are able to be collectively intelligent through four key conditions: diversity of opinions, individual independence, decentralization, and a method of aggregating the group's output. Lévy (2012) similarly asserts that collective intelligence depends 
on individuals' creativity and critical thinking skills, in order to avoid standardization and mob mentalities. Fostering diversity is most important for small groups, as large groups are less reliant on individual group members for information (Surowiecki, 2005).

Groups that aim to be collectively intelligent should not explicitly seek consensus, "which encourages tepid, lowest-common-denominator solutions which offend no one rather than exciting everyone" (Surowiecki, 2005). When groups are too reliant on a few sources of information or are unduly influenced by vocal individuals such as experts, the group begins to display herding behaviour. Surowiecki refers to this as 'social proof', stating that "[people] assume that if lots of people are doing or believe something, there must be a good reason why" (2005). This is readily apparent in the case of information cascades, in which the effect of prior decisions, made in sequence, influence present and future decisions (Surowiecki, 2005). Fortunately, the more important a decision is to an individual, the less likely such a cascade will have a significant impact on that individual's decision, lessening the effect if has on the group as a whole (Surowiecki, 2005).

\subsection{Co-Design}

Co-design refers broadly to "the creativity of designers and people not trained in design working together in the design development process", and is based in the tradition of participatory design (Sanders \& Stappers, 2008). Participatory design practice has been growing and evolving over the past four decades, and while it originally centered on the development of information technology, it has since seeped into other fields of design and development (Sanders, Brandt, \& Binder, 2010; Sanders \& Stappers, 2008). There has been a similarly gradual shift towards 'participatory development', 
which utilizes varying degrees of input from users or 'primary stakeholders' to inform the goals and implementation of development projects (Tufte \& Mefalopulos, 2009).

\subsubsection{Participatory Design Methods}

Participatory design practice often revolves around the use of in-person workshops, pre-established toolkits, and direct oversight by designers in order to enable and guide participants in contributing to design processes (Sanders et al., 2010; Sanders \& Simons, 2009). Ideally, this relationship between participants and designers is ongoing rather than a singular event, taking the form of iterative meetings that rely on a diversity of perspectives and opinions in order to provide useful output (Sanders et al., 2010).

Early research on user participation combined the design expertise of professional designers with the localized expertise of users, enabling users to assist in defining the problem and suggesting potential avenues of design and development (Bødker, 1996). While this broadly resembles the aims and approach of user crowdsourcing, participatory design methods generally involve a much smaller number of participants and rely on in-person workshops and toolkits rather than digital communication technologies (Sanders et al., 2010).

\subsubsection{Levels of Participation}

In defining participatory development and participatory communication, Tufte and Mefalopulos (2009) classify four major levels of participatory action, distinguished by the degree of creative control afforded to primary stakeholders: 
Passive participation: Primary stakeholders are informed about but not actively involved in the design and development process, which is handled by external experts.

Participation by consultation: Primary stakeholders provide feedback to specific queries from external experts in order to inform particular aspects of the design and development process, though such feedback does not necessarily have to be implemented into final outcomes.

Participation by collaboration: Primary stakeholders are involved in exploratory discussion of solutions to problems that have been pre-established by external experts. This requires the active mobilization and involvement of primary stakeholders' creative capacities.

Empowerment participation: Primary stakeholders are able to actively engage in problem definition, initiate action, and contribute towards collective and creative decision-making. This method integrates external experts as facilitators and equal partners in the process.

The authors go on to state that while participation "does not always mean everybody is engaged in every step of the way", more comprehensive participatory methods lead to progressively better project outcomes (Tufte \& Mefalopulos, 2009). They assert that empowerment participation is the most optimal method of stakeholder integration, and that in order to be "genuinely 
participatory and truly effective, communication should occur among all parties affected, ensuring that all have similar opportunities to influence the outcome of the initiative" (Tufte \& Mefalopulos, 2009).

\subsection{Post-Industrial Design \& Participatory Cultures}

According to Sanders and Stappers (2008), the development of participatory and co-design approaches has taken decades partially due to opposition from professionals and academics, which the authors assert is due to a widespread belief that most individuals lack creative or innovative potential. While this attitude has been shifting towards "egalitarian idea sharing" due to the internet, the authors claim that participatory thinking is still many years away from having a significant impact on mainstream, professional design and development (Sanders \& Stappers, 2008).

Conversely, peer-to-peer information sharing has surged with the increase in internet usage, reinforcing a non-hierarchical global community that actively nurtures collective knowledge and solves diffused problems (Kleemann et al., 2008). According to Manzini (2013), people can and should be seen as assets whose expertise and collaborative potential can be harnessed to contribute solutions to complex problems via co-design and coproduction, as evidenced through the evolving role of designers as facilitators in the post-industrial era.

\subsubsection{Post-Industrial Design}

Post-industrialism emerged in the 1970's as the beginning of a shift from top-down mass production of material goods to the multi-level production and management of immaterial resources, such as networking, coordination, and the production or transfer of knowledge (Imbesi, 2011). 
This shift was tied to a dramatic reduction in manufacturing costs (Imbesi, 2011), as well as the transformative effects of globalization, open markets, technological advances, and cultural factors (Imbesi, 2012). Importantly, post-industrialism does not purport to replace or nullify industry, and works in tandem with industrial methods of production, albeit towards different goals (Imbesi, 2011).

In the post-industrial context, innovation and creativity are of critical importance to success in the competitive global marketplace, and creative labor is able to generate significant value in the place of material goods (Imbesi, 2011). Contrary to the mass-production of rigid and singular responses to complex problems, creativity can be leveraged to facilitate the ideation and design of localized solutions to specific situations (Imbesi, 2012).

This has shifted the role of the design profession, away from simply creating or styling products and towards formulating strategic services, systems, and processes through which value can be produced and evaluated in terms of human experiences rather than market success (Imbesi, 2011). To that end, designers no longer need to be rigidly focused on the final aesthetic results of production, instead flexibly working in an interdisciplinary manner to affect the entire process of conceiving and developing designed solutions to complex human problems (Imbesi, 2011 \& 2012).

The dispersion of the means of production through technological advances and the internet has democratized design and production processes on a massive scale, as evidenced by open source and peer-to-peer models (Imbesi, 2011). In this context, designers can act to guide and direct the creative resources of society through networking, participatory practices, and design tools (Imbesi, $2008 \& 2011$ ). These developments relate to the notion of design for social innovation and participatory cultures, in which groups 
of people collaborate to design localized solutions via open sharing of both material and immaterial resources.

\subsubsection{Co-Creation \& Co-Production}

Surowiecki suggests that "[crowds] are all different, but they have in common the ability to act collectively to make decisions and solve problemseven if the people in the groups aren't always aware that's what they're doing" (2005). Lévy discusses this potential with almost utopian optimism, suggesting that the internet "could become the most perfectly integrated medium within a community for problem analysis, group discussion, the development of an awareness of complex processes, collective decisionmaking, and evaluation" (1997, p. 59). He further clarifies that the goal of such communities would be "to create a fully transparent market for ideas, arguments, projects, initiatives, expertise, and resources, one in which pertinent connections are established as quickly and cheaply as possible" (Lévy 1997, p. 75).

This relates to the ideas of empowerment participation and 'cocreation', which focus on collective ideation to explore and address openended questions, rather than collaboration to simply realize a predetermined solution (Sanders \& Simons, 2009; Tufte \& Mefalopulos, 2009). Such practices have greater impact on the design process the earlier they are implemented, and are most effective when informing the entirety of a design solution (Imbesi, 2011; Sanders \& Simons, 2009). Within these contexts, designers and generative design tools can and should operate as facilitators, applying established design principles and specialized knowledge to enable stakeholders to effectively co-create and co-produce solutions to complex problems (Imbesi, 2011 \& 2012; Sanders \& Stappers, 2008). 


\subsubsection{Digital Creative Communities}

Crowdsourcing, crowdfunding, and collective intelligence have been functionally enabled by the development and rapid dispersion of information communication technologies and the internet (Agrawal et al., 2011; Brabham, 2012; Kleemann et al., 2008). The notion of 'Web 2.0' is characterized by an increasingly mobilized and animated user base, and has been facilitated by huge rises in user count and user-generated content (Kleemann et al., 2008; Sanders \& Simons, 2009). Social media enables connection with and mobilization of the public, attracting and engaging large and predominantly young audiences (Saxton \& Wang, 2013). Additionally, it allows crowdsourcing and crowdfunding initiatives to effectively reach communities outside their geographic area, dramatically increasing their potential number of contributors (Agrawal et al., 2011; Kim \& Hann, 2013; Mollick, 2013a \& 2013b; Saxton \& Wang, 2013).

According to Mortati and Villari (2012), the crowdfunding platform Kickstarter is a successful community platform because it provides easy access to willing participants, encourages interdependence between founders and backers, is adaptable with no clear community hierarchy, and creates resiliency by fostering trust, networks, and norms. Distributed design and production are creating an environment of diffused collaboration amongst huge numbers of individuals, fostering the development of crowds that are representative of their collective intelligence (Mortati \& Villari, 2012). 'Connectivity' between people, contexts, and artifacts is critical to the success and resiliency of these communities, and is achieved via common objectives, collaboration, design participation, and collective creativity (Mortati \& Villari, 2012).

In contrast with crowdsourcing initiatives, these communities are not 
managed or directed towards specific tasks by a centralized entity, and can operate on a peer-to-peer basis as is the case in open source development or open encyclopedias (Brabham, 2012). It is worth noting that while these communities are often seen as grassroots initiatives, participatory communication can be implemented at local, national, or international levels, regardless of the diversity or number of people involved (Tufte \& Mefalopulos, 2009).

\subsection{Conclusions}

We have established via the literature review that crowdfunding has become a viable alternative method for financing design projects, primarily through the use of online crowdfunding platforms, though such literature is currently in a nascent state. Additionally, we have described co-design, participatory design practices, and the collaborative potential of collective intelligence and crowdsourcing in the post-industrial context. We posit that design-centered initiatives on reward-based crowdfunding platforms can leverage the creative contributions of motivated groups of user-investors in

order to facilitate the co-design of project outcomes during subsequent design and development processes. We further suggest that this convergence has the potential to support the development of resilient participatory cultures that are able to co-create, co-design, and co-produce solutions to complex problems via the guidance of designers and established design methodologies. 


\subsection{METHODS}

Due to the present lack of literature focused on the intersection of crowdfunding with specific co-design or crowdsourcing practices, we opted to develop a working research methodology that would allow us to address our research questions, as seen in Figure 1. The following section describes our approach to data collection and the subsequent process for data analysis.
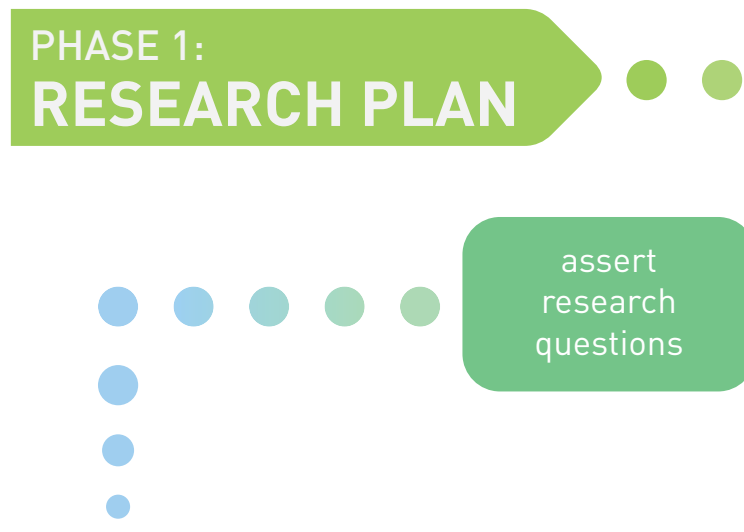

\section{PHASE 2:}

DATA COLLECTION

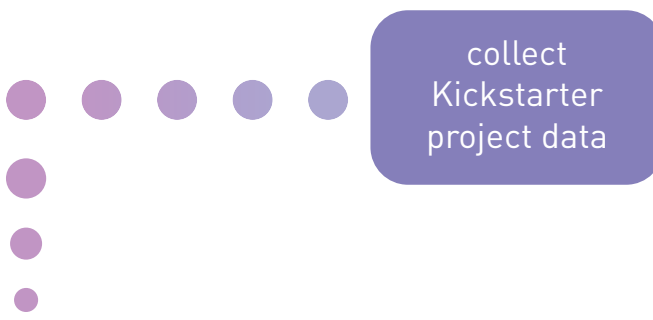

assert

subject of

research

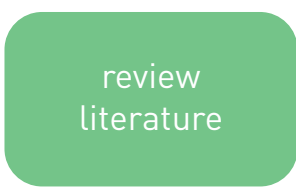

define sample

for data

collection

\section{define variables}

for data

collection

synthesize

definitions

of participatory mechanisms (Q1)

quantify the

prevalence of

participatory

mechanisms (Q2)

Figure 1. Approach \& Research Overview 


\subsection{Approach \& Research Overview}

Given our aim to assess the prevalence of participation in successful design-centered Kickstarter projects, we firstly set out to define and classify the types of participation that we intended to measure, in accordance with our first research question:

Q1: How can we classify the various types of participatory practice that the founders of successful design-centered Kickstarter projects are utilizing to influence the design of project outcomes?

To that end, we sought to gather data on a sample range of Kickstarter projects from which we could identify and classify common forms of participation. These classifications would subsequently allow us to quantitatively record occurrences of participation within our data, in order to address the second research question:

\section{Q2: How prevalent are these participatory activities in successful design-centered Kickstarter projects?}

In addition to the occurrence of participatory activities, we planned to record quantifiable project variables that were publicly available on Kickstarter, such as projects' funding goals, project type, or number of backers. The average values of these variables would then be compared to the incidence of participatory activities, in order to address our third research question: 


\section{Q3: Can the prevalence of participation in successful design-centered Kickstarter projects be correlated to other project variables?}

\subsection{Sample for Data Collection}

I gathered data from a total of 600 successful Kickstarter projects, consisting of 150 projects each from the categories of Design, Technology, Games, and Fashion. Project data was collected chronologically by fundraising end date, beginning with projects that concluded on September 1, 2013. This date was chosen to ensure that the data was relatively representative of current trends, while also providing a large enough sample to record 150 projects in each category. In order to locate projects that met these sample criteria, I used the external web service 'Kickspy', which allowed for searching and complex, specific filtering of Kickstarter projects.

\subsubsection{Kickstarter Categories}

Given our focus on rewards and user-investors, we planned to focus on 'private good' projects, in which planned outcomes would primarily benefit backers and consumers, rather than 'public good' projects, in which planned outcomes would benefit society at large (Burtch et al., 2012; Qiu, 2013). Public good crowdfunding projects follow a substitution model (Burtch et al., 2012), in which previous contributions diminish future donations, as potential donors' resources are perceived as being less necessary to achieve the project. Conversely, private good projects follow a reinforcement model (Kuppuswamy \& Bayus, 2013), in which previous contributions spur more contribution through reciprocity, as donors individually care about receiving private goods as rewards. As such, we omitted campaigns that lacked explicit 
deliverable outcomes, focusing on projects that proposed to design and deliver products, systems, or services as rewards to project backers.

Kickstarter categorizes campaigns based on their goals, prompting project founders to select from a list of available options to sort their campaign. These categories consist of Art, Comics, Dance, Design, Fashion, Film \& Video, Food, Games, Music, Photography, Publishing, Technology, and Theater, and are further broken down into numerous subcategories such as Product Design and Graphic Design (Kickstarter, 2014a; Mollick, 2013a). Kuppuswamy and Bayus (2013) observed that certain project categories, namely Design, Technology, and Games, consisted primarily of private good projects, noting that the crowd continued to contribute to such campaigns even after funding goals were met (Kuppuswamy \& Bayus, 2013). In order to get an idea of how participation is leveraged within these pertinent contexts, we used these categories as a starting point for our sample.

Due to this study's focus on potential co-design processes, we also sought to investigate the Fashion category, as we anticipated that Fashion projects would largely revolve around the design of novel products as backer rewards. A preliminary examination of Fashion projects from September 2013 found that, while such projects lacked the propensity for reinforcement seen in Design, Technology, and Games projects (Kuppuswamy \& Bayus, 2013), they still primarily proposed private goods as rewards.

\subsection{Variables for Data Collection}

We planned to record the following project variables:

1. Participatory Activities

a. Type of Activity

b. Exclusivity 
2. Kickstarter Category

3. $\quad$ Project Outcome Type

4. Funding Goal

5. Total Funds Raised

6. Project Length

7. Total Backers

8. Total Comments

9. $\quad$ Project Updates

Explanations of these variables are as follows:

1. Participatory Activities: This refers to crowdsourcing or co-design opportunities that were made available to the crowd by project founders. This variable was recorded via two supplementary values:

a. Type of Activity: Given that we began without clear definitions of participatory activities, we recorded the type of activity to be performed by participants via brief, qualitative descriptions. Examples include beta access, voting, or proprietary developer kits.

b. Exclusivity: The structure of Kickstarter encourages founders to offer participatory activities as incentives to donate, a process that potentially excludes certain members of the crowd from participation. While participatory activities can be public, they can be limited to backers only, requiring a donation of at least $\$ 1 \mathrm{USD}$, or more specifically to reward tiers, which each have specific donation requirements. Kickstarter further allows founders to implement limited 
reward tiers that have a maximum number of donors. This was recorded as a broad indicator of the exclusivity of a given participatory activity.

2. Kickstarter Category: This refers to the category that a project was classified under on Kickstarter's website. The four categories that were recorded were Design, Technology, Games, and Fashion. This was recorded in order to investigate potential trends within the various project categories, or significant differences between them.

3. Project Outcome Type: This refers to the type of product, service, or system that a founder proposed to produce and deliver to backers. Software refers to deliverables that are digital applications for one or more devices or operating systems, and which aim to deliver project outcomes through digital downloads rather than via physical artifacts. This category was created due to the low cost of distributing and testing purely digital rewards, which we anticipate could be correlated with the use of certain types of participation. Hardware refers to deliverables that are physical devices, which are either supplemented by software development tools or compatible with existing operating systems. This classification was defined due to such projects' capacity to outsource the development of software applications, which we anticipate could be correlated with the use of certain types of participation. Finally, standalone refers to deliverables that did not fall into either of the prior classifications, and generally involve the development of physical products. 
4. Funding Goal: This refers to the stated financial goal of a campaign's fundraising component, in USD. This variable was recorded as an indicator for the proposed scope of a project.

5. Total Funds Raised: This refers to the aggregate of donations received during the fundraising period, in USD. This variable was recorded as an indicator of the project's scope and popularity.

6. Project Length: This refers to the total length of a project's fundraising period, recorded in days. Given that participation requires management and preparation by founders, this variable was recorded in order to determine if participatory practice could be correlated with longer or shorter project runtimes.

7. Total Backers: This refers to the total number of Kickstarter users that donated funds to a project during its fundraising period. This variable was recorded as an indicator of a project's popularity and accessibility, and to determine the project's average donation size.

8. Total Comments: This refers to the total number of backer comments posted on a project's public Kickstarter page. While it does not account for private or external communication, this variable was recorded as an indicator of the volume of feedback provided by the crowd to a project's founder.

9. Project Updates: This refers to the total number of project updates that a founder posted to their campaign's public Kickstarter page. While it does not account for private or external communication, this variable is partially indicative of communication by project founders to the crowd. 
Pebble: E-Paper Watch for iPhone and Android

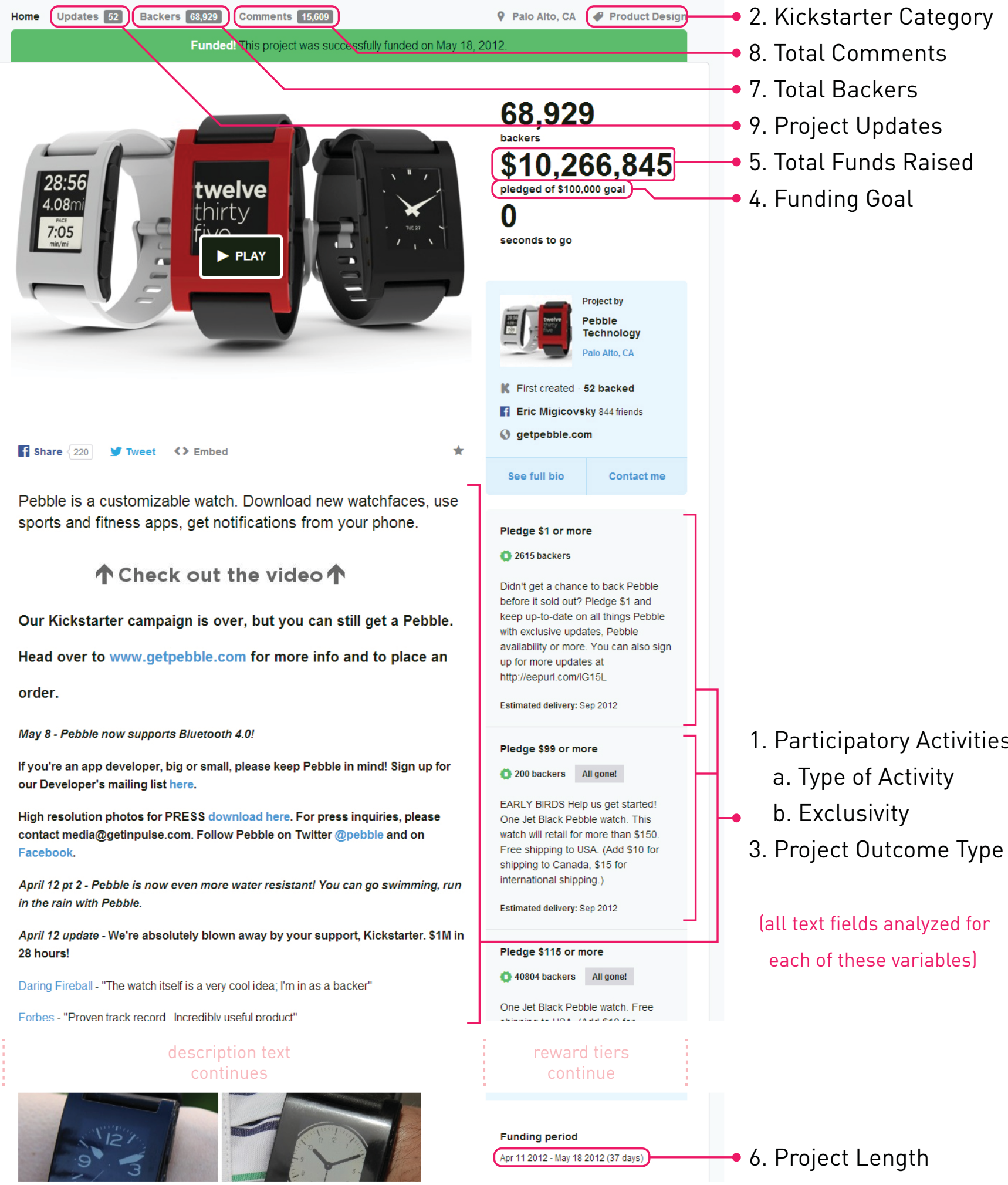

Figure 2. Sample Kickstarter Project Page with Recorded Variables (Kickstarter, 2014c) 


\subsection{Process of Data Collection}

I manually recorded project data by accessing each project's public Kickstarter page through Kickspy via Google Chrome, and recorded in Microsoft Excel. With the exception of variables 1 and 3, all values were explicitly available in on each project's page in unambiguous numerical or written form, as seen in Figure 2 on the previous page. In order to obtain values for 1 and 3, I reviewed the textual content of each campaign's proposal as well as the written descriptions of every reward tier offered in each project. Variables $1 \mathrm{~b}$ and 3 were recorded as one of a preset list of classifications as explained in the previous section, while variable 1a was left open due to the lack of clear precedents.

\subsection{Data Processing \& Analysis}

Upon completion of the data gathering process, I proceeded into three phases of exploratory data analysis. Given the aims of this research, I utilized a combination of statistical and visual graphing of project variables in order to broadly examine the assembled data for trends and correlations.

\subsubsection{Classifying Participatory Activities}

In order to address our first research question, my preliminary stage of data analysis focused on reviewing the participatory activities that had been observed in variable $1 \mathrm{a}$, as seen in Chapter 4.1. This was loosely based on Tufte and Mefalopulos' (2009) levels of participatory action in participatory development, in which different types of participatory activity were distinguished by the degree of agency afforded to participants via their input. Upon examination, I found that several of the activities recorded during data collection were very similar to one another in terms 
of the input being provided by participants, and could be grouped into five distinct classifications. I subsequently defined each of these classifications as 'participatory mechanisms' in order to synthesize a concise list of the participatory practices leveraged by founders within the sample. These mechanisms are described below:

- Open-Ended Feedback (OEF): Participants and founders engage in 1-way or 2-way dialogue regarding project outcomes, though participants have no control over design decisions.

- Collective Decision-Making (CDM): Participants collectively decide upon single elements of project outcomes from a limited set of options provided by the founder.

- Supplemental Development (SD): Participants independently develop products, services, or systems that supplement project outcomes.

- Individual Collaboration (IC): Participants individually communicate with founders to collaborate on the design of specific elements of final project outcomes.

- Open Collaboration (OC): Participants are enabled and encouraged to freely use, modify, and redistribute project outcomes to affect independent collaborative processes.

In order to further describe these participatory mechanisms, the values for variable 1a were each recoded to one of these five classifications. I used 
binary indications for each mechanism in order to identify each project by the mechanisms it utilized. Given this binary measurement, multiple occurrences of activities within the same classification were redundant and only counted once. Further, each mechanism was color-coded for purposes of consistent graphical representation. This recoded data was utilized for the remainder of the data analysis process.

\subsubsection{Determining the Exclusivity of Participatory Practices}

In order to further address our first research question, we sought to evaluate the exclusivity of the established participatory mechanisms. To that end, I measured and compared the values for variable $1 \mathrm{~b}$ for each instance of the five participatory mechanisms. The percentages of each degree of exclusivity were subsequently charted for each mechanism, for purposes of identifying trends in the data, as seen in Chapter 4.1.1. This revealed clear indications of each mechanism's level of exclusivity, providing insight into the implementation of participatory mechanisms within the sample.

\subsubsection{Quantifying the Prevalence of Participatory Practices}

The primary purpose of my data collection was to allow us to quantify the occurrence of participatory activities in successful design centered Kickstarter projects. To that end, I measured the incidence of participatory activities in the entire sample, counting the total number of projects that included affirmative values for variable 1a. In order to determine the average number of mechanisms used in these participatory projects, I then totaled the instances of participatory mechanisms and divided the sum by the number of participatory projects. I repeated these measurements within each of the four Kickstarter categories, as recorded in variable 2, and the three types of 
project deliverable, as recorded in variable 3 . This allowed us to compare the prevalence of participation across a variety of contexts in order to determine whether the type of project or deliverable could be correlated to participatory practices.

Following this overall comparison, I repeated this process individually for each participatory mechanism, including only projects that included the associated value in variable 1a. This allowed us to determine which mechanisms had been used frequently or in particular contexts, potentially indicating their value to project founders or ease of implementation under certain conditions. All findings on prevalence were then graphically represented to facilitate comparison between the various participatory mechanisms established earlier.

\subsubsection{Plotting Quantifiable Project Variables}

In addition to noting instances of participation, I recorded basic quantitative project data, such as funding goals or number of backers, such that I could potentially correlate participatory practices with individual project variables. In my final stage of data analysis, I sought to investigate correlations between the occurrence of participatory mechanisms and other quantifiable project variables, as described in chapter 3.3. The aim of this investigation was to potentially reveal relationships between participatory mechanisms and other elements of the crowdfunding process, furthering our understanding of where, why, and how participation was integrated into crowdfunding practice. This was done via comparisons of the average values for variables between seven sample groupings, which consisted respectively of all non-participatory projects, all participatory projects, and all projects that utilized the five participatory mechanisms, with one grouping per 
mechanism.

For these measurements, the independent variable was the presence of participation, as indicated in variable $1 \mathrm{a}$, and the dependent variables were the remaining recorded variables from chapter 3.3. These measurements were then graphically laid out in order to facilitate examination and comparisons of the various mechanisms. This method of analysis was chosen in order to address our third research question and broaden our understanding of how participation and individual participatory practices correlated to quantifiable variables in the sample. Correlations inferred from this process would not necessarily prove causal links, but would supplement our comprehension of individual participatory mechanisms and provide a basis for further research. 


\subsection{RESULTS \& DISCUSSION}

This study gathered data from 600 design-centered crowdfunding projects that had been successfully funded through Kickstarter. This sample consisted of 150 projects from four of the platform's project categories, including Design, Technology, Games, and Fashion. The primary goal of this data collection process was to record and describe the participatory activities utilized in successful design-centered Kickstarter projects, along with the associated project variables described in chapter 3.3. This section details the process and results of our subsequent data analysis, focusing on conclusions that address the study's primary research questions. All findings are derived from our recorded data, which can be found in Appendix A.

\subsection{Classifying Participatory Activities}

The first stage of our data analysis focused on examining the types of participatory activity observed within the sample, in order to address our first research question. During the data collection phase, instances of participation were recorded as qualitative descriptions of the activities that participants would perform, as discussed in Chapter 3.3. The activities that we observed are listed, quantified, and described below:

- Soliciting Feedback (36 instances): Founders actively solicited participants to provide them with feedback on project outcomes via the project's Kickstarter page.

- Open Source (32 instances): Founders released or planned to release the entirety of their project outcomes' design or blueprint to the general public for purposes of open participation and peer production. 
- Partial Open Source (9 instances): Founders released or planned to release some element of their project outcomes' design or blueprint to the general public for purposes of open participation and peer production.

- User Testing (96 instances): Founders gave participants early access to project deliverables for purposes of advanced testing and providing user feedback. This generally took the form of access to software betas.

- Voting on Esthetics (16 instances): Founders allowed participants to collectively decide upon a particular esthetic element of project outcomes via popular vote, either through Kickstarter, social media, or external web services.

- Voting on Functionality (12 instances): Founders allowed participants to collectively decide upon a particular functional element of project outcomes via popular vote, either through Kickstarter, social media, or external web services.

- Proprietary Developer Kits (18 instances): Founders created and distributed kits to allow participants to independently develop supplementary products or systems that would explicitly work in tandem with project outcomes.

- Design Collaboration (123 instances): Founders worked with individual participants to co-design some element of project outcomes, though founders would maintain total control over such outcomes.

- Direct Developer Contact (25 instances): Founders met with individual participants via private channels to discuss project outcomes. 
- Design Team Membership (14 instances): Founders allowed participants to join the team responsible for the project, enabling them to have an ongoing impact on the design and development of project outcomes.

Through preliminary examination of these participatory activities, we found that several of them involved very similar participatory processes, providing very similar types of creative input to founders. As such, I tentatively grouped the observed participatory activities based on participant input, as summarized by Table 1:

Table 1. Grouping Participatory Activites by Participant Input

Participatory Activities (\# of recorded instances)

\section{Participant Input}

Participants and founders engage in 1-way or 2-way dialogue regarding project outcomes, though participants have no control over design decisions.

Participants collectively decide upon single elements of project outcomes from a limited set of options.

\section{Proprietary Developer Kits (18) $\quad$ Participants independently develop products, services or systems that supplement project outcomes provided by the founder.}

Design Collaboration (123) Design Team Membership (14)
Participants individually communicate with founders to collaborate on the design of specific elements of final project outcomes.

Participants are enabled and encouraged to freely use, modify, and redistribute project outcomes to affect independant collaborative processes.

I found that each of these groupings revealed a distinct mechanism by which founders had enabled crowd members to influence project outcomes, generally via provision of some degree of participant agency. For purposes of 
further data analysis, I chose to examine participatory activities within these groupings, rather than investigating each activity separately. In aggregating these activities, I sought to affect a common language for referring to the varied participatory activities in crowdfunding practice, in order to both inform future research and encompass activities other than those observed in the sample. To that end, I subsequently classified each of these groupings as a type of 'participatory mechanism', and synthesized definitions and descriptions for each. These groupings can be seen in Figures 3 to 7.

\subsubsection{Defining Participatory Mechanisms}

\section{User Testing (96)}

Soliciting Feedback (36)

Direct Developer Contact (25)
OPEN-ENDED FEEDBACK

Figure 3. Defining Open-Ended Feedback

- Open-Ended Feedback: This describes any participatory activity in which project founders actively crowdsource feedback on nonspecific project outcomes.

This mechanism is a form of crowdsourcing, in that founders are tasked with managing and filtering contributed content in order to extract value from the crowd. The crowd is free to provide feedback on any element of a project, though founders are not obligated to implement or even assess such input. While comments and suggestions are given on a volunteer basis rather than in exchange for compensation, this participatory mechanism still requires founders to employ managerial resources in order to aggregate and 
utilize such feedback.

Due to the mechanism's lack of extrinsic incentive, the resulting creative output indicates participants' intrinsic motivations, such as enthusiasm or an interest in improving project outcomes. This relates to the enthusiasm and potential creativity of users, ensuring that solicited feedback originates from a motivated, active group of stakeholders. The quality of participant feedback is further associated with the amount of pertinent project information available to the crowd (Mollick, 2013a \& 2013b; Surowiecki, 2005). As such, most projects that actively sought feedback did so through rewards that enabled backers to participate in user testing prior to the distribution of project deliverables.

\section{Voting on Esthetics (16) COLLECTIVE
DECISION-MAKING Voting on Functionality (12)}

Figure 4. Defining Collective Decision-Making

- Collective Decision-Making: This describes any participatory activity in which project founders enable members of the crowd to influence project elements via majority vote.

This mechanism is another example of crowdsourcing, in which crowd input it aggregated in order to inform the design of project deliverables. Members of the crowd are given a degree of collective agency through voting, though their range of influence is dependent on the subject of the vote and their available options, which are determined by project founders. Within the sample, $42.9 \%$ of voting opportunities allowed participants to decide on some aspect of functionality in project outcomes, while the remainder dealt with 
purely esthetic components of final deliverables. In 2 cases, esthetic voting options were crowdsourced, indicating a rare intersection between the use of this mechanism and Open-Ended Feedback.

While other crowdfunding platforms may have implemented systems for voting, Kickstarter does not currently provide tools to explicitly facilitate the voting process. As such, founders are tasked with organizing and running the voting process independently. Instances of voting within the sample generally involved tallying votes through external web services or comments on the project's social media or Kickstarter pages.

\section{Proprietary Developer Kits (18)}

\section{SUPPLEMENTAL} DEVELOPMENT

Figure 5. Defining Supplemental Development

- Supplemental Development: This describes any participatory activity in which project founders crowdsource the development of products or services that operate in tandem with primary project outcomes.

The distribution of proprietary development tools can be considered a form of crowdsourcing and peer production, as founders are leveraging and directing the crowd's creative resources to their mutual benefit. Given that contributions made with such tools are necessarily compatible with campaign deliverables, this mechanism has the potential to generate significant benefits for participants, founders, and project backers in general. Additionally, if developers are offered incentives for contributing content of high quality, these additions are more likely to enrich the user experience of final project deliverables (Surowiecki, 2005). 
Access to developer tools provides crowd members with a great deal of individual agency, in that it allows them to act and create in a manner that is largely independent of project founders. However, this agency is typically restricted, in that participants must be able to leverage specialized skills, such as programming knowledge, in order to contribute. Additionally, founders maintain complete control over the implementation and distribution of participants' contributions, limiting the crowd's capacity to impact final project deliverables without founder approval.

\section{Design Collaboration (123) INDIVIDUAL Design Team Membership (14) $\longrightarrow$ COLLABORATION}

Figure 6. Defining Individual Collaboration

- Individual Collaboration: This describes any participatory activity in which project founders work with individual crowd members to collaborate on particular elements of final project deliverables.

This mechanism is characterized by collaboration and iterative dialogue between founders and individual participants, ostensibly to generate outcomes that are desirable to both parties. This leverages principles from co-design by enabling participants to have limited collaborative influence over project outcomes, albeit with the guidance of project founders.

While participants are granted a degree of agency in regards to specific components of final deliverables, project founders typically maintain full creative control over the project and may choose to filter or modify participants' contributions through the collaborative process. It is important 
to note that participants' agency is somewhat restricted in that they cannot participate in defining problems or ideating broad solutions, limiting their involvement to a collaborative or consultative role.

Open Source (32)

Partial Open Source (9)

\section{OPEN COLLABORATION}

Figure 7. Defining Open Collaboration

- Open Collaboration: This describes any participatory activity that revolves around the open distribution and free modification of project deliverables.

This participatory practice revolves around explicitly enabling and encouraging the crowd to freely modify, add to, and redistribute primary project outcomes. Following the initial proposal and development phases, participants are given complete agency and independence via access to blueprints for development, enabling them to design and develop without the oversight of founders. This is most visible in the case of open source projects, in which founders seek funding as a means to initiate a collaborative project, but where external contributors can revise outcomes, redefine problems, and collaborate independently of the initial founders.

While Open Collaboration bears similarities to Supplemental Development, there are significant distinctions in the collaborative process and degree of agency afforded to participants. While proprietary development kits allow crowd members to participate in a subordinate capacity, open source crowdfunded projects very closely resemble the empowering ideals of creative communities and participatory cultures, enabling the open exchange of resources, knowledge, and expertise among enthused stakeholders. 
These definitions allowed us to distinguish between the major types of participatory practice that we recorded from the sample. In order to investigate the properties and incidence of each mechanism, we recoded variable 1a, as described in Chapter 3.5.1.

\subsubsection{Exclusivity of Participatory Mechanisms}

Following the generation of these participatory mechanisms, we sought to measure their exclusivity in order to more accurately understand their implementation. To that end, I compared the values for variable $1 \mathrm{a}$ and $1 \mathrm{~b}$ in order to measure the proportionate amount of each level of exclusivity within the five mechanisms. The results of these measurements are summarized in Table 2, on the following page.

From these visualizations, I identified clear disparities in the relative exclusivity of each mechanism. These distinctions broadened our comprehension of participatory mechanisms, and are fully described below:

- Open-Ended Feedback was the only mechanism that showed no distinct trends in exclusivity, likely due to the numerous ways that founders incentivized channels for participant feedback. User testing and direct developer contact were the most exclusive forms of this mechanism, while soliciting feedback was the most inclusive.

- Collective Decision-Making was fairly inclusive, though voting rights were most commonly offered as incentives to potential backers. This is likely to ensure that project stakeholders had the most sway over project outcomes, relating to the value of user feedback. 
Table 2. Measuring the Exclusivity of Participatory Mechanisms
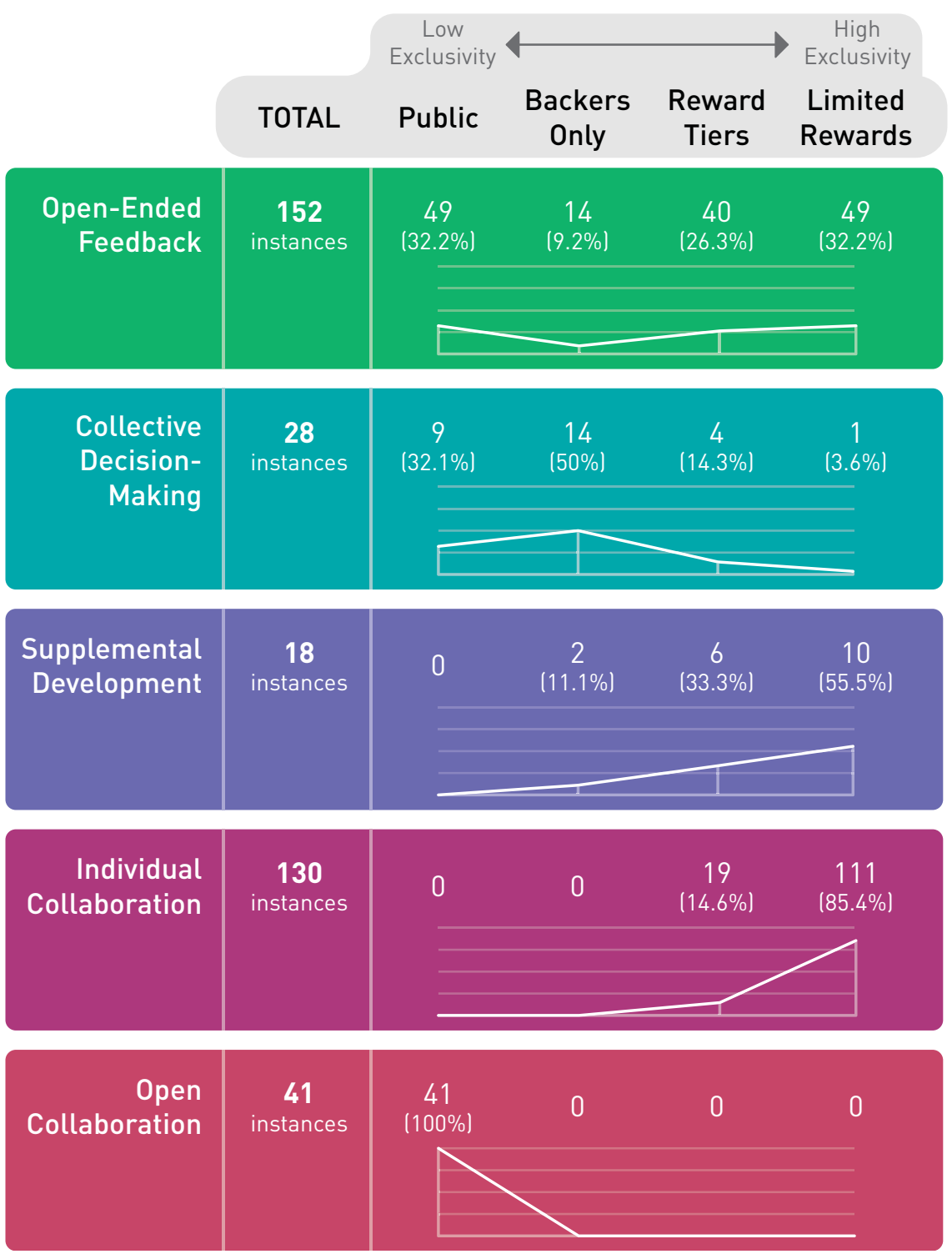

- Supplemental Development was fairly exclusive in that it always required some degree of financial donation, potentially due to the proprietary nature of the associated rewards. 
- Individual Collaboration was the most exclusive participatory mechanism, requiring individuals to opt into specific reward tiers, the majority of which had a maximum number of donors. Design team membership was more likely to be limited to a maximum number of donors. The exclusivity of this mechanism is possibly due to the relatively high degree of control ceded to participants, as well as the logistical costs of necessarily communicating with individual donors.

- Open Collaboration was the most inclusive mechanism, consisting entirely of public activities. Given that this mechanism relies on participants' freedom to access and modify project outcomes, this outcome was expected.

\subsection{Determining the Prevalence of Participatory Practices}

In order to address our second research question, I measured the number of sample projects that used participatory mechanisms, both overall and in the case of each mechanism. I first measured the entire sample, and then individually measured the rate of participation within each of the four Kickstarter categories and the three deliverable types.

\subsubsection{Overall Prevalence of Participation}

Within the sample of 600 Kickstarter projects, 250 (41.67\%) utilized participatory mechanisms, as seen in Figure 7. Of the 150 projects within each category, we found 25 (16.67\%) in Design, 87 (58\%) in Technology, 104 (69.33\%) in Games, and 34 (22.67\%) in Fashion utilized participatory mechanisms. Further, of the 82 projects that were coded as 'software', 67 
(81.71\%) included participation, as did 45 (76.27\%) of the 59 'hardware' projects. Conversely, of the 459 projects that had proposed 'standalone' project deliverables, only 138 (30.01\%) included participation. We recorded 369 distinct instances of participatory activity in the sample, indicating that some participatory projects used multiple mechanisms. Participatory projects used an overall average of 1.476 mechanisms, and more specifically 1.28 in Design, 1.41 in Technology, 1.68 in Games, and 1.14 in Fashion.

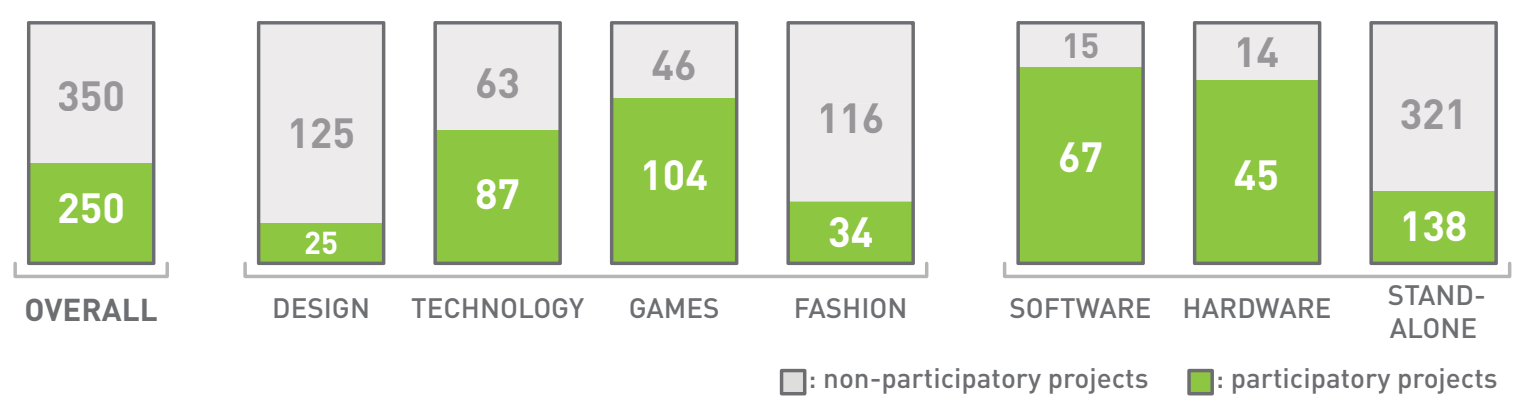

Figure 8. Overall Prevalence of Participatory Mechanisms

While these results indicate a fairly substantial amount of participation within the sample projects, it is important to note that participation was most common in the categories of Technology and Games, and was significantly more prevalent in the development of hardware and software projects. This suggests that implementing participation is easier, less costly, or more useful in certain contexts, dependent on the type of project outcome being proposed. Alternatively, it simply indicates that participatory activities are more or less popular amongst designers and entrepreneurs from different fields, potentially reflecting varying professional or academic viewpoints on the value of user input. 


\subsubsection{Prevalence of Individual Participatory Mechanisms}

In order to gain a more comprehensive understanding of the occurrence of participation in our sample, we chose to examin the prevalence of each participatory mechanism separately, as seen in Figures 9 to 13:

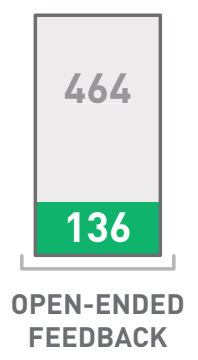

Figure 9. Prevalence of Open-Ended Feedback

Open-Ended Feedback was recorded in 136 projects overall (22.67\%).

It was leveraged most often within the Technology and Games categories, occurring in 53 (35.33\%) and $64(42.67 \%)$ projects respectively, while only appearing in 9 (6\%) Design projects and 10 (6.67\%) Fashion projects. This mechanism was observed in 53 (64.63\%) software projects, 20 (33.9\%) hardware projects and $63(13.73 \%)$ standalone projects.

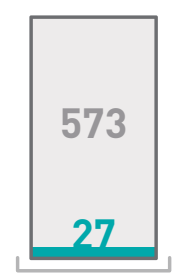

COLLECTIVE DECISIONMAKING

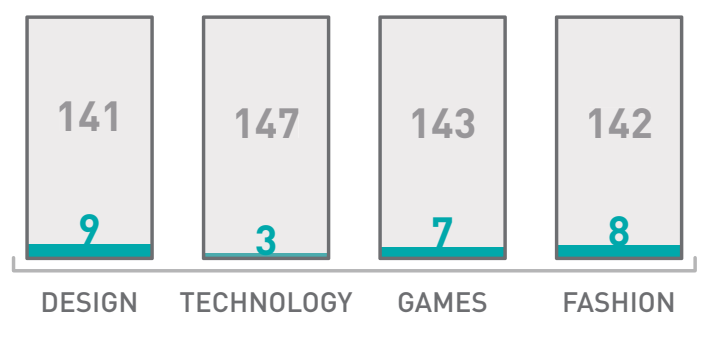

: non-participatory projects

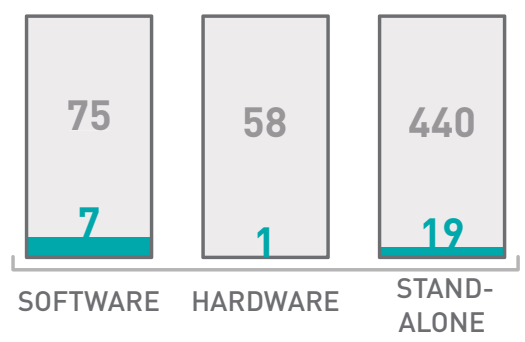

: projects using CDM

Figure 10. Prevalence of Collective Decision-Making

Collective Decision-Making was recorded in 27 projects overall (4.5\%), of which 9 (6\%) were in Design, 3 (2\%) in Technology, 7 (4.67\%) in 
Games, and 8 (5.33\%) in Fashion. This mechanism was observed in 7 (8.54\%) Software projects, 1 (\%1.7) Hardware project, and 19 (4.14\%) Standalone projects.

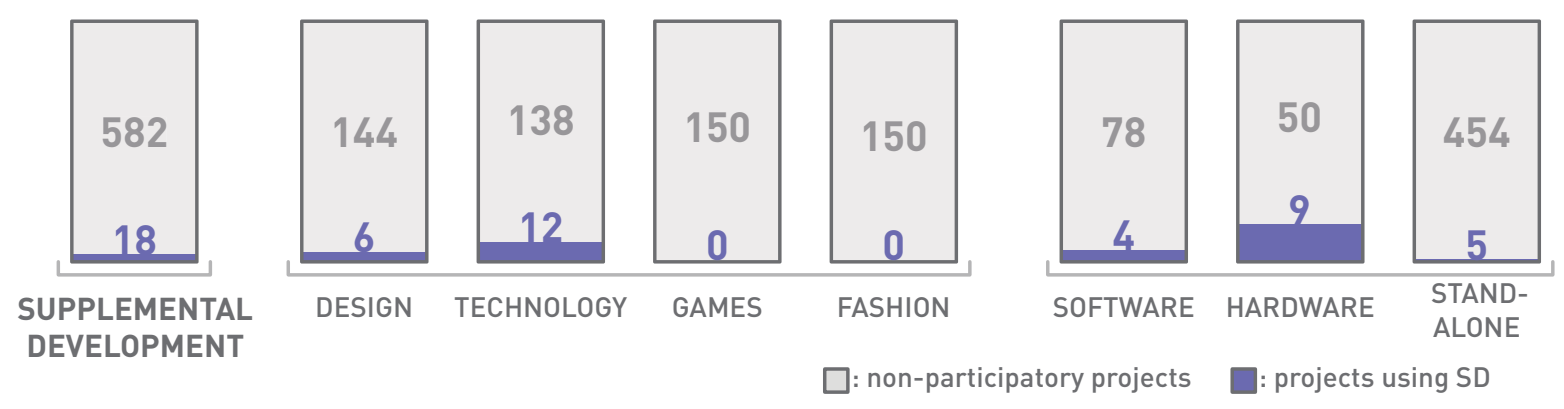

Figure 11. Prevalence of Supplemental Development

Supplemental Development was recorded in 18 projects overall (3\%), of which $6(4 \%)$ were in Design and 12 (8\%) were in Technology. This mechanism was observed in 4 (4.88\%) Software projects, 9 (15.25\%) Hardware projects, and 5 (1.09\%) Standalone projects. Interestingly, Supplemental Development was not observed at all in the Games and Fashion categories, potentially indicating severe difficulties in implementing such practices, or incompatibility with projects in those contexts.

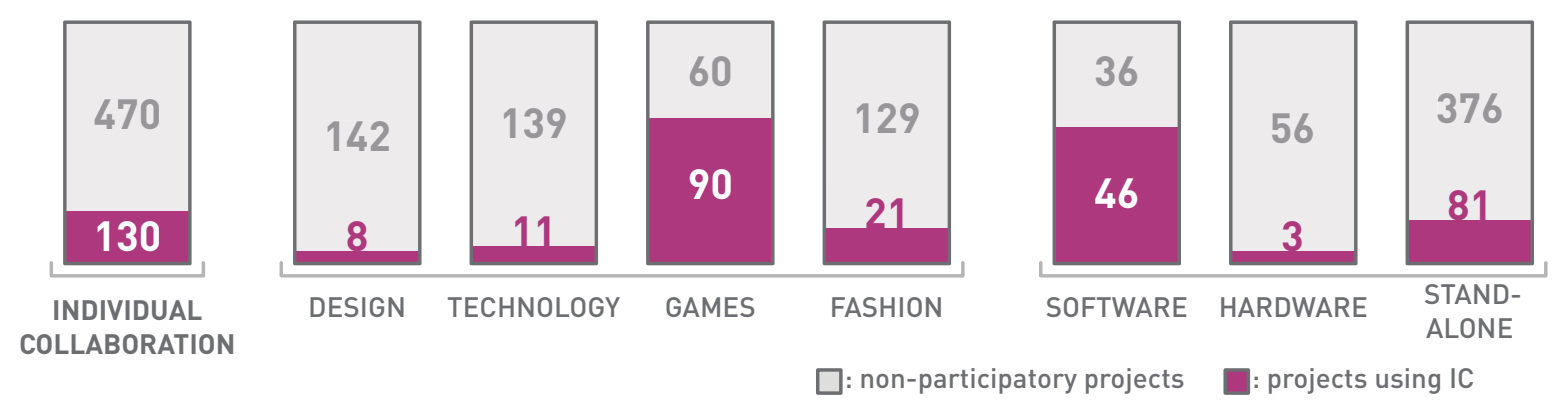

Figure 12. Prevalence of Individual Collaboration

Individual Collaboration was recorded in 130 projects overall (21.67\%), of which 8 (5.33\%) were in Design, 11 (7.33\%) in Technology, 90 
(60\%) in Games, and 21 (14\%) in Fashion. This mechanism was observed in 46 (56.1\%) Software projects, 3 (5.08\%) Hardware projects, and 81 (17.65\%) Standalone projects.
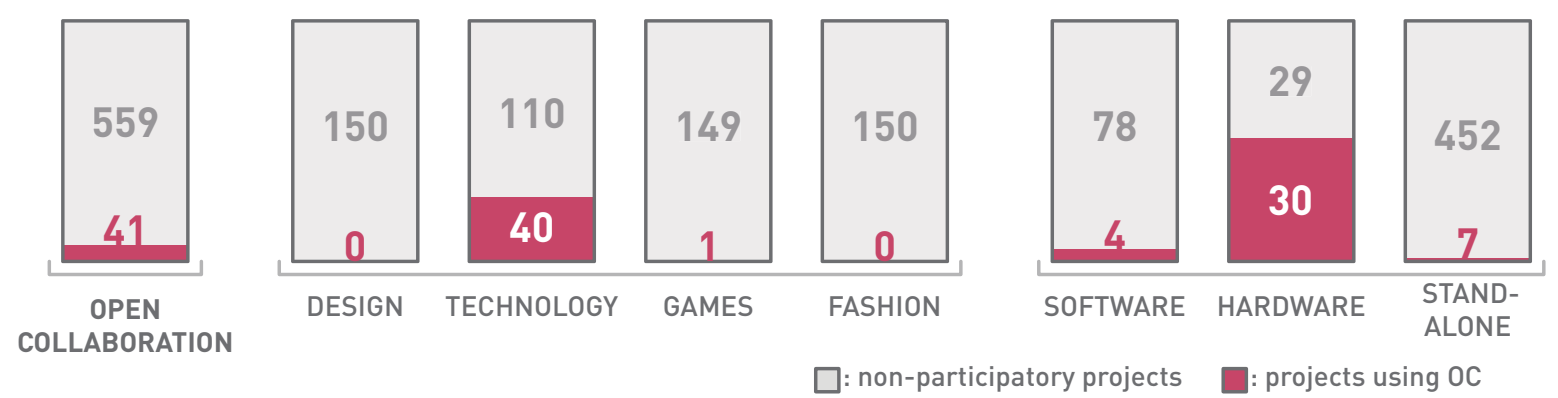

Figure 13. Prevalence of Open Collaboration

Open Collaboration was recorded in 41 projects overall (6.83\%), of which $40(26.67 \%)$ were from the Technology category, with only 1 other instance, in Games (0.67\%). This mechanism was observed in 4 (4.88\%) Software projects, 30 (50.85\%) Hardware projects, and 7 (1.53\%) Standalone projects.

These measurements very clearly indicated disparities in the contexts within which participation and different participatory mechanisms were most often leveraged. My findings on the prevalence of individual mechanisms are further discussed in Chapter 5.0.

\subsection{Plotting Quantifiable Project Variables}

The final stage of data analysis focused on comparing average values of the project variables discussed in chapter 3.3 between seven different groupings within the sample data. These measurements are summarized in Table 3, on the following page: 
Table 3. Average Values of Quantifiable Project Variables

\begin{tabular}{|c|c|c|c|c|c|c|}
\hline & $\begin{array}{l}\text { Funding } \\
\text { Goal }\end{array}$ & $\begin{array}{l}\text { Funds } \\
\text { Raised }\end{array}$ & $\begin{array}{l}\text { Project } \\
\text { Length }\end{array}$ & Backers & Comments & Updates \\
\hline $\begin{array}{r}\text { Non-Participatory } \\
\text { Projects }\end{array}$ & $\$ 14,406$ & $\begin{array}{c}\$ 39,589 \\
\text { (350\% of goals) }\end{array}$ & $\begin{array}{l}32.7 \\
\text { days }\end{array}$ & $\begin{array}{c}545 \\
\text { lavg. \$108) }\end{array}$ & 111 & 12 \\
\hline $\begin{array}{r}\text { Participatory } \\
\text { Projects }\end{array}$ & $\$ 36,055$ & $\begin{array}{c}\$ 121,270 \\
\text { (375\% of goals) }\end{array}$ & $\begin{array}{l}33.2 \\
\text { days }\end{array}$ & $\begin{array}{c}1,340 \\
\text { (avg. \$137) }\end{array}$ & 1,433 & 17.4 \\
\hline $\begin{array}{r}\text { Open-Ended } \\
\text { Feedback }\end{array}$ & $\$ 47,159$ & $\begin{array}{c}\$ 146,089 \\
\text { (353\% of goals) }\end{array}$ & $\begin{array}{l}33.1 \\
\text { days }\end{array}$ & $\begin{array}{c}1,715 \\
\text { (avg. \$142) }\end{array}$ & 2,381 & 18.4 \\
\hline $\begin{array}{r}\text { Collective } \\
\text { Decision-Making }\end{array}$ & $\$ 74,446$ & $\begin{array}{c}\$ 255,952 \\
\text { (352\% of goals) }\end{array}$ & $\begin{array}{l}32.3 \\
\text { days }\end{array}$ & $\begin{array}{c}4,125 \\
\text { (avg. } \$ 82)\end{array}$ & 11,234 & 22.2 \\
\hline $\begin{array}{l}\text { Supplemental } \\
\text { Development }\end{array}$ & $\$ 94,712$ & $\begin{array}{c}\$ 434,056 \\
\text { (468\% of goals) }\end{array}$ & $\begin{array}{l}35.7 \\
\text { days }\end{array}$ & $\begin{array}{c}2,040 \\
\text { (avg. } \$ 187 \text { ) }\end{array}$ & 1432 & 19.9 \\
\hline $\begin{array}{l}\text { Individual } \\
\text { Collaboration }\end{array}$ & $\$ 32,761$ & $\begin{array}{c}\$ 92,100 \\
\text { (266\% of goals })\end{array}$ & $\begin{array}{l}33.5 \\
\text { days }\end{array}$ & $\begin{array}{c}1,661 \\
\text { lavg. \$92) }\end{array}$ & 2,441 & 19.6 \\
\hline $\begin{array}{r}\text { Open } \\
\text { Collaboration }\end{array}$ & $\$ 42,130$ & $\begin{array}{c}\$ 146,020 \\
\text { (691\% of goals) }\end{array}$ & $\begin{array}{l}32.4 \\
\text { days }\end{array}$ & $\begin{array}{c}852 \\
\text { (avg. \$216) }\end{array}$ & 172 & 14.8 \\
\hline
\end{tabular}

In order to further our understanding of the associations between these groupings and individual project variables, I graphed and examined each of these variables separately, as seen in Figures 14 to 21:

\subsubsection{Funding Goal}

Average Funding Goal

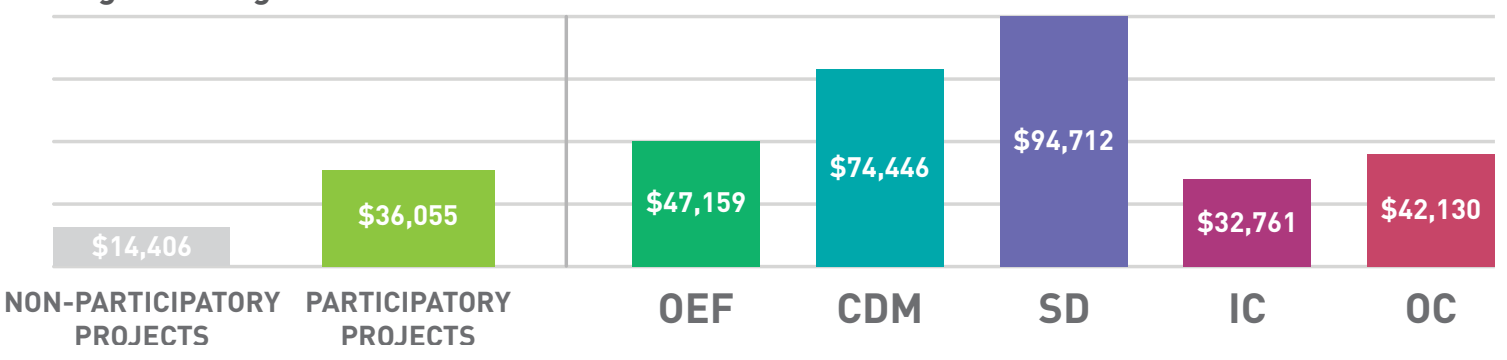

Figure 14. Graphing Average Funding Goals 
Overall, participatory projects featured funding goals that were $150 \%$ larger than non-participatory projects. This was especially evident in projects that utilized Collective Decision-Making or Supplementary Development, which featured goals that were an average of $417 \%$ and $557 \%$ larger, respectively, than those of non-participatory projects. Individual Collaboration displayed the least pronounced increase over non-participatory projects with goals that were an average of $227 \%$ larger. We can infer that the larger a project's projected funding goals are, the larger its proposed scope. As such, these findings allow us to correlate the incidence of participatory activities with larger project sizes.

\subsubsection{Total Funds Raised}

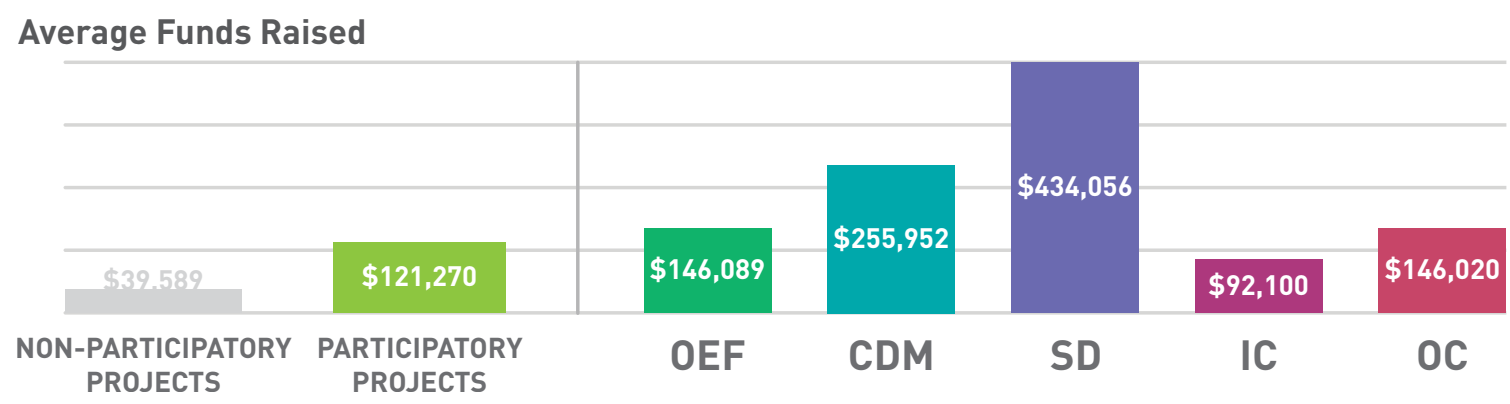

Figure 15. Graphing Average Funds Raised

As with the size of funding goals, the amount of funds raised was significantly larger in participatory projects, which gathered an average of $206 \%$ more contributions than non-participatory projects. Given that our sample only included successful projects, the amount of funds raised was necessarily greater for projects with larger goals. However, greater degrees of over-funding can be associated with reinforcement behaviours (Kuppuswamy \& Bayus, 2013), which are pertinent in that they indicate backer demand for 
project outcomes. As such, I found it more relevant to measure this variable in relation to projects' funding goals:

Average Funds Raised [Relative to Funding Goals]

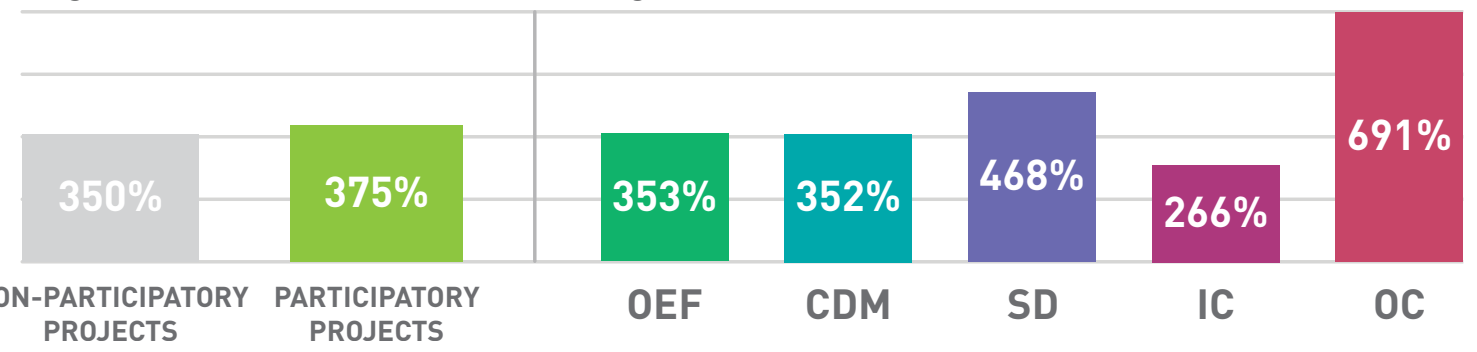

Figure 16. Graphing Average Funds Raised [Relative to Funding Goals]

From these measurements, we can see significantly less disparity between participatory projects and non-participatory projects. In particular, Open-Ended Feedback and Collective Decision-Making appeared to have the least impact on crowd's investment behaviour relative to project funding goals. Projects that used Individual Collaboration, one of the most common participatory mechanisms, actually accumulated proportionately less extra funding than non-participatory projects, while those leveraging Supplemental Development or Open Collaboration raised 34\% and 97\% more respectively.

\subsubsection{Project Length}

Average Project Length

\begin{tabular}{|c|c|c|c|c|c|c|}
\hline $\begin{array}{l}32.7 \\
\text { days }\end{array}$ & $\begin{array}{c}33.2 \\
\text { days }\end{array}$ & $\begin{array}{c}33.1 \\
\text { days }\end{array}$ & $\begin{array}{c}32.3 \\
\text { days }\end{array}$ & $\begin{array}{c}35.7 \\
\text { days }\end{array}$ & $\begin{array}{c}33.5 \\
\text { days }\end{array}$ & $\begin{array}{c}32.4 \\
\text { days }\end{array}$ \\
\hline $\begin{array}{c}\text { PROJECTS } \\
\text { PARTICIPATORY }\end{array}$ & $\begin{array}{c}\text { PARTICIPATORY } \\
\text { PROJECTS }\end{array}$ & OEF & CDM & SD & IC & OC \\
\hline
\end{tabular}

Figure 17. Graphing Average Project Length

We can observe very little variation in project length across the different sample groupings. These results indicate that participatory 
practices are not significant correlated with project length.

\subsubsection{Project Backers}

Average Project Backers

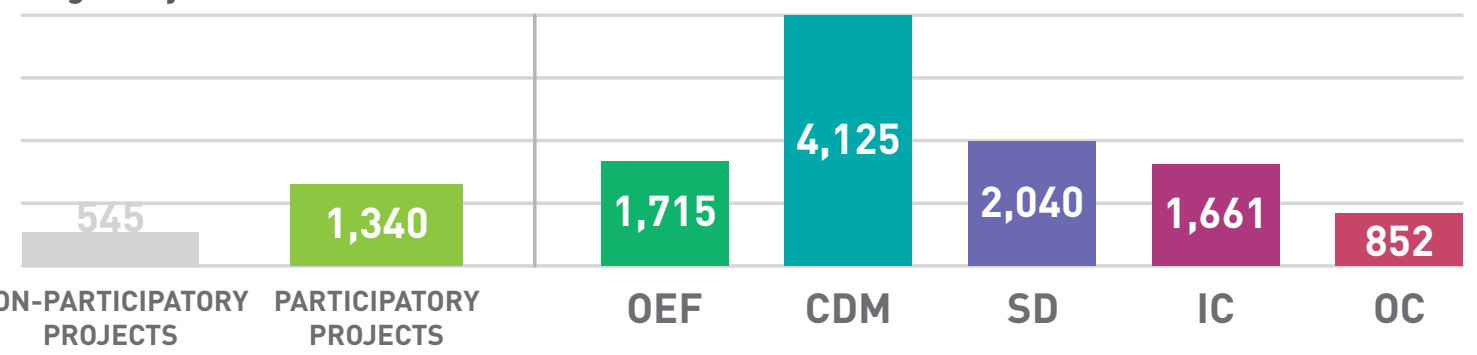

Figure 18. Graphing Average Project Backers

Participatory projects had an average of $145 \%$ more backers than nonparticipatory projects, though this amount was significantly higher in the case of participatory mechanisms other than Open Collaboration. I further measured the mean backer contribution size for each project and compared the average of those values within our sample groupings:

Average Donation Size Per Backer

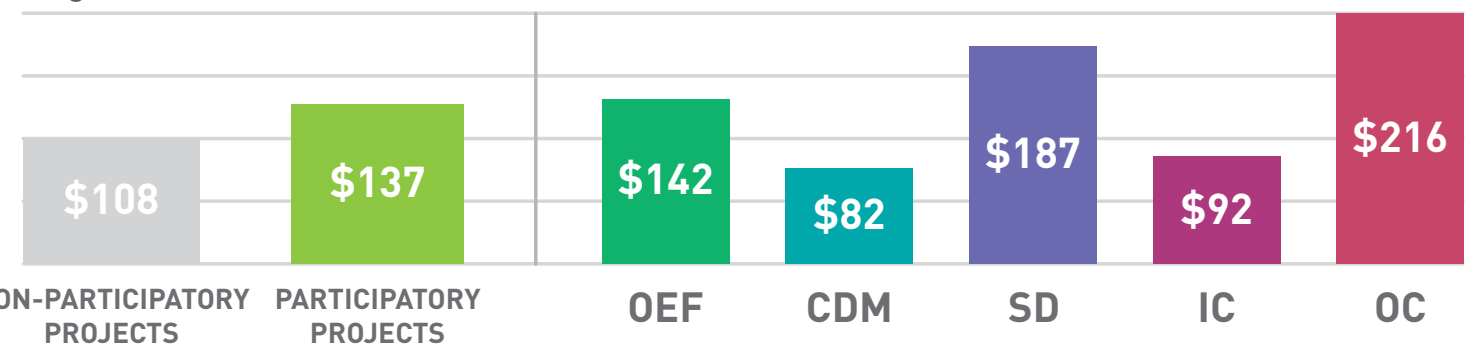

Figure 19. Graphing Average Donation Size Per Backer

These measurements show that participatory projects garnered donations that were an average of $27 \%$ greater than those of nonparticipatory projects, though this was only individually true of three participatory mechanisms. 


\subsubsection{Project Comments}

Average Project Comments

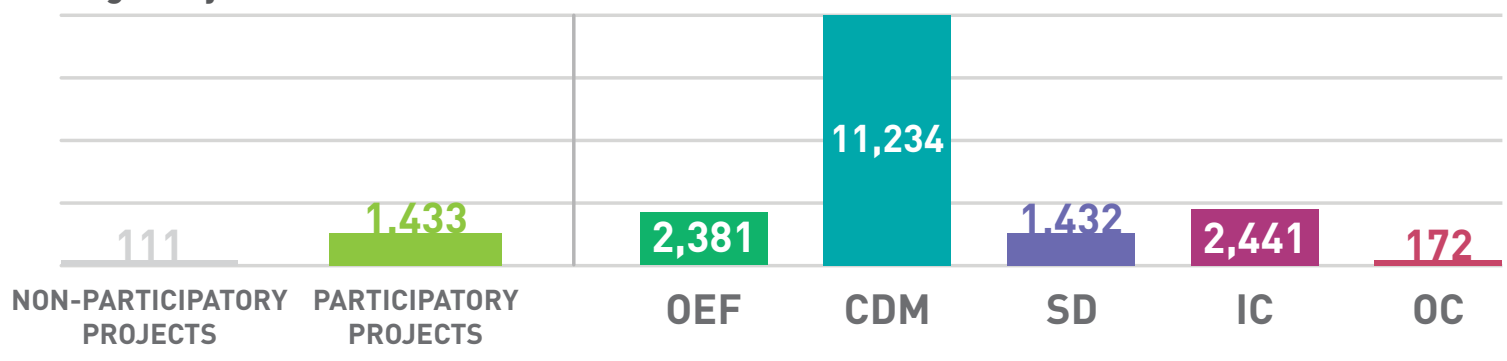

Figure 20. Graphing Average Project Comments

From our measurements, it is extremely apparent that the presence of participatory elements elicited significantly more public feedback from crowds on the sample projects' Kickstarter pages. Project comments are indicative of the crowd's intrinsic willingness to communicate with project founders or with one another, which I expected would be more prevalent in participatory projects. Overall, participatory projects received 1191\% more comments than non-participatory projects, while Collective Decision-Making in particular displayed a 10021\% increase.

\subsubsection{Project Updates}

\section{Average Project Updates}

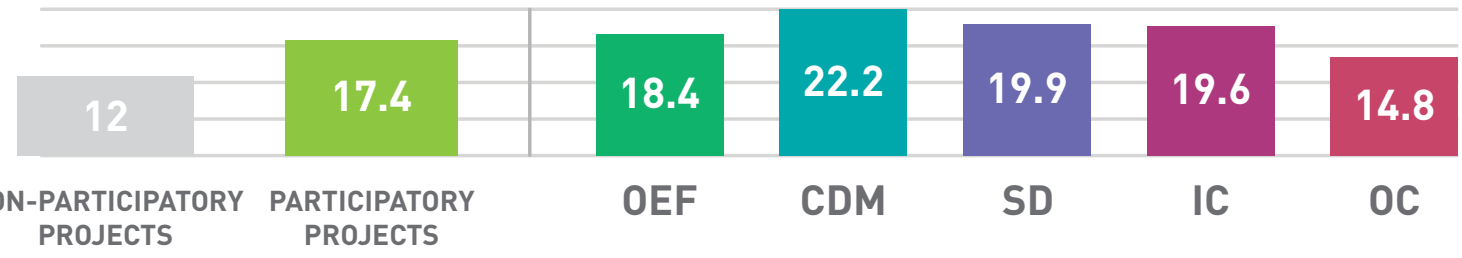

Figure 21. Graphing Average Project Updates

Founders of participatory projects posted an average of $45 \%$ more updates than founders of non-participatory projects. This disparity was most pronounced in the case of Collective Decision-Making projects and 
least pronounced in Open Collaboration projects, similarly to the trend we observed in the average number of project comments. Given that project updates are explicit instances of founders communicating with the crowd, this relation to project comments indicates a greater overall degree of dialogue between the crowd and founders of participatory projects.

\subsection{Conclusions}

My data analysis enabled us to establish a defined set of participatory mechanisms to describe the methods through which founders leveraged creative crowd input to influence project outcomes. The subsequent phases revolved around investigating these participatory mechanisms based on quantifiable observations from our sample data in order to compare the incidence of participation with additional project variables. This process provided us with numerous insights into the contexts within which founders leveraged the crowd's creative capacities to contribute towards the co-design and collaborative development of project outcomes. 


\subsection{CONCLUSIONS}

Crowdfunding is an emergent method of project financing that is facilitated through large numbers of relatively small contributions by individuals that make up a crowd, rather than by large contributions from professional investors. Reward-based crowdfunding specifically incentivizes financial contributions by offering donors non-pecuniary returns on investment, generally in the form of preorders for products or systems that the funding will be used to design and develop. Crowd investors in this context become user-investors, providing both financial backing and market validation for project outcomes. By combining this form of crowdfunding with crowdsourcing, project founders can leverage the creative capacities and local expertise of motivated user-stakeholders through participatory and co-design activities, enabling users to both inform and influence final project outcomes.

This study aimed to broadly survey the present state of crowdsourcing and collaborative design activities in reward-based crowdfunding projects. It was structured around three primary research questions that pertained to defining and quantifying participatory practices and co-design opportunities on Kickstarter, the most prominent reward-based crowdfunding platform. To that end, I collected and subsequently analyzed data on 600 successful design-centered Kickstarter projects from the categories of Design, Technology, Games, and Fashion. The following are summaries of our findings in regards to our three primary research questions:

Q1: How can we classify the various types of participatory practice that the founders of successful design-centered Kickstarter projects are utilizing to influence the design of project outcomes? 
In order to address our first research question, I recorded and identified participatory activities within the sample projects, from which we identified five distinct types of participant input. By grouping and sorting the observed activities by input, I synthesized and subsequently defined five 'participatory mechanisms' that encompassed the range of participatory activity in the sample. I went on to quantify the exclusivity of these mechanisms in order to further elucidate their properties. These mechanisms are briefly described below:

- Open-Ended Feedback (OEF) is a form of crowdsourcing that involves active solicitation of crowd feedback on any elements of a project. Participants are given no control over project outcomes. While this mechanism can be publicly inclusive, the opportunity to participate in user testing, the most common OEF activity, is often incentivized.

- Collective Decision-Making (CDM) is a form of crowdsourcing and loose collaboration in which project founders cede a degree of control to participants, generally via voting rights. Founders determine the subject and available options of a vote, but participants are given agency to collectively decide upon the outcome. This participatory mechanism is most often limited to user-investors.

- Supplemental Development (SD) is a form of crowdsourcing in which founders enable participants to independently design and create products or systems that are directly compatible with project 
outcomes. This generally takes the form of software developer kits, which are most often incentivized as exclusive rewards for backers of particular reward tiers.

- Individual Collaboration (IC) is a form of co-design that facilitates direct collaboration between individual crowd members and project founders, generally as a limited incentive for large financial donations. Participants collaborate with founders to influence the design of project outcomes, though founders retain control over all final decisions.

- Open Collaboration (OC) is a mixture of crowdsourcing and codesign in which founders do not assert ownership over their project, as in the case of open source projects. The crowd is enabled to freely modify or redistribute project outcomes, and crowd members are encouraged to collaborate with founders and one another in an ongoing capacity. This mechanism is the least exclusive and affords participants with the greatest degree of agency.

\section{Q2: How prevalent are these participatory activities in successful design-centered Kickstarter projects?}

In order to address our second research question, I measured the incidence of each of these participatory mechanisms in varying contexts. I found that each mechanism's prevalence was correlated to particular project deliverables and Kickstarter categories, which indicated that their context played a role in their implementation. The following are summaries of my 
findings on the prevalence of participator mechanisms and participation in general:

- Open-Ended Feedback was the most prevalent participatory mechanism. It was observed in $22.67 \%$ of sample projects, and accounted for $54.4 \%$ of all participatory projects. It was most prevalent in the Technology and Games Kickstarter categories and in projects that proposed software as primary deliverables, which we associate with a high incidence of user testing activities in those contexts.

- Collective Decision-Making was observed in only 4.5\% of projects, and accounted for $10.8 \%$ of all participatory projects. While it was evenly distributed amongst most project categories and reward types, it was rarely implemented in the Technology category or hardware projects.

- Supplemental Development was the least prevalent participatory mechanism, observed in only $3 \%$ of sample projects and accounting for $7.2 \%$ of participatory projects. We only observed instances of this mechanism as backer rewards or reward tier opportunities, indicating a relatively high degree of exclusivity. They were only found in the Design and Technology Kickstarter categories, and were most prevalent in hardware projects.

- Individual Collaboration was observed in $21.67 \%$ of projects, and accounted for $52 \%$ of all participatory projects. It was most 
prevalent in the Games category, in which it was notably evident in $60 \%$ of surveyed projects, as well as in projects that proposed software or standalone deliverables.

- Open Collaboration was observed in $6.83 \%$ of projects, and accounted for $16 \%$ of all participatory projects. It was observed almost entirely in hardware projects and the Technology category, likely due to the influence of the technology-centric open source movement.

- Overall, participatory practice was observed in 250 of the 600 surveyed projects. It was most prevalent in the Technology and Games categories, in which is was observed in 58\% and $69.33 \%$ of projects respectively. This prevalence was even more pronounced when projects were broken down by their proposed deliverables, as $76.27 \%$ of hardware projects and $81.71 \%$ of software projects implemented participatory elements. Participation was relatively uncommon in the Design and Fashion categories of Kickstarter, in which less than a quarter of projects were participatory.

\section{Q3: Can the prevalence of participation in successful design-centered Kickstarter projects be correlated to other project variables?}

In order to address our third research question, I investigated how other quantifiable project variables had intersected with the incidence of participatory mechanisms. From this process I was able to observe 
correlations between participatory practices and variables such as project scope, degree of communication between the crowd and project founders, and average donation size. These measurements, both overall and for each mechanism, indicated significant disparities in all project variables other than Project Length. The following are my notable findings on each participatory mechanism, and for participatory projects in general:

- Open-Ended Feedback notably had 30.8\% larger funding goals, raised $20.5 \%$ more funds, attracted $30 \%$ more backers, and accumulated $66.2 \%$ more comments on their Kickstarter pages. This mechanism is the most broadly utilized and least peculiar in terms of its prevalence, exclusivity, and association with quantifiable project variables.

- Collective Decision-Making notably had 106.5\% larger funding goals, attracted $207.8 \%$ more backers, raised $111.1 \%$ more funds total and $40.1 \%$ less funds per backer, accumulated $683.9 \%$ more comments on their Kickstarter pages, and released 27.6\% more project updates. Our analysis indicates that this mechanism is correlated with projects of large scope, both in terms of funding goals and backer response.

- Supplemental Development notably had 162.7\% larger funding goals, attracted $52.2 \%$ more backers, raised $257.9 \%$ more funds total, and $36.5 \%$ more funds per backer. While our sample size for this mechanism was fairly small, our analysis indicated that it was very limited in terms of its implementation, but was correlated with 
projects of particularly large scope and fundraising activity.

- Individual Collaboration notably raised 24.1\% less funding and $32.85 \%$ less funds per backer, and accumulated $70.34 \%$ more comments on their Kickstarter pages. This mechanism was associated with projects of smaller scope than other forms of participation, and was principally implemented within a limited number of contexts.

- Open Collaboration notably raised $84.27 \%$ more funding relative to their funding goals and $57.66 \%$ more funds per backer, attracted $36.42 \%$ fewer backers, accumulated $88 \%$ fewer comments, and posted 14.94\% fewer project updates on their Kickstarter pages. Our analysis indicated that this mechanism was associated with significant financial responses from backers, though also with a relatively limited degree of communication between backers and founders.

- Overall, the presence of participatory activities was associated with projects of significantly larger scope than non-participatory projects, in terms of funding goals, funds raised, number of backers, and degree of communication between founders and the crowd. Given the logistical and managerial costs of leveraging crowdsourcing (Brabham, 2012), we tentatively posit that founders who are prepared to undertake larger projects are more able to implement participatory mechanisms, which may account for our findings. 


\subsection{Limitations}

While the process of measuring project variables allows us to make numerous observations about trends in the implementation of participatory mechanisms, the reasoning for such correlations is largely associative at this point. Further, given that each mechanism displayed different degrees of prevalence based on Kickstarter categories and deliverable type, the variables examined could feasibly be related to project context, or vice versa. As such, we are not asserting that these findings indicate causal relationships, but rather help to build a basis for our understanding of the contexts in which participatory mechanisms are commonly implemented.

\subsection{Contribution to the Field}

The purpose of this research was to address what we identified to be a significant lack of crowdfunding literature pertaining to crowdsourcing or codesign practices. This study has provided broad, explorative insights into the contexts within which participatory practices, crowdsourcing, and co-design activities are leveraged in reward-based crowdfunding projects. The following are our primary contributions:

- Through my analysis, I defined five 'participatory mechanisms' that represent the common methods leveraged by project founders in a sample of successful design-centered projects on Kickstarter. These descriptive mechanisms can be used as a basis for discussing participatory practices in alternative crowdfunding contexts.

- I identified and quantified a number of contexts in which participation and specific participatory mechanisms were most 
often implemented. This provides precedents for future research on participatory practices in design-centered crowdfunding.

- I correlated participation to projects of larger scope, in terms of funding goals, funds raised, number of backers, and degree of communication between founders and the crowd.

\subsection{Suggestions for Future Research}

The primary purpose of this study is to frame future research in order to address a gap in crowdfunding literature. Given the broad and explorative aims of this research, we encourage further verification of our findings in order to challenge and strengthen our comprehension of the relationships between participation and other project variables.

The following are prospective research questions that seek to address identified gaps in crowdfunding literature:

Is the presence of participatory mechanisms a determinant of successful funding in crowdfunding projects?

Given that our investigation focused on Kickstarter projects that had been successfully funded, further research can address participatory mechanisms as a determinant of successful funding, both broadly and for each individual mechanism.

What factors influence founders of reward-based crowdfunding projects to implement crowdsourcing or other participatory mechanisms into the crowdfunding process? 
While our research indicates particular contexts within which participatory practice often occurs, the exact causes for this prevalence are not yet clear. Given that founders must actively opt into participatory practices by building participatory activities into their project proposals and reward structures, it is relevant to discover what motivates them to do so.

How does crowdsourcing and collaboration with user-investors impact the quality of project outcomes in reward-based crowdfunding projects?

Presently, crowdfunding literature focuses largely on measurable variables as determinants of crowdfunding success, where success is defined by the achievement of funding goals rather than necessarily delivering proposed outcomes. Similarly, this research measures the prevalence of participation, but not the effects it has on subsequent design and development processes. While existing literature on co-design practices and crowdsourcing seem to indicate that their convergence with crowdfunding would lead to positive project outcomes, this should be verified through indepth case studies. 


\section{BIBLIOGRAPHY}

Agrawal, A., Catalini, C., Goldfarb, A. (2011). The Geography of Crowdfunding. NET Institute Working Paper No. 10-08. Available at SSRN: http://ssrn.com/abstract=1692661

Ahlers, G. K. C., Cumming, D. J., Guenther, C., \& Schweizer, D. (2012). Signaling in Equity Crowdfunding. Available at SSRN: http://ssrn. com/abstract $=2161587$

Anderson, C. (2009). The Longer Long Tail: How Endless Choice is Creating Unlimited Demand. New York: Random House Business.

Belleflamme, P., Lambert, T., Schwienbacher, A. (2013a). Crowdfunding: Tapping the Right Crowd. Forthcoming; International Conference of the French Finance Association (AFFI), May 11-13, 2011. Available at SSRN: http://ssrn.com/abstract $=1836873$

Belleflamme, P., Lambert, T., Schwienbacher, A. (2013b). Individual Crowdfunding Practices. Venture Capital: An International Journal of Entrepreneurial Finance, Forthcoming. Available at SSRN: http://ssrn.com/abstract $=2151179$

Bødker, S. (1996). Creating Conditions for Participation: Conflicts and Resources in Systems Development. Human-Computer Interaction, Vol. 11(3), 215-236.

Brabham, D. C. (2012). Crowdsourcing: A Model for Leveraging Online Communities. In A. Delwiche \& J. J. Henderson (Eds.), The Participatory Cultures Handbook (pp. 120-129). London: Routledge Publishing. 
Burtch, G., Ghose, A., Wattal, S. (2012). An Empirical Examination of the Antecedents and Consequences of Contribution Patterns in Crowd-Funded Markets. Available at SSRN: http://ssrn.com/ abstract $=1928168$

Giudici, G., Guerini, M., Lamastra, C. R. (2013). Why Crowdfunding Projects Can Succeed: The Role of Proponents' Individual and Territorial Social Capital. Available at SSRN: http://ssrn.com/ abstract $=2255944$

Giudici, G., Nava, R., Lamastra, C. R., Verecondo, C. (2012). Crowdfunding: The New Frontier For Financing Entrepreneurship? Available at SSRN: http://ssrn.com/abstract=2157429

Howe, J. (2006). The Rise of Crowdsourcing. Wired Magazine. Available at Wired: http://wired.com/wired/archive/14.06/crowds_pr.html Imbesi, L. (2008). Design for Self-Production: The Digital Democratization of the Creative Profession. In E. Salmi, J. Maciak, C. Vilain, \& J. Franc (Eds.), Cumulus Working Papers: Saint-Erienne, (pp. 54-56). Helsinki: Kyriiri Oy.

Imbesi, L. (2011). Design for Post-Industrial Societies. Available at Academia. edu: http://www.academia.edu/1089486/Design_for_Post-Industrial_ Societies

Imbesi, L. (2012). From The Culture of Project to Spread Creativity: Mutations of Design as a Profession in the Society of Knowledge. In P. Israsena, J. Tangsantikul, \& D. Durling (Eds.), Design Research Society 2012: Bangkok. Conference Proceedings: Volume 3. Paper presented at DRS2012: Bangkok (pp. 776-790). Bangkok: Chulalongkorn University. 
Jeffries, A. (2013). How Kickstarter stole CES: the rise of the indie hardware developer. The Verge. Retrieved from http://.theverge. com/2013/1/10/3861406/kickstarter-at-ces

Kickspy (2014). Search Kickstarter - All successful projects. Retrieved from http://kickspy.com/projects

Kickstarter Inc. (2014a). Kickstarter. Retrieved from http://kickstarter.com Kickstarter Inc. (2014b). Oculus Rift: Step Into The Game by Oculus -

Kickstarter. Retrieved from http://kickstarter.com

Kickstarter Inc. (2014c). Pebble: E-Paper Watch for iPhone and Android by Pebble Technology - Kickstarter. Retrieved from http://kickstarter. com

Kim, K. \& Hann, I. H. (2013). Does Crowdfunding Democratize Access to Capital? A Geographical Analysis. Available at SSRN: http://ssrn. com/abstract $=2334590$

Kim, K. \& Viswanathan, S. (2013). The Experts in the Crowd: The Role of Reputable Investors in a Crowdfunded Market. TPRC 41: The 41st Research Conference on Communication, Information and Internet Policy. Available at SSRN: http://ssrn.com/abstract=2258243:

Kleemann, F., Voß, G.G., \& Rieder, K. (2008). Un(der)paid Innovators: The Commercial Utilization of Consumer Work through Crowdsourcing. Science, Technology \& Innovation Studies, Vol. 4 (No. 1), pp. 5-26. Kuppuswamy, V., \& Bayus, B. L. (2013). Crowdfunding Creative Ideas: The Dynamics of Project Backers in Kickstarter. UNC Kenan-Flagler Research Paper No. 2013-15. Available at SSRN: http://ssrn.com/ abstract $=2234765$ 
Lehner, O. M. (2013). Crowdfunding Social Ventures: A Model and Research Agenda. Presented first at the 2012 Research Colloquium on Social Entrepreneurship, 16th - 19th July, University of Oxford, Skoll Center of SAID Business School UK. Available at SSRN: http://ssrn. com/abstract $=2102525$

Lévy, P. (1997). Collective Intelligence - Mankind's Emerging World in Cyberspace. New York: Plenum Press.

Lévy, P. (2012). The Creative Conversation of Collective Intelligence. In A. Delwiche \& J. J. Henderson (Eds.), The Participatory Cultures Handbook (pp. 99-108). London: Routledge Publishing.

Manzini, E. (2013). People-As-Assets: Grassroots Innovation and Design in the (Economic, Social, Environmental) Crisis. FIELDS: An Interdisciplinary Design Journal, Volume 1, pp. 6-7.

Mollick, E. (2013a). The Dynamics of Crowdfunding: An Exploratory Study. Journal of Business Venturing, Volume 29, Issue 1, January 2014, Pages 1-16. Available at SSRN: http://ssrn.com/abstract=2088298

Mollick, E. (2013b). Swept Away by the Crowd? Crowdfunding, Venture Capital, and the Selection of Entrepreneurs. Available at SSRN: http://ssrn.com/abstract=2239204

Mortati, M. \& Villari, B. (2012). Connected Communities of Makers. 10th European Academy of Design Conference - Crafting The Future. Available at Academia.edu: http://academia.edu/3341192/ Connected_Communities_Of_Makers

Poetz, M. K. \& Schreier, M. (2012). The Value of Crowdsourcing: Can Users Really Compete with Professionals in Generating New Product Ideas? Journal of Product Innovation Management, Vol. 29 (No. 2), pp. 245-256. 
Qiu, C. (2013). Issues in Crowdfunding: Theoretical and Empirical

Investigation on Kickstarter. Available at SSRN: http://ssrn.com/ abstract $=2345872$

Rubinton, B. J. (2011). Crowdfunding: Disintermediated Investment Banking. Available at SSRN: http://ssrn.com/abstract=1807204

Sanders, E. B.-N., Brandt, E., \& Binder, T. (2010). A Framework for Organizing the Tools and Techniques of Participatory Design. Available at ACM Digital Library: http://dl.acm.org/citation. $\mathrm{cfm}$ ?id=1900476

Sanders, E. B.-N. \& Simons, G. (2009). A Social Vision for Value Co-creation in Design. Available at Technology Innovation Management Review: http://timreview.ca/article/310

Sanders, E. B.-N. \& Stappers, P. J. (2008). Co-creation and the new landscapes of design. Available at MakeTools: http://www. maketools.com/papers.html

Saxton, G. D., \& Wang, L. (2013). The Social Network Effect: The Determinants of Giving through Social Media. Available at SSRN: http://ssrn.com/abstract $=2247138$

Schwienbacher, A. \& Lerralde, B. (2010). Crowdfunding of Small Entrepreneurial Ventures. Handbook Of Entrepreneurial Finance, Oxford University Press, Forthcoming. Available at SSRN: http:// ssrn.com/abstract $=1699183$

Shah, S. K., Smith, S. W., Reedy, E. J. (2012). Who Are User Entrepreneurs? Findings on Innovation, Founder Characteristics, and Firm Characteristics. Available at SSRN: http://ssrn.com/ abstract $=2018517$

Surowiecki, J. (2005). The Wisdom of Crowds. New York: Anchor Books. 
Tufte, T. \& Mefalopolus, P. (2009). Participatory Communication: A Practical Guide. Washington: The World Bank. 


\section{Appendix A}

All columns numerically correspond to the project variables listed in chapter

3.3. Columns 4-9 are strictly recorded as values. Columns 1-3 are coded:

\section{1a: Type of Participatory Activity}

$1=$ Instance of Open-Ended Feedback

$2=$ Instance of Collective Decision-Making

$3=$ Instance of Supplemental Development

$4=$ Instance of Individual Collaboration

$5=$ Instance of Open Collaboration

\section{1b: Exclusivity of Participatory Activity}

$1=$ Corresponding Activity was Public

$2=$ Corresponding Activity was Backer-Only

$3=$ Corresponding Activity was Reward Tier Only

$4=$ Corresponding Activity was Limited Reward Tier Only

\section{2: Kickstarter Project Category}

$1=$ Design

$2=$ Technology

$3=$ Games

$4=$ Fashion

\section{3: Project Deliverable Type}

$1=$ Standalone

$2=$ Hardware

$3=$ Software 


\begin{tabular}{|c|c|c|c|c|c|c|c|c|c|c|c|}
\hline \multicolumn{2}{|c|}{$1 a 1 b$} & 2 & 3 & 4 & 5 & $(5 / 4)$ & 6 & 7 & $(5 / 7)$ & 8 & 9 \\
\hline 1 & 1 & 1 & 1 & $\$ 90,000$ & $\$ 323,697$ & $359.66 \%$ & 40 & 1769 & $\$ 182.98$ & 1241 & 18 \\
\hline 4 & 4 & & & & & & & & & & \\
\hline 1 & 3 & 1 & 1 & $\$ 58,000$ & $\$ 156,789$ & $270.33 \%$ & 42 & 2633 & $\$ 59.55$ & 248 & 15 \\
\hline 3 & 3 & & & & & & & & & & \\
\hline 3 & 2 & 1 & 2 & $\$ 150,000$ & $\$ 616,232$ & $410.82 \%$ & 37 & 4141 & $\$ 148.81$ & 3215 & 18 \\
\hline 2 & 1 & 1 & 1 & $\$ 20,000$ & $\$ 136,640$ & $683.20 \%$ & 45 & 338 & $\$ 404.26$ & 342 & 31 \\
\hline 1 & 4 & 1 & 1 & $\$ 175,000$ & $\$ 547,126$ & $312.64 \%$ & 45 & 3982 & $\$ 137.40$ & 1543 & 21 \\
\hline 3 & 4 & & & & & & & & & & \\
\hline 2 & 2 & 1 & 1 & $\$ 10,000$ & $\$ 18,209$ & $182.09 \%$ & 33 & 474 & $\$ 38.42$ & 46 & 30 \\
\hline 3 & 3 & 1 & 2 & $\$ 100,000$ & $\$ 1,643,117$ & $1643.12 \%$ & 45 & 4459 & $\$ 368.49$ & 742 & 45 \\
\hline 2 & 2 & 1 & 1 & $\$ 5,000$ & $\$ 6,318$ & $126.36 \%$ & 35 & 392 & $\$ 16.12$ & 115 & 8 \\
\hline 4 & 4 & 1 & 1 & $\$ 16,421$ & $\$ 17,083$ & $104.03 \%$ & 42 & 98 & $\$ 174.31$ & 61 & 14 \\
\hline 4 & 4 & 1 & 1 & $\$ 38,000$ & $\$ 45,247$ & $119.07 \%$ & 37 & 107 & $\$ 422.87$ & 76 & 10 \\
\hline 2 & 1 & 1 & 2 & $\$ 100,000$ & $\$ 1,032,352$ & $1032.35 \%$ & 30 & 4378 & $\$ 235.80$ & 16728 & 57 \\
\hline 3 & 4 & & & & & & & & & & \\
\hline 2 & 2 & 1 & 3 & $\$ 30,000$ & $\$ 37,049$ & $123.50 \%$ & 39 & 551 & $\$ 67.24$ & 62 & 18 \\
\hline 4 & 4 & 1 & 1 & $\$ 20,000$ & $\$ 20,373$ & $101.87 \%$ & 36 & 249 & $\$ 81.82$ & 172 & 3 \\
\hline 2 & 2 & 1 & 1 & $\$ 18,884$ & $\$ 31,031$ & $164.32 \%$ & 34 & 629 & $\$ 49.33$ & 185 & 15 \\
\hline 1 & 3 & 1 & 1 & $\$ 75,000$ & $\$ 79,113$ & $105.48 \%$ & 35 & 503 & $\$ 157.28$ & 17 & 18 \\
\hline 1 & 4 & 1 & 1 & $\$ 27,000$ & $\$ 28,520$ & $105.63 \%$ & 33 & 158 & $\$ 180.51$ & 43 & 17 \\
\hline 2 & 3 & & & & & & & & & & \\
\hline 4 & 3 & 1 & 1 & $\$ 25,000$ & $\$ 64,602$ & $258.41 \%$ & 30 & 956 & $\$ 67.58$ & 34 & 12 \\
\hline 1 & 4 & 1 & 1 & $\$ 25,000$ & $\$ 25,051$ & $100.20 \%$ & 41 & 130 & $\$ 192.70$ & 3 & 5 \\
\hline 4 & 4 & 1 & 1 & $\$ 25,000$ & $\$ 27,688$ & $110.75 \%$ & 30 & 96 & $\$ 288.42$ & 5 & 1 \\
\hline 1 & 4 & 1 & 1 & $\$ 50,000$ & $\$ 136,284$ & $272.57 \%$ & 31 & 1878 & $\$ 72.57$ & 347 & 24 \\
\hline ? & 3 & & & & & & & & & & \\
\hline 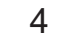 & 4 & & & & & & & & & & \\
\hline 1 & 1 & 1 & 3 & $\$ 30,000$ & $\$ 44,947$ & $149.82 \%$ & 30 & 1915 & $\$ 23.47$ & 64 & 9 \\
\hline 1 & 1 & 1 & 1 & $\$ 3,000$ & $\$ 18,350$ & $611.67 \%$ & 31 & 69 & $\$ 265.94$ & 23 & 4 \\
\hline 3 & 4 & 1 & 2 & $\$ 55,000$ & $\$ 123,660$ & $224.84 \%$ & 30 & 1382 & $\$ 89.48$ & 53 & 9 \\
\hline 4 & 4 & 1 & 1 & $\$ 40,000$ & $\$ 695,139$ & $1737.85 \%$ & 47 & 28818 & $\$ 24.12$ & 862 & 13 \\
\hline 2 & 2 & 1 & 1 & $\$ 1,500$ & $\$ 3,209$ & $213.93 \%$ & 40 & 135 & $\$ 23.77$ & 30 & 14 \\
\hline 0 & - & 1 & 1 & $\$ 3,500$ & $\$ 3,520$ & $100.57 \%$ & 30 & 27 & $\$ 130.37$ & 2 & 5 \\
\hline 0 & - & 1 & 1 & $\$ 10,000$ & $\$ 18,016$ & $180.16 \%$ & 30 & 269 & $\$ 66.97$ & 59 & 15 \\
\hline 0 & - & 1 & 1 & $\$ 7,500$ & $\$ 18,943$ & $252.57 \%$ & 35 & 1463 & $\$ 12.95$ & 121 & 11 \\
\hline 0 & - & 1 & 1 & $\$ 10,500$ & $\$ 31,311$ & $298.20 \%$ & 35 & 763 & $\$ 41.04$ & 57 & 10 \\
\hline 0 & - & 1 & 1 & $\$ 10,000$ & $\$ 11,216$ & $112.16 \%$ & 30 & 98 & $\$ 114.45$ & 6 & 5 \\
\hline 0 & - & 1 & 1 & $\$ 8,000$ & $\$ 248,253$ & $3103.16 \%$ & 45 & 5622 & $\$ 44.16$ & 647 & 5 \\
\hline 0 & - & 1 & 1 & $\$ 10,000$ & $\$ 17,207$ & $172.07 \%$ & 60 & 27 & $\$ 637.30$ & 2 & 2 \\
\hline 0 & - & 1 & 1 & $\$ 10,000$ & $\$ 118,066$ & $1180.66 \%$ & 45 & 3138 & $\$ 37.62$ & 738 & 14 \\
\hline
\end{tabular}




\begin{tabular}{|c|c|c|c|c|c|c|c|c|c|}
\hline 0 & -1 & 1 & $\$ 15,000$ & $\$ 70,328$ & $468.85 \%$ & 45 & 1893 & $\$ 37.15$ & 507 \\
\hline 0 & -1 & 1 & $\$ 2,000$ & $\$ 17,543$ & $877.15 \%$ & 30 & 741 & $\$ 23.67$ & 43 \\
\hline 0 & -1 & 1 & $\$ 2,500$ & $\$ 6,388$ & $255.52 \%$ & 30 & 143 & $\$ 44.67$ & 8 \\
\hline 0 & -1 & 1 & $\$ 5,000$ & $\$ 7,825$ & $156.50 \%$ & 60 & 82 & $\$ 95.43$ & 3 \\
\hline 0 & -1 & 1 & $\$ 15,000$ & $\$ 21,742$ & $144.95 \%$ & 40 & 841 & $\$ 25.85$ & 107 \\
\hline 0 & -1 & 1 & $\$ 40,000$ & $\$ 79,822$ & $199.56 \%$ & 30 & 1552 & $\$ 51.43$ & 98 \\
\hline 0 & -1 & 1 & $\$ 2,000$ & $\$ 2,779$ & $138.95 \%$ & 30 & 75 & $\$ 37.05$ & 10 \\
\hline 0 & -1 & 1 & $\$ 1,500$ & $\$ 2,116$ & $141.07 \%$ & 31 & 40 & $\$ 52.90$ & 2 \\
\hline 0 & -1 & 1 & $\$ 2,000$ & $\$ 2,362$ & $118.10 \%$ & 30 & 98 & $\$ 24.10$ & 21 \\
\hline 0 & -1 & 1 & $\$ 10,000$ & $\$ 10,997$ & $109.97 \%$ & 35 & 229 & $\$ 48.02$ & 122 \\
\hline 0 & -1 & 1 & $\$ 1,500$ & $\$ 37,909$ & $2527.27 \%$ & 36 & 718 & $\$ 52.80$ & 79 \\
\hline 0 & -1 & 1 & $\$ 10,000$ & $\$ 30,083$ & $300.83 \%$ & 35 & 1287 & $\$ 23.37$ & 139 \\
\hline 0 & -1 & 1 & $\$ 400$ & $\$ 888$ & $222.00 \%$ & 7 & 18 & $\$ 49.33$ & 3 \\
\hline 0 & -1 & 1 & $\$ 30,000$ & $\$ 167,226$ & $557.42 \%$ & 35 & 569 & $\$ 293.89$ & 241 \\
\hline 0 & -1 & 1 & $\$ 8,200$ & $\$ 23,613$ & $287.96 \%$ & 27 & 406 & $\$ 58.16$ & 96 \\
\hline 0 & -1 & 1 & $\$ 2,052$ & $\$ 3,536$ & $172.32 \%$ & 20 & 144 & $\$ 24.55$ & 36 \\
\hline 0 & -1 & 1 & $\$ 8,000$ & $\$ 10,235$ & $127.94 \%$ & 31 & 245 & $\$ 41.78$ & 87 \\
\hline 0 & -1 & 1 & $\$ 500$ & $\$ 912$ & $182.40 \%$ & 29 & 67 & $\$ 13.61$ & 7 \\
\hline 0 & -1 & 1 & $\$ 10,500$ & $\$ 25,420$ & $242.10 \%$ & 30 & 3908 & $\$ 6.50$ & 292 \\
\hline 0 & -1 & 1 & $\$ 16,443$ & $\$ 19,903$ & $121.04 \%$ & 30 & 95 & $\$ 209.50$ & 9 \\
\hline 0 & -1 & 1 & $\$ 11,500$ & $\$ 19,184$ & $166.82 \%$ & 30 & 143 & $\$ 134.15$ & 57 \\
\hline 0 & -1 & 1 & $\$ 3,800$ & $\$ 5,645$ & $148.55 \%$ & 30 & 62 & $\$ 91.05$ & 2 \\
\hline 0 & -1 & 1 & $\$ 150,000$ & $\$ 206,188$ & $137.46 \%$ & 30 & 2617 & $\$ 78.79$ & 151 \\
\hline 0 & -1 & 1 & $\$ 19,723$ & $\$ 24,115$ & $122.27 \%$ & 45 & 145 & $\$ 166.31$ & 6 \\
\hline 0 & -1 & 1 & $\$ 10,000$ & $\$ 10,017$ & $100.17 \%$ & 30 & 55 & $\$ 182.13$ & 2 \\
\hline 0 & -1 & 1 & $\$ 10,000$ & $\$ 12,706$ & $127.06 \%$ & 30 & 148 & $\$ 85.85$ & 13 \\
\hline 0 & -1 & 1 & $\$ 25,000$ & $\$ 48,345$ & $193.38 \%$ & 23 & 820 & $\$ 58.96$ & 61 \\
\hline 0 & -1 & 1 & $\$ 8,500$ & $\$ 31,546$ & $371.13 \%$ & 20 & 182 & $\$ 173.33$ & 208 \\
\hline 0 & -1 & 1 & $\$ 3,000$ & $\$ 5,455$ & $181.83 \%$ & 30 & 155 & $\$ 35.19$ & 10 \\
\hline 0 & -1 & 1 & $\$ 10,000$ & $\$ 111,179$ & $1111.79 \%$ & 41 & 994 & $\$ 111.85$ & 1160 \\
\hline 0 & -1 & 1 & $\$ 30,000$ & $\$ 33,982$ & $113.27 \%$ & 33 & 121 & $\$ 280.84$ & 5 \\
\hline 0 & -1 & 1 & $\$ 2,500$ & $\$ 10,926$ & $437.04 \%$ & 30 & 175 & $\$ 62.43$ & 141 \\
\hline 0 & -1 & 1 & $\$ 50,000$ & $\$ 117,064$ & $234.13 \%$ & 47 & 142 & $\$ 824.39$ & 21 \\
\hline 0 & -1 & 1 & $\$ 1,000$ & $\$ 1,206$ & $120.60 \%$ & 45 & 7 & $\$ 172.29$ & 6 \\
\hline 0 & -1 & 1 & $\$ 13,000$ & $\$ 13,021$ & $100.16 \%$ & 40 & 567 & $\$ 22.96$ & 123 \\
\hline 0 & -1 & 1 & $\$ 15,000$ & $\$ 20,862$ & $139.08 \%$ & 34 & 471 & $\$ 44.29$ & 168 \\
\hline 0 & -1 & 1 & $\$ 20,000$ & $\$ 102,924$ & $514.62 \%$ & 34 & 1219 & $\$ 84.43$ & 123 \\
\hline 0 & -1 & 1 & $\$ 3,000$ & $\$ 92,044$ & $3068.13 \%$ & 35 & 660 & $\$ 139.46$ & 207 \\
\hline 0 & -1 & 1 & $\$ 600$ & $\$ 727$ & $121.17 \%$ & 60 & 30 & $\$ 24.23$ & 1 \\
\hline 0 & -1 & 1 & $\$ 1,500$ & $\$ 19,778$ & $1318.53 \%$ & 60 & 367 & $\$ 53.89$ & 123 \\
\hline 0 & -1 & 1 & $\$ 2,000$ & $\$ 4,201$ & $210.05 \%$ & 35 & 215 & $\$ 19.54$ & 36 \\
\hline
\end{tabular}




\begin{tabular}{|c|c|c|c|c|c|c|c|c|c|}
\hline 0 & -1 & 1 & $\$ 11,000$ & $\$ 22,570$ & $205.18 \%$ & 30 & 248 & $\$ 91.01$ & 38 \\
\hline 0 & $-\quad 1$ & 1 & $\$ 25,300$ & $\$ 35,224$ & $139.23 \%$ & 30 & 298 & $\$ 118.20$ & 26 \\
\hline 0 & -1 & 1 & $\$ 4,926$ & $\$ 4,926$ & $100.00 \%$ & 30 & 73 & $\$ 67.48$ & 9 \\
\hline 0 & -1 & 1 & $\$ 6,000$ & $\$ 10,226$ & $170.43 \%$ & 30 & 351 & $\$ 29.13$ & 34 \\
\hline 0 & -1 & 1 & $\$ 5,800$ & $\$ 6,859$ & $118.26 \%$ & 30 & 159 & $\$ 43.14$ & 4 \\
\hline 0 & -1 & 1 & $\$ 3,000$ & $\$ 3,623$ & $120.77 \%$ & 30 & 54 & $\$ 67.09$ & 1 \\
\hline 0 & -1 & 1 & $\$ 20,000$ & $\$ 331,939$ & $1659.70 \%$ & 45 & 5827 & $\$ 56.97$ & 133 \\
\hline 0 & -1 & 1 & $\$ 45,000$ & $\$ 51,930$ & $115.40 \%$ & 30 & 624 & $\$ 83.22$ & 89 \\
\hline 0 & -1 & 1 & $\$ 1,000$ & $\$ 1,037$ & $103.70 \%$ & 30 & 12 & $\$ 86.42$ & 6 \\
\hline 0 & -1 & 1 & $\$ 2,000$ & $\$ 2,372$ & $118.60 \%$ & 21 & 36 & $\$ 65.89$ & 0 \\
\hline 0 & -1 & 1 & $\$ 1,000$ & $\$ 2,667$ & $266.70 \%$ & 25 & 42 & $\$ 63.50$ & 34 \\
\hline 0 & -1 & 1 & $\$ 15,000$ & $\$ 169,153$ & $1127.69 \%$ & 40 & 3153 & $\$ 53.65$ & 352 \\
\hline 0 & -1 & 1 & $\$ 3,000$ & $\$ 5,527$ & $184.23 \%$ & 25 & 217 & $\$ 25.47$ & 72 \\
\hline 0 & -1 & 1 & $\$ 9,000$ & $\$ 28,558$ & $317.31 \%$ & 36 & 751 & $\$ 38.03$ & 131 \\
\hline 0 & -1 & 1 & $\$ 300$ & $\$ 325$ & $108.33 \%$ & 35 & 7 & $\$ 46.43$ & 2 \\
\hline 0 & -1 & 1 & $\$ 10,000$ & $\$ 12,342$ & $123.42 \%$ & 31 & 261 & $\$ 47.29$ & 168 \\
\hline 0 & -1 & 1 & $\$ 10,000$ & $\$ 15,725$ & $157.25 \%$ & 30 & 84 & $\$ 187.20$ & 7 \\
\hline 0 & -1 & 1 & $\$ 8,000$ & $\$ 108,187$ & $1352.34 \%$ & 30 & 5106 & $\$ 21.19$ & 405 \\
\hline 0 & -1 & 1 & $\$ 11,500$ & $\$ 11,797$ & $102.58 \%$ & 29 & 247 & $\$ 47.76$ & 51 \\
\hline 0 & -1 & 1 & $\$ 25,000$ & $\$ 35,267$ & $141.07 \%$ & 45 & 551 & $\$ 64.01$ & 65 \\
\hline 0 & -1 & 1 & $\$ 10,000$ & $\$ 11,000$ & $110.00 \%$ & 35 & 239 & $\$ 46.03$ & 46 \\
\hline 0 & -1 & 1 & $\$ 50,000$ & $\$ 155,519$ & $311.04 \%$ & 30 & 2274 & $\$ 68.39$ & 58 \\
\hline 0 & -1 & 1 & $\$ 32,912$ & $\$ 37,046$ & $112.56 \%$ & 30 & 302 & $\$ 122.67$ & 68 \\
\hline 0 & -1 & 1 & $\$ 12,644$ & $\$ 13,910$ & $110.01 \%$ & 29 & 156 & $\$ 89.17$ & 142 \\
\hline 0 & -1 & 1 & $\$ 20,000$ & $\$ 31,568$ & $157.84 \%$ & 52 & 243 & $\$ 129.91$ & 39 \\
\hline 0 & -1 & 1 & $\$ 1,500$ & $\$ 4,661$ & $310.73 \%$ & 33 & 102 & $\$ 45.70$ & 48 \\
\hline 0 & -1 & 1 & $\$ 19,705$ & $\$ 81,167$ & $411.91 \%$ & 30 & 2864 & $\$ 28.34$ & 116 \\
\hline 0 & -1 & 1 & $\$ 500$ & $\$ 2,183$ & $436.60 \%$ & 25 & 238 & $\$ 9.17$ & 23 \\
\hline 0 & -1 & 1 & $\$ 1,850$ & $\$ 3,214$ & $173.73 \%$ & 30 & 51 & $\$ 63.02$ & 28 \\
\hline 0 & -1 & 1 & $\$ 10,000$ & $\$ 225,348$ & $2253.48 \%$ & 58 & 2690 & $\$ 83.77$ & 410 \\
\hline 0 & -1 & 1 & $\$ 3,500$ & $\$ 3,894$ & $111.26 \%$ & 45 & 118 & $\$ 33.00$ & 25 \\
\hline 0 & -1 & 1 & $\$ 6,000$ & $\$ 6,183$ & $103.05 \%$ & 41 & 208 & $\$ 29.73$ & 37 \\
\hline 0 & -1 & 1 & $\$ 15,000$ & $\$ 168,289$ & $1121.93 \%$ & 30 & 4242 & $\$ 39.67$ & 166 \\
\hline 0 & -1 & 1 & $\$ 8,046$ & $\$ 16,646$ & $206.88 \%$ & 30 & 360 & $\$ 46.24$ & 62 \\
\hline 0 & -1 & 1 & $\$ 2,800$ & $\$ 4,485$ & $160.18 \%$ & 30 & 170 & $\$ 26.38$ & 18 \\
\hline 0 & -1 & 1 & $\$ 12,000$ & $\$ 36,363$ & $303.03 \%$ & 30 & 74 & $\$ 491.39$ & 19 \\
\hline 0 & -1 & 1 & $\$ 400$ & $\$ 624$ & $156.00 \%$ & 24 & 10 & $\$ 62.40$ & 0 \\
\hline 0 & -1 & 1 & $\$ 26,000$ & $\$ 41,215$ & $158.52 \%$ & 45 & 358 & $\$ 115.13$ & 34 \\
\hline 0 & -1 & 1 & $\$ 20,000$ & $\$ 21,891$ & $109.46 \%$ & 32 & 94 & $\$ 232.88$ & 15 \\
\hline 0 & -1 & 1 & $\$ 10,000$ & $\$ 12,369$ & $123.69 \%$ & 31 & 461 & $\$ 26.83$ & 49 \\
\hline 0 & -1 & 1 & $\$ 14,500$ & $\$ 14,810$ & $102.14 \%$ & 30 & 156 & $\$ 94.94$ & 0 \\
\hline
\end{tabular}




\begin{tabular}{|c|c|c|c|c|c|c|c|c|c|c|c|}
\hline 0 & - & 1 & 1 & $\$ 12,000$ & $\$ 23,470$ & $195.58 \%$ & 30 & 111 & $\$ 211.44$ & 32 & 10 \\
\hline 0 & - & 1 & 1 & $\$ 3,000$ & $\$ 15,442$ & $514.73 \%$ & 30 & 259 & $\$ 59.62$ & 620 & 29 \\
\hline 0 & - & 1 & 1 & $\$ 25,000$ & $\$ 85,481$ & $341.92 \%$ & 32 & 1546 & $\$ 55.29$ & 165 & 12 \\
\hline 0 & - & 1 & 1 & $\$ 3,400$ & $\$ 4,594$ & $135.12 \%$ & 30 & 161 & $\$ 28.53$ & 29 & 4 \\
\hline 0 & - & 1 & 1 & $\$ 800$ & $\$ 2,338$ & $292.25 \%$ & 30 & 147 & $\$ 15.90$ & 45 & 3 \\
\hline 0 & - & 1 & 1 & $\$ 15,000$ & $\$ 25,718$ & $171.45 \%$ & 33 & 603 & $\$ 42.65$ & 125 & 13 \\
\hline 0 & - & 1 & 1 & $\$ 40,000$ & $\$ 62,114$ & $155.29 \%$ & 40 & 134 & $\$ 463.54$ & 58 & 6 \\
\hline 0 & - & 1 & 1 & $\$ 75,000$ & $\$ 100,673$ & $134.23 \%$ & 30 & 476 & $\$ 211.50$ & 55 & 9 \\
\hline 0 & - & 1 & 1 & $\$ 5,000$ & $\$ 6,467$ & $129.34 \%$ & 30 & 57 & $\$ 113.46$ & 3 & . \\
\hline 0 & - & 1 & 1 & $\$ 2,000$ & $\$ 5,118$ & $255.90 \%$ & 30 & 108 & $\$ 47.39$ & 26 & 15 \\
\hline 0 & - & 1 & 1 & $\$ 2,450$ & $\$ 2,606$ & $106.37 \%$ & 30 & 54 & $\$ 48.26$ & 9 & \\
\hline 0 & - & 1 & 1 & $\$ 30,000$ & $\$ 193,539$ & $645.13 \%$ & 30 & 3204 & $\$ 60.41$ & 154 & \\
\hline 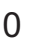 & - & 1 & 1 & $\$ 49,263$ & $\$ 79,052$ & $160.47 \%$ & 60 & 233 & $\$ 339.28$ & 14 & 34 \\
\hline 0 & - & 1 & 1 & $\$ 4,000$ & $\$ 8,136$ & $203.40 \%$ & 39 & 166 & $\$ 49.01$ & 45 & 17 \\
\hline U & - & 1 & 1 & $\$ 20,000$ & $\$ 20,692$ & $103.46 \%$ & 33 & 257 & $\$ 80.51$ & 1 & 6 \\
\hline 0 & - & 1 & 1 & $\$ 6,500$ & $\$ 7,123$ & $109.58 \%$ & 30 & 141 & $\$ 50.52$ & 7 & 6 \\
\hline 0 & - & 1 & 1 & $\$ 3,000$ & $\$ 18,461$ & $615.37 \%$ & 40 & 111 & $\$ 166.32$ & 46 & 33 \\
\hline 0 & - & 1 & 1 & $\$ 600$ & $\$ 677$ & $112.83 \%$ & 30 & 24 & $\$ 28.21$ & 11 & 6 \\
\hline 0 & - & 1 & 1 & $\$ 90,316$ & $\$ 109,292$ & $121.01 \%$ & 45 & 782 & $\$ 139.76$ & 371 & 9 \\
\hline 0 & - & 1 & 1 & $\$ 10,000$ & $\$ 20,125$ & $201.25 \%$ & 42 & 599 & $\$ 33.60$ & 42 & 8 \\
\hline 0 & - & 1 & 1 & $\$ 15,000$ & $\$ 31,838$ & $212.25 \%$ & 33 & 588 & $\$ 54.15$ & 157 & \\
\hline 0 & - & 1 & 3 & $\$ 15,000$ & $\$ 15,388$ & $102.59 \%$ & 30 & 191 & $\$ 80.57$ & 16 & 21 \\
\hline 0 & - & 1 & 1 & $\$ 32,842$ & $\$ 42,681$ & $129.96 \%$ & 30 & 76 & $\$ 561.60$ & 6 & 5 \\
\hline 0 & - & 1 & 1 & $\$ 14,000$ & $\$ 817,165$ & $5836.89 \%$ & 36 & 14253 & $\$ 57.33$ & 819 & 16 \\
\hline 0 & - & 1 & 1 & $\$ 14,000$ & $\$ 24,314$ & $173.67 \%$ & 32 & 1176 & $\$ 20.68$ & 146 & 4 \\
\hline 0 & - & 1 & 1 & $\$ 2,000$ & $\$ 2,667$ & $133.35 \%$ & 30 & 285 & $\$ 9.36$ & 23 & 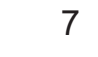 \\
\hline 0 & - & 1 & 1 & $\$ 11,495$ & $\$ 41,926$ & $364.74 \%$ & 30 & 504 & $\$ 83.19$ & 21 & 8 \\
\hline 0 & - & 1 & 1 & $\$ 50,000$ & $\$ 452,457$ & $904.91 \%$ & 30 & 4491 & $\$ 100.75$ & 655 & 21 \\
\hline 0 & - & 1 & 1 & $\$ 30,000$ & $\$ 83,633$ & $278.78 \%$ & 30 & 335 & $\$ 249.65$ & 197 & 18 \\
\hline 0 & - & 1 & 1 & $\$ 14,000$ & $\$ 126,873$ & $906.24 \%$ & 48 & 1523 & $\$ 83.30$ & 162 & 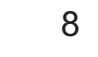 \\
\hline 0 & - & 1 & 1 & $\$ 35,000$ & $\$ 55,026$ & $157.22 \%$ & 60 & 1063 & $\$ 51.76$ & 78 & 12 \\
\hline 0 & - & 1 & 1 & $\$ 9,500$ & $\$ 10,263$ & $108.03 \%$ & 45 & 210 & $\$ 48.87$ & 34 & 5 \\
\hline 0 & - & 1 & 1 & $\$ 2,000$ & $\$ 4,998$ & $249.90 \%$ & 40 & 655 & $\$ 7.63$ & 55 & 10 \\
\hline 0 & - & 1 & 1 & $\$ 10,000$ & $\$ 10,884$ & $108.84 \%$ & 30 & 115 & $\$ 94.64$ & 22 & 12 \\
\hline 0 & - & 1 & 1 & $\$ 4,500$ & $\$ 17,252$ & $383.38 \%$ & 38 & 721 & $\$ 23.93$ & 138 & 6 \\
\hline 5 & 1 & 2 & 2 & $\$ 11,494$ & $\$ 14,190$ & $123.46 \%$ & 45 & 226 & $\$ 62.79$ & 61 & 14 \\
\hline 1 & 4 & 2 & 2 & $\$ 75,000$ & $\$ 325,343$ & $433.79 \%$ & 32 & 437 & $\$ 744.49$ & 67 & 23 \\
\hline 5 & 1 & 2 & 2 & $\$ 80,000$ & $\$ 602,960$ & $753.70 \%$ & 35 & 1991 & $\$ 302.84$ & 118 & 20 \\
\hline 1 & 3 & 2 & 3 & $\$ 20,000$ & $\$ 27,362$ & $136.81 \%$ & 31 & 174 & $\$ 157.25$ & 28 & $\delta$ \\
\hline 1 & 2 & 2 & 1 & $\$ 5,000$ & $\$ 99,720$ & $1994.40 \%$ & 35 & 759 & $\$ 131.38$ & 265 & 18 \\
\hline 5 & 1 & 2 & 2 & $\$ 14,000$ & $\$ 166,098$ & $1186.41 \%$ & 30 & 303 & $\$ 548.18$ & 26 & 12 \\
\hline
\end{tabular}




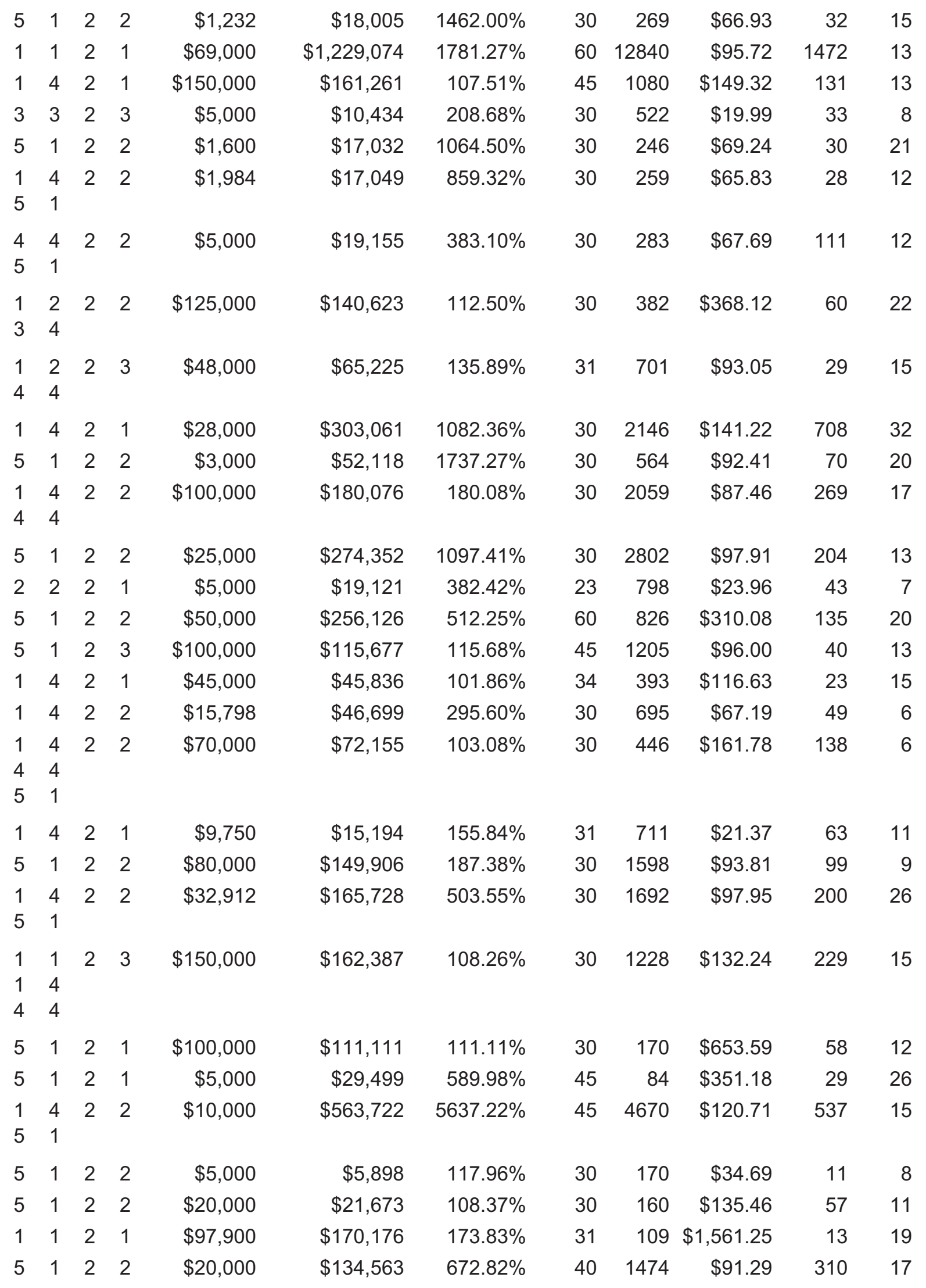




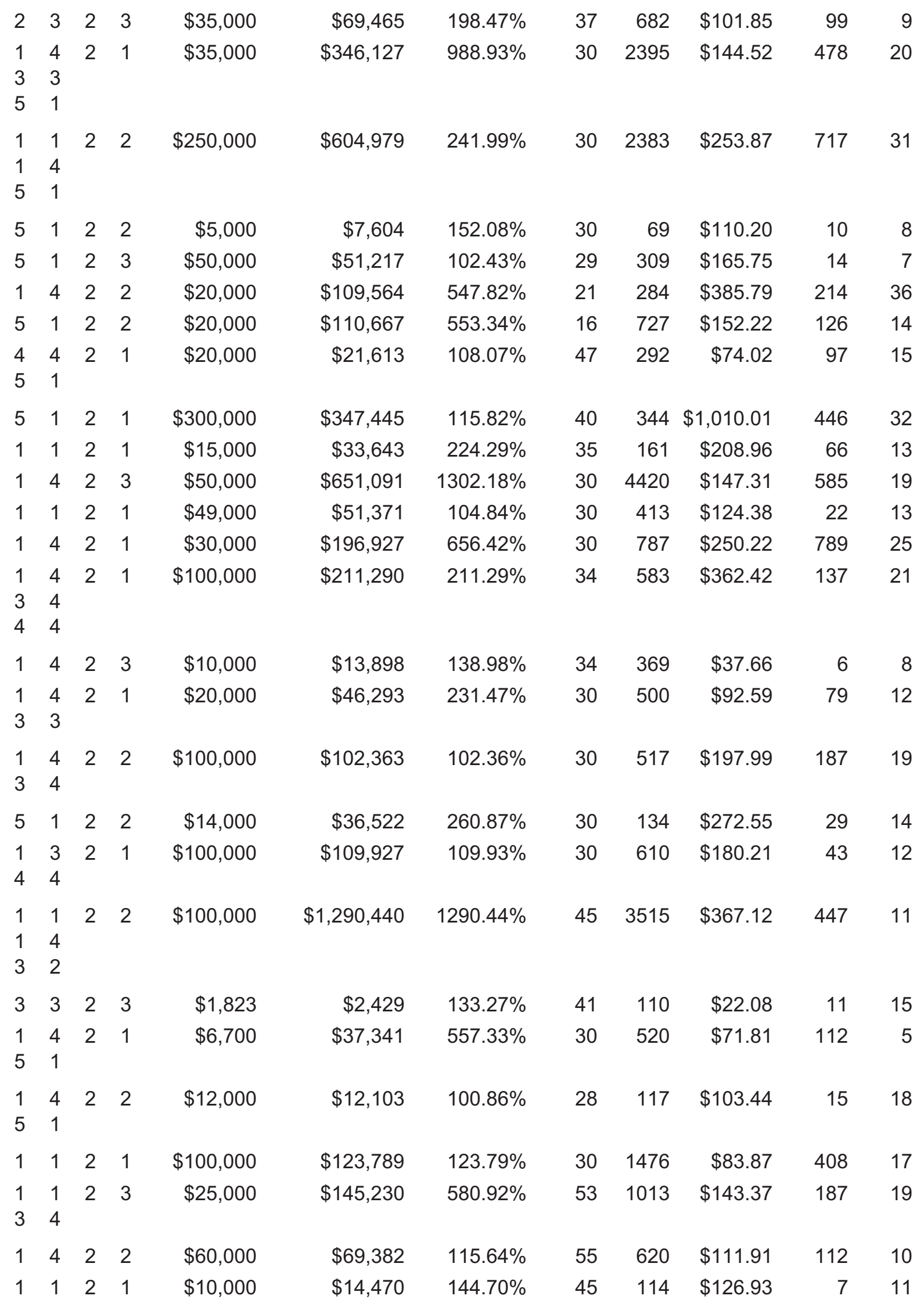




\begin{tabular}{|c|c|c|c|c|c|c|c|c|c|c|c|}
\hline $\begin{array}{l}1 \\
4\end{array}$ & $\begin{array}{l}3 \\
4\end{array}$ & 2 & 3 & $\$ 15,000$ & $\$ 15,120$ & $100.80 \%$ & 35 & 98 & $\$ 154.29$ & 1 & 2 \\
\hline 4 & 3 & 2 & 3 & $\$ 8,285$ & $\$ 8,884$ & $107.24 \%$ & 30 & 142 & $\$ 62.57$ & 4 & 4 \\
\hline 1 & 1 & 2 & 1 & $\$ 24,000$ & $\$ 183,014$ & $762.56 \%$ & 30 & 3090 & $\$ 59.23$ & 605 & 11 \\
\hline $\begin{array}{l}1 \\
3\end{array}$ & $\begin{array}{l}1 \\
4\end{array}$ & 2 & 2 & $\$ 400,000$ & $\$ 1,052,111$ & $263.03 \%$ & 31 & 3863 & $\$ 272.36$ & 1222 & 16 \\
\hline $\begin{array}{l}1 \\
5\end{array}$ & $\begin{array}{l}4 \\
1\end{array}$ & 2 & 2 & $\$ 35,595$ & $\$ 37,223$ & $104.57 \%$ & 45 & 203 & $\$ 183.36$ & 24 & 9 \\
\hline 5 & 1 & 2 & 1 & $\$ 82,780$ & $\$ 480,763$ & $580.77 \%$ & 31 & 1971 & $\$ 243.92$ & 312 & 8 \\
\hline 1 & $\begin{array}{l}1 \\
4 \\
4 \\
1\end{array}$ & 2 & 2 & $\$ 95,000$ & $\$ 267,373$ & $281.45 \%$ & 30 & 1967 & $\$ 135.93$ & 352 & 17 \\
\hline 5 & 1 & 2 & 2 & $\$ 24,050$ & $\$ 51,058$ & $212.30 \%$ & 30 & 72 & $\$ 709.14$ & 13 & 11 \\
\hline 4 & $\begin{array}{l}4 \\
1\end{array}$ & 2 & 3 & $\$ 8,278$ & $\$ 15,058$ & $181.90 \%$ & 30 & 134 & $\$ 112.37$ & 8 & 23 \\
\hline 1 & 4 & 2 & 2 & $\$ 25,000$ & $\$ 116,592$ & $466.37 \%$ & 24 & 96 & $\$ 1,214.50$ & 63 & 12 \\
\hline 1 & 3 & 2 & 3 & $\$ 10,000$ & $\$ 10,304$ & $103.04 \%$ & 32 & 177 & $\$ 58.21$ & 30 & 9 \\
\hline 5 & 1 & 2 & 2 & $\$ 9,000$ & $\$ 413,531$ & $4594.79 \%$ & 28 & 1409 & $\$ 293.49$ & 1855 & 29 \\
\hline 1 & 4 & 2 & 3 & $\$ 152,000$ & $\$ 152,795$ & $100.52 \%$ & 40 & 194 & $\$ 787.60$ & 23 & 8 \\
\hline $\begin{array}{l}1 \\
5\end{array}$ & $\begin{array}{l}4 \\
1\end{array}$ & 2 & 2 & $\$ 95,000$ & $\$ 125,140$ & $131.73 \%$ & 30 & 112 & $\$ 1,117.32$ & 13 & 18 \\
\hline 1 & 3 & 2 & 3 & $\$ 2,500$ & $\$ 2,525$ & $101.00 \%$ & 30 & 37 & $\$ 68.24$ & 1 & 2 \\
\hline 5 & 1 & 2 & 2 & $\$ 24,834$ & $\$ 203,485$ & $819.38 \%$ & 30 & 1895 & $\$ 107.38$ & 107 & 12 \\
\hline 5 & 1 & 2 & 2 & $\$ 3,000$ & $\$ 7,445$ & $248.17 \%$ & 15 & 271 & $\$ 27.47$ & 7 & 6 \\
\hline 5 & 1 & 2 & 2 & $\$ 828$ & $\$ 2,950$ & $356.40 \%$ & 14 & 133 & $\$ 22.18$ & 25 & 5 \\
\hline $\begin{array}{l}1 \\
3\end{array}$ & $\begin{array}{l}4 \\
4\end{array}$ & 2 & 3 & $\$ 60,000$ & $\$ 79,024$ & $131.71 \%$ & 30 & 386 & $\$ 204.73$ & 54 & 13 \\
\hline $\begin{array}{l}1 \\
2\end{array}$ & $\begin{array}{l}1 \\
1\end{array}$ & 2 & 1 & $\$ 40,000$ & $\$ 62,508$ & $156.27 \%$ & 30 & 4107 & $\$ 15.22$ & 345 & 14 \\
\hline 1 & 1 & 2 & 1 & $\$ 19,000$ & $\$ 396,111$ & $2084.79 \%$ & 40 & 5279 & $\$ 75.04$ & 746 & 8 \\
\hline 1 & 2 & 2 & 1 & $\$ 10,000$ & $\$ 13,435$ & $134.35 \%$ & 30 & 236 & $\$ 56.93$ & 33 & 10 \\
\hline 1 & 2 & 2 & 2 & $\$ 5,000$ & $\$ 12,065$ & $241.30 \%$ & 30 & 98 & $\$ 123.11$ & 21 & 15 \\
\hline 1 & 2 & 2 & 1 & $\$ 25,000$ & $\$ 36,435$ & $145.74 \%$ & 30 & 500 & $\$ 72.87$ & 98 & 17 \\
\hline 0 & - & 2 & 3 & $\$ 2,500$ & $\$ 2,797$ & $111.88 \%$ & 45 & 78 & $\$ 35.86$ & 4 & 4 \\
\hline 0 & - & 2 & 1 & $\$ 600$ & $\$ 7,448$ & $1241.33 \%$ & 45 & 77 & $\$ 96.73$ & 26 & 7 \\
\hline 0 & - & 2 & 1 & $\$ 50,000$ & $\$ 57,853$ & $115.71 \%$ & 40 & 758 & $\$ 76.32$ & 248 & 14 \\
\hline 0 & - & 2 & 2 & $\$ 49,260$ & $\$ 76,652$ & $155.61 \%$ & 35 & 198 & $\$ 387.13$ & 1 & 19 \\
\hline 0 & - & 2 & 2 & $\$ 2,000$ & $\$ 3,862$ & $193.10 \%$ & 30 & 122 & $\$ 31.66$ & 52 & 0 \\
\hline 0 & - & 2 & 2 & $\$ 20,525$ & $\$ 21,530$ & $104.90 \%$ & 30 & 341 & $\$ 63.14$ & 52 & 31 \\
\hline 0 & - & 2 & 1 & $\$ 25,000$ & $\$ 30,965$ & $123.86 \%$ & 30 & 439 & $\$ 70.54$ & 114 & 13 \\
\hline
\end{tabular}




\begin{tabular}{|c|c|c|c|c|c|c|c|c|c|c|}
\hline 0 & - & 2 & 2 & $\$ 2,000$ & $\$ 3,735$ & $186.75 \%$ & 7 & 82 & $\$ 45.55$ & 12 \\
\hline 0 & - & 2 & 3 & $\$ 3,500$ & $\$ 15,449$ & $441.40 \%$ & 45 & 292 & $\$ 52.91$ & 72 \\
\hline 0 & - & 2 & 1 & $\$ 6,000$ & $\$ 6,337$ & $105.62 \%$ & 31 & 125 & $\$ 50.70$ & 13 \\
\hline 0 & - & 2 & 1 & $\$ 5,000$ & $\$ 91,525$ & $1830.50 \%$ & 21 & 5092 & $\$ 17.97$ & 250 \\
\hline 0 & - & 2 & 1 & $\$ 100,000$ & $\$ 105,589$ & $105.59 \%$ & 17 & 127 & $\$ 831.41$ & 11 \\
\hline 0 & - & 2 & 1 & $\$ 20,000$ & $\$ 24,594$ & $122.97 \%$ & 45 & 571 & $\$ 43.07$ & 82 \\
\hline 0 & - & 2 & 1 & $\$ 50,000$ & $\$ 168,517$ & $337.03 \%$ & 33 & 3306 & $\$ 50.97$ & 156 \\
\hline 0 & - & 2 & 1 & $\$ 30,000$ & $\$ 59,030$ & $196.77 \%$ & 35 & 979 & $\$ 60.30$ & 245 \\
\hline 0 & - & 2 & 1 & $\$ 35,000$ & $\$ 43,336$ & $123.82 \%$ & 30 & 204 & $\$ 212.43$ & 54 \\
\hline 0 & - & 2 & 1 & $\$ 100,000$ & $\$ 115,513$ & $115.51 \%$ & 31 & 437 & $\$ 264.33$ & 94 \\
\hline 0 & - & 2 & 1 & $\$ 2,000$ & $\$ 6,305$ & $315.25 \%$ & 40 & 124 & $\$ 50.85$ & 4 \\
\hline 0 & - & 2 & 1 & $\$ 52,000$ & $\$ 56,356$ & $108.38 \%$ & 30 & 117 & $\$ 481.68$ & 13 \\
\hline 0 & - & 2 & 1 & $\$ 5,000$ & $\$ 9,318$ & $186.36 \%$ & 30 & 50 & $\$ 186.36$ & 13 \\
\hline 0 & - & 2 & 2 & $\$ 3,000$ & $\$ 6,948$ & $231.60 \%$ & 30 & 114 & $\$ 60.95$ & 2 \\
\hline 0 & - & 2 & 2 & $\$ 1,000$ & $\$ 2,568$ & $256.80 \%$ & 34 & 62 & $\$ 41.42$ & 5 \\
\hline 0 & - & 2 & 2 & $\$ 44,477$ & $\$ 49,093$ & $110.38 \%$ & 33 & 303 & $\$ 162.02$ & 30 \\
\hline 0 & - & 2 & 2 & $\$ 12,000$ & $\$ 14,961$ & $124.68 \%$ & 21 & 61 & $\$ 245.26$ & 20 \\
\hline 0 & - & 2 & 1 & $\$ 50,000$ & $\$ 129,224$ & $258.45 \%$ & 45 & 148 & $\$ 873.14$ & 158 \\
\hline 0 & - & 2 & 1 & $\$ 7,000$ & $\$ 12,799$ & $182.84 \%$ & 40 & 312 & $\$ 41.02$ & 35 \\
\hline 0 & - & 2 & 1 & $\$ 50,000$ & $\$ 69,874$ & $139.75 \%$ & 35 & 292 & $\$ 239.29$ & 24 \\
\hline 0 & - & 2 & 1 & $\$ 10,000$ & $\$ 32,687$ & $326.87 \%$ & 44 & 144 & $\$ 226.99$ & 23 \\
\hline 0 & - & 2 & 1 & $\$ 5,830$ & $\$ 6,024$ & $103.33 \%$ & 30 & 7 & $\$ 860.57$ & 1 \\
\hline 0 & - & 2 & 1 & $\$ 750$ & $\$ 2,075$ & $276.67 \%$ & 30 & 36 & $\$ 57.64$ & 4 \\
\hline 0 & - & 2 & 1 & $\$ 30,000$ & $\$ 216,231$ & $720.77 \%$ & 30 & 2310 & $\$ 93.61$ & 1079 \\
\hline 0 & - & 2 & 1 & $\$ 32,000$ & $\$ 83,972$ & $262.41 \%$ & 35 & 558 & $\$ 150.49$ & 98 \\
\hline 0 & - & 2 & 1 & $\$ 30,000$ & $\$ 37,104$ & $123.68 \%$ & 27 & 191 & $\$ 194.26$ & 54 \\
\hline 0 & - & 2 & 3 & $\$ 165,690$ & $\$ 189,496$ & $114.37 \%$ & 31 & 381 & $\$ 497.37$ & 33 \\
\hline 0 & - & 2 & 1 & $\$ 2,651$ & $\$ 33,544$ & $1265.31 \%$ & 30 & 150 & $\$ 223.63$ & 56 \\
\hline 0 & - & 2 & 1 & $\$ 15,000$ & $\$ 60,143$ & $400.95 \%$ & 30 & 812 & $\$ 74.07$ & 26 \\
\hline 0 & - & 2 & 2 & $\$ 4,971$ & $\$ 5,213$ & $104.87 \%$ & 30 & 97 & $\$ 53.74$ & 2 \\
\hline 0 & - & 2 & 3 & $\$ 8,000$ & $\$ 8,062$ & $100.78 \%$ & 30 & 32 & $\$ 251.94$ & 2 \\
\hline 0 & - & 2 & 1 & $\$ 2,000$ & $\$ 14,986$ & $749.30 \%$ & 50 & 102 & $\$ 146.92$ & 7 \\
\hline 0 & - & 2 & 3 & $\$ 50,000$ & $\$ 82,578$ & $165.16 \%$ & 46 & 3784 & $\$ 21.82$ & 199 \\
\hline 0 & - & 2 & 1 & $\$ 5,000$ & $\$ 8,023$ & $160.46 \%$ & 45 & 126 & $\$ 63.67$ & 30 \\
\hline 0 & - & 2 & 1 & $\$ 8,500$ & $\$ 8,660$ & $101.88 \%$ & 41 & 38 & $\$ 227.89$ & 0 \\
\hline 0 & - & 2 & 1 & $\$ 23,667$ & $\$ 38,972$ & $164.67 \%$ & 33 & 441 & $\$ 88.37$ & 98 \\
\hline 0 & - & 2 & 1 & $\$ 25,000$ & $\$ 98,666$ & $394.66 \%$ & 32 & 2162 & $\$ 45.64$ & 55 \\
\hline 0 & - & 2 & 1 & $\$ 4,142$ & $\$ 6,816$ & $164.56 \%$ & 35 & 162 & $\$ 42.08$ & 27 \\
\hline 0 & - & 2 & 3 & $\$ 75,000$ & $\$ 275,930$ & $367.91 \%$ & 30 & 2752 & $\$ 100.27$ & 195 \\
\hline 0 & - & 2 & 2 & $\$ 4,000$ & $\$ 7,005$ & $175.13 \%$ & 30 & 155 & $\$ 45.19$ & 22 \\
\hline 0 & - & 2 & 1 & $\$ 60,000$ & $\$ 72,949$ & $121.58 \%$ & 30 & 144 & $\$ 506.59$ & 200 \\
\hline
\end{tabular}




\begin{tabular}{|c|c|c|c|c|c|c|c|c|c|c|}
\hline 0 & -2 & 1 & $\$ 3,500$ & $\$ 7,518$ & $214.80 \%$ & 30 & 54 & $\$ 139.22$ & 6 & 1 \\
\hline 0 & -2 & 1 & $\$ 5,000$ & $\$ 5,576$ & $111.52 \%$ & 30 & 25 & $\$ 223.04$ & 4 & 13 \\
\hline 0 & -2 & 1 & $\$ 323$ & $\$ 3,957$ & $1224.60 \%$ & 60 & 96 & $\$ 41.22$ & 43 & 6 \\
\hline 0 & -2 & 3 & $\$ 100,000$ & $\$ 140,105$ & $140.11 \%$ & 45 & 197 & $\$ 711.19$ & 33 & 11 \\
\hline 0 & -2 & 3 & $\$ 8,600$ & $\$ 10,416$ & $121.12 \%$ & 37 & 67 & $\$ 155.46$ & 26 & 17 \\
\hline 0 & -2 & 1 & $\$ 4,000$ & $\$ 14,313$ & $357.83 \%$ & 40 & 298 & $\$ 48.03$ & 25 & 9 \\
\hline 0 & -2 & 2 & $\$ 10,500$ & $\$ 22,583$ & $215.08 \%$ & 30 & 130 & $\$ 173.72$ & 58 & 13 \\
\hline 0 & -2 & 2 & $\$ 3,000$ & $\$ 15,132$ & $504.40 \%$ & 47 & 250 & $\$ 60.53$ & 35 & 14 \\
\hline 0 & -2 & 3 & $\$ 120,000$ & $\$ 127,228$ & $106.02 \%$ & 30 & 1268 & $\$ 100.34$ & 155 & 12 \\
\hline 0 & -2 & 3 & $\$ 15,000$ & $\$ 293,014$ & $1953.43 \%$ & 25 & 5329 & $\$ 54.98$ & 1044 & 13 \\
\hline 0 & -2 & 2 & $\$ 20,000$ & $\$ 38,617$ & $193.09 \%$ & 33 & 409 & $\$ 94.42$ & 30 & 8 \\
\hline 0 & -2 & 1 & $\$ 4,700$ & $\$ 7,745$ & $164.79 \%$ & 30 & 54 & $\$ 143.43$ & 14 & 11 \\
\hline 0 & -2 & 1 & $\$ 7,000$ & $\$ 26,349$ & $376.41 \%$ & 30 & 280 & $\$ 94.10$ & 34 & 9 \\
\hline 0 & -2 & 3 & $\$ 4,139$ & $\$ 4,578$ & $110.60 \%$ & 30 & 92 & $\$ 49.76$ & 4 & 9 \\
\hline 0 & -2 & 2 & $\$ 91,058$ & $\$ 432,526$ & $475.00 \%$ & 30 & 2523 & $\$ 171.43$ & 401 & 14 \\
\hline 1 & $\begin{array}{ll}1 & 3 \\
4 & \end{array}$ & 3 & $\$ 1,500$ & $\$ 3,846$ & $256.40 \%$ & 60 & 192 & $\$ 20.03$ & 712 & 41 \\
\hline 1 & 13 & 1 & $\$ 800$ & $\$ 3,337$ & $417.13 \%$ & 45 & 123 & $\$ 27.13$ & 33 & 31 \\
\hline 4 & 33 & 1 & $\$ 15,000$ & $\$ 15,586$ & $103.91 \%$ & 38 & 89 & $\$ 175.12$ & 0 & 13 \\
\hline 4 & 43 & 1 & $\$ 500$ & $\$ 501$ & $100.20 \%$ & 60 & 10 & $\$ 50.10$ & 0 & 16 \\
\hline 4 & 33 & 1 & $\$ 3,000$ & $\$ 4,161$ & $138.70 \%$ & 36 & 113 & $\$ 36.82$ & 13 & 7 \\
\hline 1 & $\begin{array}{ll}3 & 3 \\
4 & \end{array}$ & 3 & $\$ 7,500$ & $\$ 8,586$ & $114.48 \%$ & 38 & 188 & $\$ 45.67$ & 1877 & 29 \\
\hline 4 & 43 & 1 & $\$ 8,012$ & $\$ 13,704$ & $171.04 \%$ & 35 & 539 & $\$ 25.42$ & 209 & 31 \\
\hline 1 & 13 & 3 & $\$ 3,400$ & $\$ 3,481$ & $102.38 \%$ & 54 & 10 & $\$ 348.10$ & 0 & 0 \\
\hline 4 & 43 & 1 & $\$ 7,500$ & $\$ 7,953$ & $106.04 \%$ & 40 & 82 & $\$ 96.99$ & 15 & 12 \\
\hline 1 & $\begin{array}{ll}3 & 3 \\
4 & \end{array}$ & 3 & $\$ 65,796$ & $\$ 81,176$ & $123.38 \%$ & 45 & 1203 & $\$ 67.48$ & 699 & 26 \\
\hline 4 & 43 & 1 & $\$ 30,000$ & $\$ 39,476$ & $131.59 \%$ & 45 & 509 & $\$ 77.56$ & 160 & 27 \\
\hline 1 & $\begin{array}{ll}4 & 3 \\
3 & \end{array}$ & 3 & $\$ 2,056$ & $\$ 9,980$ & $485.36 \%$ & 60 & 249 & $\$ 40.08$ & 928 & 38 \\
\hline 4 & 43 & 1 & $\$ 2,500$ & $\$ 4,334$ & $173.36 \%$ & 42 & 184 & $\$ 23.55$ & 818 & 15 \\
\hline 1 & $\begin{array}{ll}1 & 3 \\
4 & \end{array}$ & 1 & $\$ 8,225$ & $\$ 93,792$ & $1140.40 \%$ & 31 & 459 & $\$ 204.34$ & 2356 & 85 \\
\hline 1 & $\begin{array}{ll}4 & 3 \\
4 & \end{array}$ & 1 & $\$ 26,000$ & $\$ 61,152$ & $235.20 \%$ & 45 & 749 & $\$ 81.64$ & 892 & 23 \\
\hline 4 & 43 & 1 & $\$ 5,000$ & $\$ 5,403$ & $108.06 \%$ & 32 & 115 & $\$ 46.98$ & 40 & 21 \\
\hline 1 & 33 & 3 & $\$ 15,000$ & $\$ 19,626$ & $130.84 \%$ & 30 & 116 & $\$ 169.19$ & 96 & 8 \\
\hline 1 & 13 & 1 & $\$ 3,000$ & $\$ 3,086$ & $102.87 \%$ & 30 & 113 & $\$ 27.31$ & 16 & 8 \\
\hline & 13 & 1 & $\$ 10,000$ & $\$ 10,283$ & $102.83 \%$ & 30 & 35 & $\$ 293.80$ & 10 & 13 \\
\hline
\end{tabular}




\begin{tabular}{|c|c|c|c|c|c|c|c|c|c|c|}
\hline $\begin{array}{l}1 \\
4\end{array}$ & $\begin{array}{l}3 \\
3\end{array}$ & 3 & 3 & $\$ 10,000$ & $\$ 12,540$ & $125.40 \%$ & 30 & 897 & $\$ 13.98$ & 154 \\
\hline $\begin{array}{l}1 \\
4\end{array}$ & $\begin{array}{l}1 \\
3\end{array}$ & 3 & 1 & $\$ 5,000$ & $\$ 13,870$ & $277.40 \%$ & 35 & 104 & $\$ 133.37$ & 120 \\
\hline $\begin{array}{l}1 \\
4\end{array}$ & $\begin{array}{l}3 \\
4\end{array}$ & 3 & 3 & $\$ 15,000$ & $\$ 18,001$ & $120.01 \%$ & 30 & 199 & $\$ 90.46$ & 28 \\
\hline $\begin{array}{l}1 \\
4\end{array}$ & $\begin{array}{l}3 \\
4\end{array}$ & 3 & 3 & $\$ 15,000$ & $\$ 54,007$ & $360.05 \%$ & 30 & 3014 & $\$ 17.92$ & 556 \\
\hline 4 & 4 & 3 & 1 & $\$ 7,000$ & $\$ 27,613$ & $394.47 \%$ & 30 & 644 & $\$ 42.88$ & 141 \\
\hline 4 & 4 & 3 & 1 & $\$ 8,000$ & $\$ 9,058$ & $113.23 \%$ & 45 & 250 & $\$ 36.23$ & 92 \\
\hline $\begin{array}{l}1 \\
4\end{array}$ & $\begin{array}{l}4 \\
4\end{array}$ & 3 & 3 & $\$ 65,000$ & $\$ 67,765$ & $104.25 \%$ & 30 & 1227 & $\$ 55.23$ & 171 \\
\hline $\begin{array}{l}1 \\
4\end{array}$ & $\begin{array}{l}1 \\
4\end{array}$ & 3 & 3 & $\$ 2,500$ & $\$ 8,591$ & $343.64 \%$ & 32 & 230 & $\$ 37.35$ & 168 \\
\hline $\begin{array}{l}1 \\
1 \\
1 \\
4\end{array}$ & $\begin{array}{l}1 \\
2 \\
4 \\
4\end{array}$ & 3 & 3 & $\$ 5,000$ & $\$ 56,031$ & $1120.62 \%$ & 45 & 819 & $\$ 68.41$ & 705 \\
\hline 4 & 4 & 3 & 1 & $\$ 10,000$ & $\$ 10,411$ & $104.11 \%$ & 30 & 271 & $\$ 38.42$ & 209 \\
\hline 5 & 1 & 3 & 3 & $\$ 50$ & $\$ 148$ & $296.00 \%$ & 30 & 19 & $\$ 7.79$ & 0 \\
\hline 4 & 4 & 3 & 1 & $\$ 2,500$ & $\$ 12,006$ & $480.24 \%$ & 30 & 383 & $\$ 31.35$ & 65 \\
\hline $\begin{array}{l}1 \\
4\end{array}$ & $\begin{array}{l}1 \\
4\end{array}$ & 3 & 1 & $\$ 12,000$ & $\$ 16,179$ & $134.83 \%$ & 30 & 265 & $\$ 61.05$ & 71 \\
\hline $\begin{array}{l}1 \\
1 \\
4\end{array}$ & $\begin{array}{l}2 \\
4 \\
4\end{array}$ & 3 & 3 & $\$ 3,000$ & $\$ 7,099$ & $236.63 \%$ & 30 & 519 & $\$ 13.68$ & 48 \\
\hline 4 & 4 & 3 & 1 & $\$ 10,500$ & $\$ 13,018$ & $123.98 \%$ & 30 & 520 & $\$ 25.03$ & 88 \\
\hline $\begin{array}{l}1 \\
4\end{array}$ & $\begin{array}{l}1 \\
4\end{array}$ & 3 & 3 & $\$ 60,000$ & $\$ 68,319$ & $113.87 \%$ & 40 & 570 & $\$ 119.86$ & 251 \\
\hline 4 & 4 & 3 & 3 & $\$ 75,000$ & $\$ 171,010$ & $228.01 \%$ & 30 & 183 & $\$ 934.48$ & 267 \\
\hline $\begin{array}{l}1 \\
4\end{array}$ & $\begin{array}{l}3 \\
4\end{array}$ & 3 & 1 & $\$ 10,000$ & $\$ 29,570$ & $295.70 \%$ & 45 & 988 & $\$ 29.93$ & 383 \\
\hline $\begin{array}{l}1 \\
4\end{array}$ & $\begin{array}{l}1 \\
4\end{array}$ & 3 & 3 & $\$ 80,000$ & $\$ 84,919$ & $106.15 \%$ & 30 & 1753 & $\$ 48.44$ & 228 \\
\hline 4 & 4 & 3 & 3 & $\$ 20,000$ & $\$ 25,455$ & $127.28 \%$ & 40 & 313 & $\$ 81.33$ & 28 \\
\hline $\begin{array}{l}1 \\
1 \\
4\end{array}$ & $\begin{array}{l}1 \\
4 \\
4\end{array}$ & 3 & 3 & $\$ 100,000$ & $\$ 1,014,600$ & $1014.60 \%$ & 29 & 15802 & $\$ 64.21$ & 9555 \\
\hline 4 & 4 & 3 & 1 & $\$ 5,000$ & $\$ 6,251$ & $125.02 \%$ & 30 & 84 & $\$ 74.42$ & 25 \\
\hline 2 & 2 & 3 & 1 & $\$ 1,000$ & $\$ 4,739$ & $473.90 \%$ & 30 & 157 & $\$ 30.18$ & 29 \\
\hline 4 & 4 & 3 & 1 & $\$ 4,000$ & $\$ 5,305$ & $132.63 \%$ & 40 & 102 & $\$ 52.01$ & 80 \\
\hline 4 & 4 & 3 & 1 & $\$ 15,000$ & $\$ 37,732$ & $251.55 \%$ & 30 & 1062 & $\$ 35.53$ & 149 \\
\hline
\end{tabular}




\begin{tabular}{|c|c|c|c|c|c|c|c|c|c|c|}
\hline $\begin{array}{l}1 \\
4\end{array}$ & $\begin{array}{l}1 \\
4\end{array}$ & 3 & 1 & $\$ 3,000$ & $\$ 4,196$ & $139.87 \%$ & 33 & 153 & $\$ 27.42$ & 24 \\
\hline 1 & 3 & 3 & 3 & $\$ 15,000$ & $\$ 16,194$ & $107.96 \%$ & 30 & 122 & $\$ 132.74$ & 5 \\
\hline $\begin{array}{l}1 \\
4\end{array}$ & $\begin{array}{l}4 \\
4\end{array}$ & 3 & 1 & $\$ 300$ & $\$ 2,340$ & $780.00 \%$ & 29 & 71 & $\$ 32.96$ & 19 \\
\hline 4 & 4 & 3 & 3 & $\$ 1,500$ & $\$ 20,691$ & $1379.40 \%$ & 21 & 439 & $\$ 47.13$ & 78 \\
\hline 4 & 4 & 3 & 1 & $\$ 4,935$ & $\$ 5,084$ & $103.03 \%$ & 38 & 54 & $\$ 94.16$ & 4 \\
\hline 4 & 4 & 3 & 1 & $\$ 3,000$ & $\$ 6,541$ & $218.03 \%$ & 34 & 220 & $\$ 29.73$ & 52 \\
\hline $\begin{array}{l}1 \\
1\end{array}$ & $\begin{array}{l}1 \\
3 \\
3\end{array}$ & 3 & 3 & $\$ 125,000$ & $\$ 345,835$ & $276.67 \%$ & 30 & 7496 & $\$ 46.14$ & 1760 \\
\hline 4 & 4 & 3 & 1 & $\$ 1,000$ & $\$ 3,815$ & $381.50 \%$ & 30 & 39 & $\$ 97.82$ & 14 \\
\hline $\begin{array}{l}1 \\
4\end{array}$ & $\begin{array}{l}3 \\
3\end{array}$ & 3 & 3 & $\$ 30,000$ & $\$ 30,637$ & $102.12 \%$ & 30 & 56 & $\$ 547.09$ & 8 \\
\hline $\begin{array}{l}1 \\
4\end{array}$ & $\begin{array}{l}3 \\
4\end{array}$ & 3 & 3 & $\$ 7,000$ & $\$ 7,278$ & $103.97 \%$ & 30 & 151 & $\$ 48.20$ & 75 \\
\hline $\begin{array}{l}1 \\
1 \\
4\end{array}$ & $\begin{array}{l}1 \\
2 \\
4\end{array}$ & 3 & 1 & $\$ 5,000$ & $\$ 22,050$ & $441.00 \%$ & 30 & 666 & $\$ 33.11$ & 91 \\
\hline $\begin{array}{l}1 \\
4\end{array}$ & $\begin{array}{l}4 \\
4\end{array}$ & 3 & 3 & $\$ 7,500$ & $\$ 33,037$ & $440.49 \%$ & 40 & 262 & $\$ 126.10$ & 37 \\
\hline $\begin{array}{l}1 \\
4\end{array}$ & $\begin{array}{l}1 \\
4\end{array}$ & 3 & 1 & $\$ 9,500$ & $\$ 11,666$ & $122.80 \%$ & 29 & 295 & $\$ 39.55$ & 85 \\
\hline $\begin{array}{l}1 \\
4\end{array}$ & $\begin{array}{l}4 \\
4\end{array}$ & 3 & 1 & $\$ 16,000$ & $\$ 18,090$ & $113.06 \%$ & 30 & 106 & $\$ 170.66$ & 3 \\
\hline 4 & 4 & 3 & 1 & $\$ 300$ & $\$ 1,561$ & $520.33 \%$ & 30 & 59 & $\$ 26.46$ & 25 \\
\hline $\begin{array}{l}1 \\
4\end{array}$ & $\begin{array}{l}4 \\
4\end{array}$ & 3 & 3 & $\$ 7,000$ & $\$ 7,090$ & $101.29 \%$ & 30 & 218 & $\$ 32.52$ & 48 \\
\hline 1 & 1 & 3 & 1 & $\$ 7,500$ & $\$ 13,388$ & $178.51 \%$ & 31 & 526 & $\$ 25.45$ & 90 \\
\hline 4 & 4 & 3 & 1 & $\$ 1,000$ & $\$ 1,900$ & $190.00 \%$ & 30 & 62 & $\$ 30.65$ & 8 \\
\hline 4 & 4 & 3 & 3 & $\$ 82$ & $\$ 243$ & $295.99 \%$ & 12 & 17 & $\$ 14.32$ & 0 \\
\hline 4 & 4 & 3 & 1 & $\$ 8,000$ & $\$ 52,693$ & $658.66 \%$ & 37 & 566 & $\$ 93.10$ & 557 \\
\hline $\begin{array}{l}1 \\
1\end{array}$ & $\begin{array}{l}1 \\
4\end{array}$ & 3 & 3 & $\$ 22,500$ & $\$ 34,061$ & $151.38 \%$ & 28 & 530 & $\$ 64.27$ & 449 \\
\hline 4 & 4 & 3 & 1 & $\$ 4,000$ & $\$ 5,094$ & $127.35 \%$ & 29 & 156 & $\$ 32.65$ & 29 \\
\hline 4 & 4 & 3 & 3 & $\$ 12,000$ & $\$ 12,110$ & $100.92 \%$ & 30 & 366 & $\$ 33.09$ & 69 \\
\hline $\begin{array}{l}1 \\
4\end{array}$ & $\begin{array}{l}2 \\
4\end{array}$ & 3 & 1 & $\$ 22,000$ & $\$ 28,221$ & $128.28 \%$ & 30 & 353 & $\$ 79.95$ & 218 \\
\hline $\begin{array}{l}1 \\
4\end{array}$ & $\begin{array}{l}3 \\
4\end{array}$ & 3 & 3 & $\$ 15,000$ & $\$ 15,753$ & $105.02 \%$ & 29 & 471 & $\$ 33.45$ & 48 \\
\hline 1 & 3 & 3 & 3 & $\$ 20,000$ & $\$ 25,457$ & $127.29 \%$ & 34 & 1244 & $\$ 20.46$ & 123 \\
\hline
\end{tabular}




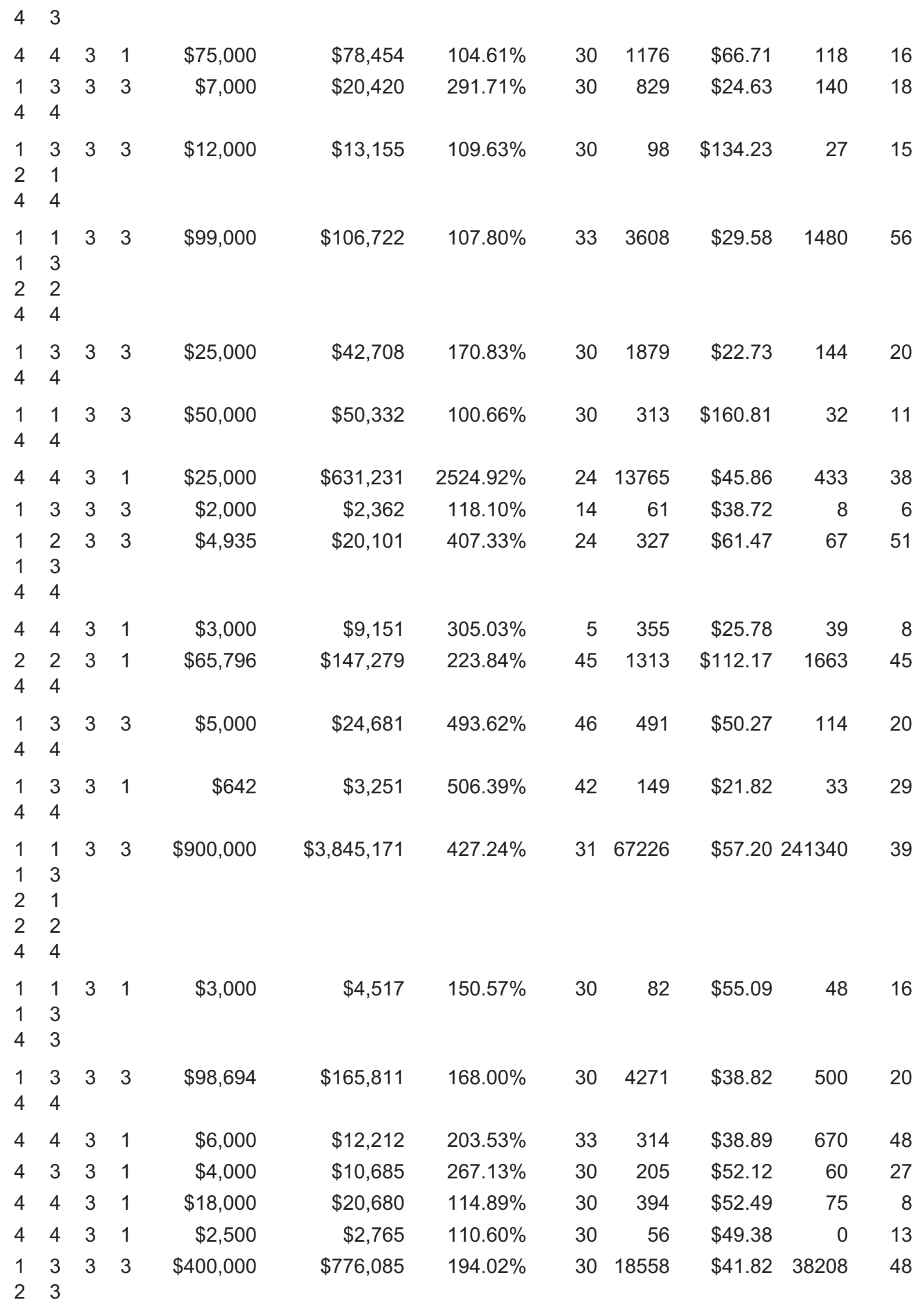




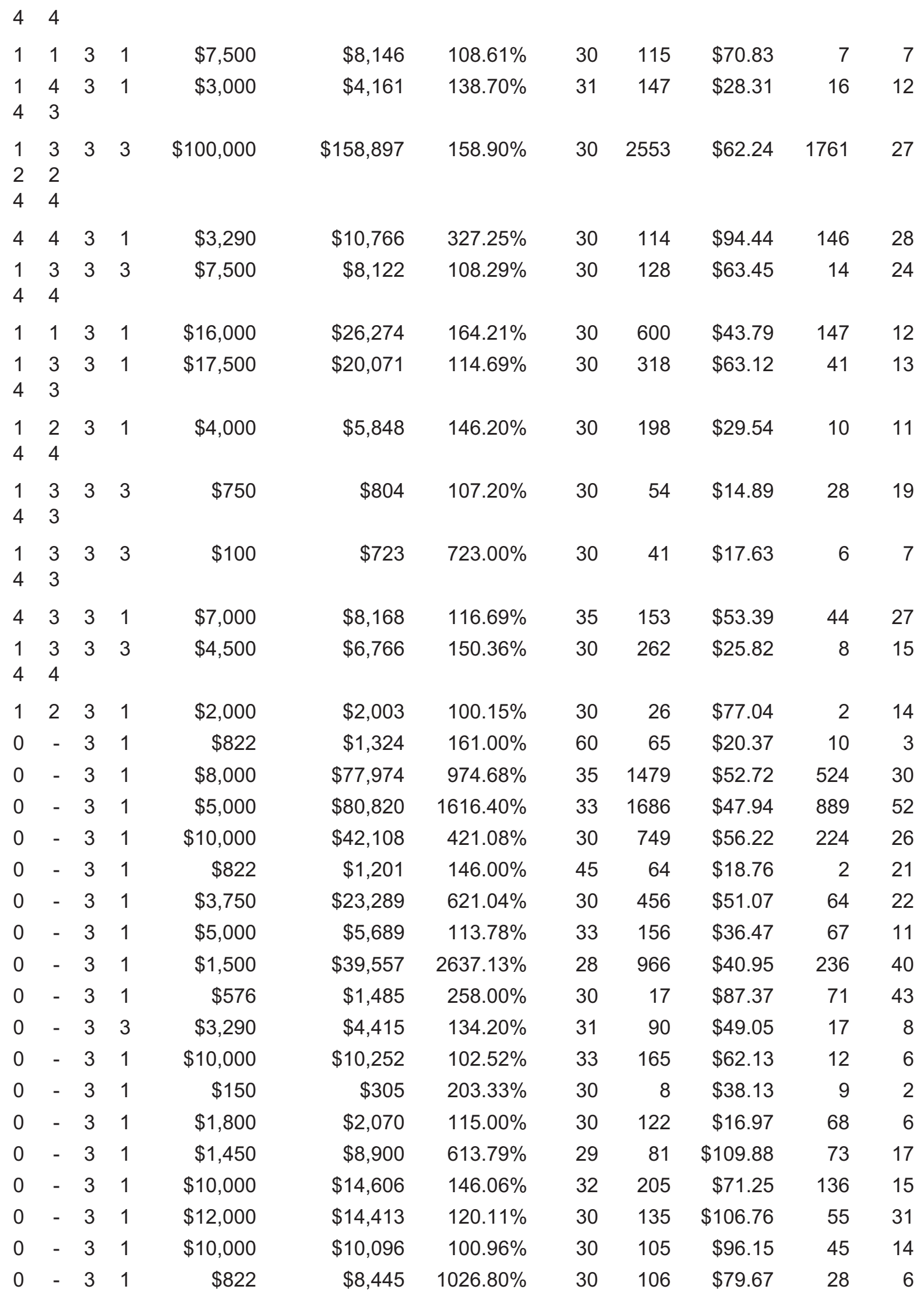




\begin{tabular}{|c|c|c|c|c|c|c|c|c|c|c|c|}
\hline 0 & - & 3 & 1 & $\$ 8,000$ & $\$ 11,469$ & $143.36 \%$ & 18 & 97 & $\$ 118.24$ & 29 & 10 \\
\hline 0 & - & 3 & 1 & $\$ 9,500$ & $\$ 12,878$ & $135.56 \%$ & 30 & 185 & $\$ 69.61$ & 72 & 11 \\
\hline 0 & - & 3 & 1 & $\$ 5,000$ & $\$ 154,754$ & $3095.08 \%$ & 29 & 1609 & $\$ 96.18$ & 2752 & 42 \\
\hline 0 & - & 3 & 1 & $\$ 14,350$ & $\$ 14,930$ & $104.04 \%$ & 33 & 230 & $\$ 64.91$ & 40 & 33 \\
\hline 0 & - & 3 & 1 & $\$ 50,000$ & $\$ 718,153$ & $1436.31 \%$ & 32 & 3756 & $\$ 191.20$ & 7508 & 66 \\
\hline 0 & - & 3 & 1 & $\$ 3,500$ & $\$ 8,531$ & $243.74 \%$ & 31 & 422 & $\$ 20.22$ & 92 & 15 \\
\hline 0 & - & 3 & 1 & $\$ 1,000$ & $\$ 34,650$ & $3465.00 \%$ & 30 & 595 & $\$ 58.24$ & 143 & 29 \\
\hline 0 & - & 3 & 1 & $\$ 4,000$ & $\$ 8,160$ & $204.00 \%$ & 30 & 227 & $\$ 35.95$ & 34 & 27 \\
\hline 0 & - & 3 & 1 & $\$ 1,500$ & $\$ 9,071$ & $604.73 \%$ & 30 & 164 & $\$ 55.31$ & 56 & 9 \\
\hline 0 & - & 3 & 1 & $\$ 20,000$ & $\$ 62,983$ & $314.92 \%$ & 30 & 1592 & $\$ 39.56$ & 216 & 17 \\
\hline 0 & - & 3 & 3 & $\$ 20,000$ & $\$ 20,315$ & $101.58 \%$ & 30 & 237 & $\$ 85.72$ & 27 & 18 \\
\hline 0 & - & 3 & 3 & $\$ 250$ & $\$ 293$ & $117.20 \%$ & 30 & 19 & $\$ 15.42$ & 4 & 0 \\
\hline 0 & - & 3 & 1 & $\$ 15,000$ & $\$ 26,613$ & $177.42 \%$ & 30 & 471 & $\$ 56.50$ & 139 & 19 \\
\hline 0 & - & 3 & 1 & $\$ 500$ & $\$ 3,261$ & $652.20 \%$ & 30 & 56 & $\$ 58.23$ & 11 & 8 \\
\hline 0 & - & 3 & 1 & $\$ 2,500$ & $\$ 2,681$ & $107.24 \%$ & 26 & 56 & $\$ 47.88$ & 0 & 1 \\
\hline 0 & - & 3 & 1 & $\$ 25,000$ & $\$ 25,926$ & $103.70 \%$ & 45 & 107 & $\$ 242.30$ & 0 & 15 \\
\hline 0 & - & 3 & 1 & $\$ 1,500$ & $\$ 5,128$ & $341.87 \%$ & 40 & 204 & $\$ 25.14$ & 35 & 22 \\
\hline 0 & - & 3 & 1 & $\$ 5,000$ & $\$ 5,193$ & $103.86 \%$ & 30 & 140 & $\$ 37.09$ & 12 & 27 \\
\hline 0 & - & 3 & 1 & $\$ 1,000$ & $\$ 8,815$ & $881.50 \%$ & 31 & 170 & $\$ 51.85$ & 49 & 15 \\
\hline 0 & - & 3 & 1 & $\$ 20,000$ & $\$ 103,494$ & $517.47 \%$ & 30 & 977 & $\$ 105.93$ & 1119 & 43 \\
\hline 0 & - & 3 & 1 & $\$ 6,497$ & $\$ 8,488$ & $130.63 \%$ & 32 & 117 & $\$ 72.54$ & 40 & 24 \\
\hline 0 & - & 3 & 1 & $\$ 10,000$ & $\$ 16,007$ & $160.07 \%$ & 30 & 326 & $\$ 49.10$ & 78 & 17 \\
\hline 0 & - & 3 & 1 & $\$ 7,000$ & $\$ 7,552$ & $107.89 \%$ & 29 & 103 & $\$ 73.32$ & 25 & 9 \\
\hline 0 & - & 3 & 1 & $\$ 11,000$ & $\$ 23,743$ & $215.85 \%$ & 25 & 626 & $\$ 37.93$ & 235 & 46 \\
\hline 0 & - & 3 & 1 & $\$ 25,000$ & $\$ 43,613$ & $174.45 \%$ & 39 & 774 & $\$ 56.35$ & 390 & 19 \\
\hline 0 & - & 3 & 1 & $\$ 3,500$ & $\$ 7,458$ & $213.09 \%$ & 30 & 249 & $\$ 29.95$ & 35 & 19 \\
\hline 0 & - & 3 & 1 & $\$ 20,000$ & $\$ 22,240$ & $111.20 \%$ & 30 & 84 & $\$ 264.76$ & 129 & 7 \\
\hline 0 & - & 3 & 1 & $\$ 16,449$ & $\$ 37,606$ & $228.62 \%$ & 30 & 779 & $\$ 48.27$ & 321 & 58 \\
\hline 4 & 4 & 4 & 1 & $\$ 10,000$ & $\$ 12,089$ & $120.89 \%$ & 53 & 160 & $\$ 75.56$ & 7 & 5 \\
\hline 4 & 4 & 4 & 1 & $\$ 20,000$ & $\$ 71,999$ & $360.00 \%$ & 30 & 1185 & $\$ 60.76$ & 119 & 28 \\
\hline 4 & 4 & 4 & 1 & $\$ 20,000$ & $\$ 23,737$ & $118.69 \%$ & 30 & 386 & $\$ 61.49$ & 7 & 13 \\
\hline 2 & 4 & 4 & 1 & $\$ 12,000$ & $\$ 16,236$ & $135.30 \%$ & 30 & 410 & $\$ 39.60$ & 50 & 8 \\
\hline 1 & 2 & 4 & 1 & $\$ 49,668$ & $\$ 197,776$ & $398.20 \%$ & 30 & 1818 & $\$ 108.79$ & 216 & 12 \\
\hline 2 & 1 & & & & & & & & & & \\
\hline 4 & 4 & & & & & & & & & & \\
\hline 4 & 4 & 4 & 1 & $\$ 6,000$ & $\$ 7,135$ & $118.92 \%$ & 30 & 109 & $\$ 65.46$ & 0 & 4 \\
\hline 4 & 4 & 4 & 1 & $\$ 15,000$ & $\$ 16,408$ & $109.39 \%$ & 30 & 88 & $\$ 186.45$ & 23 & 8 \\
\hline 4 & 3 & 4 & 1 & $\$ 7,500$ & $\$ 11,912$ & $158.83 \%$ & 31 & 149 & $\$ 79.95$ & 5 & 7 \\
\hline 2 & 2 & 4 & 1 & $\$ 10,000$ & $\$ 23,047$ & $230.47 \%$ & 34 & 366 & $\$ 62.97$ & 35 & 4 \\
\hline 4 & 4 & 4 & 1 & $\$ 3,000$ & $\$ 3,283$ & $109.43 \%$ & 25 & 76 & $\$ 43.20$ & 7 & 13 \\
\hline 4 & 4 & 4 & 1 & $\$ 5,000$ & $\$ 5,395$ & $107.90 \%$ & 29 & 97 & $\$ 55.62$ & 7 & 12 \\
\hline
\end{tabular}




\begin{tabular}{|c|c|c|c|c|c|c|c|c|c|c|}
\hline 1 & 4 & 4 & 1 & $\$ 5,000$ & $\$ 5,281$ & $105.62 \%$ & 30 & 139 & $\$ 37.99$ & 9 \\
\hline 1 & 3 & 4 & 1 & $\$ 2,000$ & $\$ 2,060$ & $103.00 \%$ & 14 & 7 & $\$ 294.29$ & 0 \\
\hline 4 & 4 & 4 & 1 & $\$ 20,000$ & $\$ 24,392$ & $121.96 \%$ & 30 & 346 & $\$ 70.50$ & 6 \\
\hline 1 & 1 & 4 & 1 & $\$ 18,000$ & $\$ 21,159$ & $117.55 \%$ & 33 & 232 & $\$ 91.20$ & 7 \\
\hline 2 & 1 & 4 & 1 & $\$ 300$ & $\$ 8,014$ & $2671.33 \%$ & 28 & 155 & $\$ 51.70$ & 29 \\
\hline 2 & 2 & 4 & 1 & $\$ 1,656$ & $\$ 3,058$ & $184.70 \%$ & 30 & 59 & $\$ 51.83$ & 14 \\
\hline 4 & 4 & 4 & 1 & $\$ 15,000$ & $\$ 17,816$ & $118.77 \%$ & 33 & 192 & $\$ 92.79$ & 2 \\
\hline 4 & 4 & 4 & 1 & $\$ 30,000$ & $\$ 98,896$ & $329.65 \%$ & 60 & 1220 & $\$ 81.06$ & 95 \\
\hline 4 & 4 & 4 & 1 & $\$ 20,000$ & $\$ 37,861$ & $189.31 \%$ & 45 & 176 & $\$ 215.12$ & 8 \\
\hline 4 & 4 & 4 & 1 & $\$ 20,000$ & $\$ 23,725$ & $118.63 \%$ & 33 & 73 & $\$ 325.00$ & 0 \\
\hline 4 & 3 & 4 & 1 & $\$ 50,000$ & $\$ 50,488$ & $100.98 \%$ & 30 & 116 & $\$ 435.24$ & 7 \\
\hline 1 & 1 & 4 & 1 & $\$ 3,500$ & $\$ 3,510$ & $100.29 \%$ & 30 & 57 & $\$ 61.58$ & 7 \\
\hline 2 & 2 & & & & & & & & & \\
\hline 1 & 1 & 4 & 1 & $\$ 4,750$ & $\$ 15,063$ & $317.12 \%$ & 23 & 348 & $\$ 43.28$ & 51 \\
\hline 2 & 1 & & & & & & & & & \\
\hline 4 & 4 & 4 & 1 & $\$ 3,500$ & $\$ 3,525$ & $100.71 \%$ & 31 & 32 & $\$ 110.16$ & 0 \\
\hline 4 & 4 & 4 & 1 & $\$ 6,000$ & $\$ 6,786$ & $113.10 \%$ & 30 & 63 & $\$ 107.71$ & 7 \\
\hline 4 & 4 & 4 & 1 & $\$ 20,000$ & $\$ 20,894$ & $104.47 \%$ & 35 & 77 & $\$ 271.35$ & 2 \\
\hline 1 & 1 & 4 & 1 & $\$ 25,000$ & $\$ 30,342$ & $121.37 \%$ & 30 & 372 & $\$ 81.56$ & 26 \\
\hline 1 & 4 & 4 & 1 & $\$ 2,000$ & $\$ 19,880$ & $994.00 \%$ & 21 & 181 & $\$ 109.83$ & 22 \\
\hline 4 & 4 & 4 & 1 & $\$ 10,000$ & $\$ 10,226$ & $102.26 \%$ & 30 & 154 & $\$ 66.40$ & 4 \\
\hline 4 & 4 & 4 & 1 & $\$ 15,000$ & $\$ 120,195$ & $801.30 \%$ & 42 & 980 & $\$ 122.65$ & 37 \\
\hline 1 & 1 & 4 & 1 & $\$ 579$ & $\$ 874$ & $150.86 \%$ & 30 & 26 & $\$ 33.62$ & 17 \\
\hline 1 & 1 & 4 & 1 & $\$ 6,909$ & $\$ 7,387$ & $106.93 \%$ & 21 & 98 & $\$ 75.38$ & 2 \\
\hline 4 & 4 & & & & & & & & & \\
\hline 2 & 1 & 4 & 1 & $\$ 8,000$ & $\$ 11,232$ & $140.40 \%$ & 28 & 117 & $\$ 96.00$ & 16 \\
\hline 0 & - & 4 & 1 & $\$ 2,500$ & $\$ 2,950$ & $118.00 \%$ & 44 & 66 & $\$ 44.70$ & 12 \\
\hline 0 & - & 4 & 1 & $\$ 9,700$ & $\$ 13,096$ & $135.01 \%$ & 46 & 183 & $\$ 71.56$ & 4 \\
\hline 0 & - & 4 & 1 & $\$ 1,976$ & $\$ 2,785$ & $140.94 \%$ & 45 & 62 & $\$ 44.92$ & 23 \\
\hline 0 & - & 4 & 1 & $\$ 750$ & $\$ 1,137$ & $151.60 \%$ & 31 & 31 & $\$ 36.68$ & 1 \\
\hline 0 & - & 4 & 1 & $\$ 5,000$ & $\$ 6,569$ & $131.38 \%$ & 30 & 97 & $\$ 67.72$ & 2 \\
\hline 0 & - & 4 & 1 & $\$ 1,500$ & $\$ 1,669$ & $111.27 \%$ & 30 & 33 & $\$ 50.58$ & 5 \\
\hline 0 & - & 4 & 1 & $\$ 15,000$ & $\$ 41,689$ & $277.93 \%$ & 31 & 662 & $\$ 62.97$ & 28 \\
\hline 0 & - & 4 & 1 & $\$ 20,000$ & $\$ 21,629$ & $108.15 \%$ & 30 & 326 & $\$ 66.35$ & 36 \\
\hline 0 & - & 4 & 1 & $\$ 2,000$ & $\$ 2,411$ & $120.55 \%$ & 35 & 30 & $\$ 80.37$ & 1 \\
\hline 0 & - & 4 & 1 & $\$ 3,000$ & $\$ 3,575$ & $119.17 \%$ & 31 & 32 & $\$ 111.72$ & 7 \\
\hline 0 & - & 4 & 1 & $\$ 5,300$ & $\$ 6,467$ & $122.02 \%$ & 30 & 58 & $\$ 111.50$ & 0 \\
\hline 0 & - & 4 & 1 & $\$ 3,925$ & $\$ 4,066$ & $103.59 \%$ & 39 & 47 & $\$ 86.51$ & 0 \\
\hline 0 & - & 4 & 1 & $\$ 3,311$ & $\$ 3,737$ & $112.85 \%$ & 30 & 58 & $\$ 64.43$ & 0 \\
\hline 0 & - & 4 & 1 & $\$ 3,000$ & $\$ 21,119$ & $703.97 \%$ & 45 & 118 & $\$ 178.97$ & 6 \\
\hline 0 & - & 4 & 1 & $\$ 150$ & $\$ 201$ & $134.00 \%$ & 21 & 6 & $\$ 33.50$ & 0 \\
\hline
\end{tabular}




\begin{tabular}{|c|c|c|c|c|c|c|c|c|c|}
\hline 0 & -4 & 1 & $\$ 4,000$ & $\$ 4,450$ & $111.25 \%$ & 30 & 56 & $\$ 79.46$ & 3 \\
\hline 0 & -4 & 1 & $\$ 10,000$ & $\$ 271,043$ & $2710.43 \%$ & 30 & 3307 & $\$ 81.96$ & 223 \\
\hline 0 & -4 & 1 & $\$ 12,500$ & $\$ 13,027$ & $104.22 \%$ & 45 & 126 & $\$ 103.39$ & 11 \\
\hline 0 & -4 & 1 & $\$ 18,000$ & $\$ 20,448$ & $113.60 \%$ & 45 & 222 & $\$ 92.11$ & 25 \\
\hline 0 & -4 & 1 & $\$ 45,000$ & $\$ 65,929$ & $146.51 \%$ & 45 & 1431 & $\$ 46.07$ & 112 \\
\hline 0 & -4 & 1 & $\$ 7,500$ & $\$ 14,725$ & $196.33 \%$ & 35 & 572 & $\$ 25.74$ & 199 \\
\hline 0 & -4 & 1 & $\$ 250$ & $\$ 1,264$ & $505.60 \%$ & 21 & 49 & $\$ 25.80$ & 9 \\
\hline 0 & -4 & 1 & $\$ 7,000$ & $\$ 7,894$ & $112.77 \%$ & 40 & 102 & $\$ 77.39$ & 2 \\
\hline 0 & -4 & 1 & $\$ 5,000$ & $\$ 6,912$ & $138.24 \%$ & 22 & 119 & $\$ 58.08$ & 3 \\
\hline 0 & -4 & 1 & $\$ 5,000$ & $\$ 7,923$ & $158.46 \%$ & 32 & 65 & $\$ 121.89$ & 54 \\
\hline 0 & -4 & 1 & $\$ 1,000$ & $\$ 1,070$ & $107.00 \%$ & 30 & 25 & $\$ 42.80$ & 7 \\
\hline 0 & -4 & 1 & $\$ 2,760$ & $\$ 2,923$ & $105.91 \%$ & 30 & 105 & $\$ 27.84$ & 9 \\
\hline 0 & -4 & 1 & $\$ 40,000$ & $\$ 43,142$ & $107.86 \%$ & 30 & 115 & $\$ 375.15$ & 11 \\
\hline 0 & -4 & 1 & $\$ 650$ & $\$ 1,678$ & $258.15 \%$ & 30 & 67 & $\$ 25.04$ & 6 \\
\hline U & -4 & 1 & $\$ 2,700$ & $\$ 3,053$ & $113.07 \%$ & 30 & 51 & $\$ 59.86$ & 4 \\
\hline 0 & -4 & 1 & $\$ 828$ & $\$ 937$ & $113.20 \%$ & 30 & 12 & $\$ 78.09$ & 1 \\
\hline 0 & -4 & 1 & $\$ 5,000$ & $\$ 5,675$ & $113.50 \%$ & 30 & 81 & $\$ 70.06$ & 12 \\
\hline 0 & -4 & 1 & $\$ 20,000$ & $\$ 22,597$ & $112.99 \%$ & 20 & 243 & $\$ 92.99$ & 153 \\
\hline 0 & -4 & 1 & $\$ 1,656$ & $\$ 11,723$ & $708.10 \%$ & 46 & 431 & $\$ 27.20$ & 48 \\
\hline 0 & -4 & 1 & $\$ 600$ & $\$ 1,825$ & $304.17 \%$ & 50 & 7 & $\$ 260.71$ & 1 \\
\hline 0 & -4 & 1 & $\$ 10,000$ & $\$ 80,370$ & $803.70 \%$ & 38 & 2853 & $\$ 28.17$ & 288 \\
\hline 0 & -4 & 1 & $\$ 250,000$ & $\$ 272,523$ & $109.01 \%$ & 45 & 624 & $\$ 436.74$ & 8 \\
\hline 0 & -4 & 1 & $\$ 1,000$ & $\$ 5,413$ & $541.30 \%$ & 34 & 127 & $\$ 42.62$ & 21 \\
\hline 0 & -4 & 1 & $\$ 13,000$ & $\$ 17,318$ & $133.22 \%$ & 27 & 120 & $\$ 144.32$ & 16 \\
\hline 0 & -4 & 1 & $\$ 400$ & $\$ 445$ & $111.25 \%$ & 30 & 11 & $\$ 40.45$ & 0 \\
\hline 0 & -4 & 1 & $\$ 3,500$ & $\$ 3,696$ & $105.60 \%$ & 45 & 48 & $\$ 77.00$ & 0 \\
\hline 0 & -4 & 1 & $\$ 7,500$ & $\$ 7,850$ & $104.67 \%$ & 30 & 28 & $\$ 280.36$ & 0 \\
\hline 0 & -4 & 1 & $\$ 1,000$ & $\$ 1,491$ & $149.10 \%$ & 25 & 33 & $\$ 45.18$ & 1 \\
\hline 0 & -4 & 1 & $\$ 3,800$ & $\$ 4,094$ & $107.74 \%$ & 30 & 51 & $\$ 80.27$ & 0 \\
\hline 0 & -4 & 1 & $\$ 10,000$ & $\$ 56,775$ & $567.75 \%$ & 30 & 223 & $\$ 254.60$ & 26 \\
\hline 0 & -4 & 1 & $\$ 10,000$ & $\$ 10,712$ & $107.12 \%$ & 30 & 181 & $\$ 59.18$ & 30 \\
\hline 0 & -4 & 1 & $\$ 12,000$ & $\$ 12,211$ & $101.76 \%$ & 30 & 58 & $\$ 210.53$ & 0 \\
\hline 0 & -4 & 1 & $\$ 20,000$ & $\$ 22,428$ & $112.14 \%$ & 28 & 135 & $\$ 166.13$ & 25 \\
\hline 0 & -4 & 1 & $\$ 40,000$ & $\$ 42,665$ & $106.66 \%$ & 30 & 237 & $\$ 180.02$ & 6 \\
\hline 0 & -4 & 1 & $\$ 18,150$ & $\$ 18,400$ & $101.38 \%$ & 30 & 163 & $\$ 112.88$ & 13 \\
\hline 0 & -4 & 1 & $\$ 6,000$ & $\$ 6,074$ & $101.23 \%$ & 30 & 63 & $\$ 96.41$ & 2 \\
\hline 0 & -4 & 1 & $\$ 1,000$ & $\$ 13,849$ & $1384.90 \%$ & 27 & 131 & $\$ 105.72$ & 45 \\
\hline 0 & -4 & 1 & $\$ 8,000$ & $\$ 36,466$ & $455.83 \%$ & 35 & 747 & $\$ 48.82$ & 315 \\
\hline 0 & -4 & 1 & $\$ 1,750$ & $\$ 2,249$ & $128.51 \%$ & 30 & 39 & $\$ 57.67$ & 0 \\
\hline 0 & -4 & 1 & $\$ 17,500$ & $\$ 46,571$ & $266.12 \%$ & 30 & 625 & $\$ 74.51$ & 168 \\
\hline 0 & -4 & 1 & $\$ 1,500$ & $\$ 4,467$ & $297.80 \%$ & 33 & 111 & $\$ 40.24$ & 24 \\
\hline
\end{tabular}




\begin{tabular}{|c|c|c|c|c|c|c|c|c|c|c|}
\hline 0 & -4 & 1 & $\$ 25,000$ & $\$ 27,492$ & $109.97 \%$ & 30 & 122 & $\$ 225.34$ & 4 & 9 \\
\hline 0 & -4 & 1 & $\$ 5,300$ & $\$ 5,610$ & $105.85 \%$ & 20 & 116 & $\$ 48.36$ & 8 & 13 \\
\hline 0 & -4 & 1 & $\$ 15,000$ & $\$ 16,321$ & $108.81 \%$ & 30 & 184 & $\$ 88.70$ & 4 & 10 \\
\hline 0 & -4 & 1 & $\$ 600$ & $\$ 1,253$ & $208.83 \%$ & 20 & 40 & $\$ 31.33$ & 1 & 10 \\
\hline 0 & -4 & 1 & $\$ 10,000$ & $\$ 10,227$ & $102.27 \%$ & 35 & 88 & $\$ 116.22$ & 2 & 5 \\
\hline 0 & -4 & 1 & $\$ 10,000$ & $\$ 10,036$ & $100.36 \%$ & 30 & 128 & $\$ 78.41$ & 0 & 5 \\
\hline 0 & -4 & 1 & $\$ 10,000$ & $\$ 10,006$ & $100.06 \%$ & 37 & 45 & $\$ 222.36$ & 2 & 0 \\
\hline 0 & -4 & 1 & $\$ 500$ & $\$ 2,025$ & $405.00 \%$ & 30 & 50 & $\$ 40.50$ & 5 & 5 \\
\hline 0 & -4 & 1 & $\$ 10,000$ & $\$ 10,061$ & $100.61 \%$ & 30 & 19 & $\$ 529.53$ & 0 & 1 \\
\hline 0 & -4 & 1 & $\$ 5,000$ & $\$ 5,219$ & $104.38 \%$ & 30 & 75 & $\$ 69.59$ & 0 & 12 \\
\hline 0 & -4 & 1 & $\$ 4,000$ & $\$ 4,253$ & $106.33 \%$ & 23 & 41 & $\$ 103.73$ & 3 & 7 \\
\hline 0 & -4 & 1 & $\$ 5,000$ & $\$ 5,547$ & $110.94 \%$ & 30 & 154 & $\$ 36.02$ & 20 & 10 \\
\hline 0 & -4 & 1 & $\$ 745$ & $\$ 2,816$ & $378.00 \%$ & 30 & 103 & $\$ 27.34$ & 15 & 7 \\
\hline 0 & -4 & 1 & $\$ 5,000$ & $\$ 6,231$ & $124.62 \%$ & 25 & 109 & $\$ 57.17$ & 0 & 4 \\
\hline 0 & -4 & 1 & $\$ 579$ & $\$ 1,810$ & $312.29 \%$ & 20 & 60 & $\$ 30.16$ & 4 & 7 \\
\hline 0 & -4 & 1 & $\$ 10,000$ & $\$ 10,087$ & $100.87 \%$ & 30 & 66 & $\$ 152.83$ & 5 & 4 \\
\hline 0 & -4 & 1 & $\$ 166$ & $\$ 1,671$ & $1009.00 \%$ & 30 & 55 & $\$ 30.37$ & 9 & 9 \\
\hline 0 & -4 & 1 & $\$ 400$ & $\$ 1,191$ & $297.75 \%$ & 14 & 46 & $\$ 25.89$ & 7 & 10 \\
\hline 0 & -4 & 1 & $\$ 350$ & $\$ 820$ & $234.29 \%$ & 21 & 32 & $\$ 25.63$ & 0 & 2 \\
\hline 0 & -4 & 1 & $\$ 5,000$ & $\$ 5,486$ & $109.72 \%$ & 20 & 79 & $\$ 69.44$ & 0 & 5 \\
\hline 0 & -4 & 1 & $\$ 20,000$ & $\$ 221,509$ & $1107.55 \%$ & 44 & 1784 & $\$ 124.16$ & 69 & 9 \\
\hline 0 & -4 & 1 & $\$ 1,656$ & $\$ 2,235$ & $135.00 \%$ & 45 & 44 & $\$ 50.80$ & 14 & 4 \\
\hline 0 & -4 & 1 & $\$ 10,000$ & $\$ 10,837$ & $108.37 \%$ & 35 & 199 & $\$ 54.46$ & 68 & 4 \\
\hline 0 & -4 & 1 & $\$ 3,000$ & $\$ 3,197$ & $106.57 \%$ & 40 & 42 & $\$ 76.12$ & 0 & 0 \\
\hline 0 & -4 & 1 & $\$ 11,500$ & $\$ 55,600$ & $483.48 \%$ & 40 & 1640 & $\$ 33.90$ & 147 & 8 \\
\hline 0 & -4 & 1 & $\$ 10,000$ & $\$ 23,153$ & $231.53 \%$ & 29 & 236 & $\$ 98.11$ & 25 & 6 \\
\hline 0 & -4 & 1 & $\$ 4,500$ & $\$ 4,520$ & $100.44 \%$ & 30 & 48 & $\$ 94.17$ & 7 & 5 \\
\hline 0 & -4 & 1 & $\$ 8,000$ & $\$ 9,485$ & $118.56 \%$ & 36 & 39 & $\$ 243.21$ & 3 & 0 \\
\hline 0 & -4 & 1 & $\$ 8,278$ & $\$ 13,112$ & $158.40 \%$ & 27 & 299 & $\$ 43.85$ & 43 & 10 \\
\hline 0 & -4 & 1 & $\$ 20,000$ & $\$ 29,821$ & $149.11 \%$ & 30 & 252 & $\$ 118.34$ & 17 & 11 \\
\hline 0 & -4 & 1 & $\$ 1,000$ & $\$ 1,315$ & $131.50 \%$ & 30 & 23 & $\$ 57.17$ & 0 & 5 \\
\hline 0 & -4 & 1 & $\$ 5,000$ & $\$ 41,651$ & $833.02 \%$ & 38 & 456 & $\$ 91.34$ & 34 & 4 \\
\hline 0 & -4 & 1 & $\$ 6,000$ & $\$ 7,026$ & $117.10 \%$ & 33 & 67 & $\$ 104.87$ & 1 & 4 \\
\hline 0 & -4 & 1 & $\$ 30,000$ & $\$ 70,326$ & $234.42 \%$ & 30 & 483 & $\$ 145.60$ & 51 & 17 \\
\hline 0 & -4 & 1 & $\$ 10,000$ & $\$ 73,564$ & $735.64 \%$ & 30 & 716 & $\$ 102.74$ & 102 & 17 \\
\hline 0 & -4 & 1 & $\$ 20,000$ & $\$ 21,502$ & $107.51 \%$ & 30 & 241 & $\$ 89.22$ & 85 & 6 \\
\hline 0 & -4 & 1 & $\$ 6,000$ & $\$ 25,675$ & $427.92 \%$ & 30 & 443 & $\$ 57.96$ & 127 & 10 \\
\hline 0 & -4 & 1 & $\$ 1,000$ & $\$ 1,695$ & $169.50 \%$ & 30 & 38 & $\$ 44.61$ & 0 & 4 \\
\hline 0 & -4 & 1 & $\$ 16,449$ & $\$ 19,999$ & $121.58 \%$ & 30 & 350 & $\$ 57.14$ & 19 & 13 \\
\hline 0 & -4 & 1 & $\$ 15,000$ & $\$ 26,924$ & $179.49 \%$ & 30 & 263 & $\$ 102.37$ & 7 & 8 \\
\hline 0 & -4 & 1 & $\$ 12,500$ & $\$ 12,516$ & $100.13 \%$ & 30 & 126 & $\$ 99.33$ & 3 & \\
\hline
\end{tabular}




$\begin{array}{rrrrrrrrrrrr}0 & - & 4 & 1 & \$ 1,650 & \$ 3,453 & 209.27 \% & 30 & 84 & \$ 41.11 & 42 & 33 \\ 0 & - & 4 & 1 & \$ 400 & \$ 414 & 103.50 \% & 30 & 16 & \$ 25.88 & 9 & 8 \\ 0 & - & 4 & 1 & \$ 11,514 & \$ 14,852 & 128.99 \% & 30 & 118 & \$ 125.86 & 15 & 4 \\ 0 & - & 4 & 1 & \$ 2,000 & \$ 3,571 & 178.55 \% & 14 & 52 & \$ 68.67 & 3 & 4 \\ 0 & - & 4 & 1 & \$ 12,337 & \$ 19,328 & 156.67 \% & 22 & 47 & \$ 411.23 & 0 & 8 \\ 0 & - & 4 & 1 & \$ 5,500 & \$ 5,721 & 104.02 \% & 30 & 80 & \$ 71.51 & 4 & 11 \\ 0 & - & 4 & 1 & \$ 15,000 & \$ 28,285 & 188.57 \% & 30 & 147 & \$ 192.41 & 8 & 5 \\ 0 & - & 4 & 1 & \$ 15,000 & \$ 15,199 & 101.33 \% & 30 & 40 & \$ 379.98 & 0 & 3 \\ 0 & - & 4 & 1 & \$ 4,000 & \$ 8,535 & 213.38 \% & 30 & 133 & \$ 64.17 & 2 & 4 \\ 0 & - & 4 & 1 & \$ 1,000 & \$ 1,159 & 115.90 \% & 30 & 29 & \$ 39.97 & 0 & 3 \\ 0 & - & 4 & 1 & \$ 20,000 & \$ 26,885 & 134.43 \% & 30 & 172 & \$ 156.31 & 10 & 6 \\ 0 & - & 4 & 1 & \$ 500 & \$ 537 & 107.40 \% & 21 & 11 & \$ 48.82 & 3 & 5 \\ 0 & - & 4 & 1 & \$ 150 & \$ 1,140 & 760.00 \% & 20 & 31 & \$ 36.77 & 15 & 3 \\ 0 & - & 4 & 1 & \$ 295 & \$ 404 & 136.95 \% & 13 & 21 & \$ 19.24 & 4 & 7 \\ 0 & - & 4 & 1 & \$ 4,500 & \$ 4,766 & 105.91 \% & 21 & 33 & \$ 144.42 & 0 & 4 \\ 0 & - & 4 & 1 & \$ 200 & \$ 872 & 436.00 \% & 15 & 39 & \$ 22.36 & 3 & 11 \\ 0 & - & 4 & 1 & \$ 10,000 & \$ 10,041 & 100.41 \% & 15 & 60 & \$ 167.35 & 1 & 2 \\ 0 & - & 4 & 1 & \$ 20,000 & \$ 26,325 & 131.63 \% & 34 & 323 & \$ 81.50 & 6 & 7 \\ 0 & - & 4 & 1 & \$ 1,000 & \$ 1,397 & 139.70 \% & 31 & 30 & \$ 46.57 & 3 & 9\end{array}$

